\title{
THE DISCOVERY OF UNSUSPECTED DANGERS
}

\section{Prologue. How Arthropods Came to Transmit Human Diseases}

Before proceeding with my main subject, I am tempted to a short discussion of the extraordinary phenomenon of arthropod transmission of pathogenic organisms, which involves a little speculation about their evolutionary history.

There are some developments in evolution which seem fairly easy to explain on Darwinian principles, i.e. the selection of the more viable from minor, random changes, or the "survival of the fittest"; for example, the increase in size of horses with more powerful legs (well supported by fossil evidence); but it is less simple to understand the more radical innovations, such as the acquisition of wings by insects, which would seem valuable only when fully developed and scarcely so in rudimentary form. Such problems have stimulated recent discussions about evolutionary theory, one book, 'The Blind Watchmaker' by Richard Dawkins, generally supporting Darwinism, while another, 'Darwinism, the Refutation of a Myth', by Søren Løvtrups question some of the more simplistic interpretations. Certainly, any knowledgeable biologist would be able to provide examples of the most extraordinary phenomena, which would seem almost impossible to have evolved from small random mutations (except for the extreme difficulty of finding an alternative solution).

Having said that, the steps in the development of arthropod transmission of diseases will seem comparatively easy to accept. Purely for simplicity, I have adopted a teleological method of describing the ways in which pathogens "found it convenient" to be transmitted by arthropods. Initially, of course, there is the problem of the origin of any kind of pathogen, though (as we shall note) this is but the initial stage of the invasion of a higher animal (or plant) by a microorganism. (For the rest of this discussion, plants will be neglected.) That, however, was not simple, since, before the arrival of higher animals, microorganisms must have had to rely on solar energy and minerals, but when the higher animals arrived, their dead bodies would offer opportunities for saprophytes and the living ones for parasitism. In both cases, of course, this would demand substantial modifications in the microorganism's biochemical systems. In addition, the invaded animals would develop defence mechanisms against the invaders, though in the initial stages they would suffer "disease". If that were fatal, it would also be terminal for the invading microorganism; and, in any case, 
the death of the "host" must eventually occur, requiring transfer to another one. Various ways of accomplishing this were "discovered". Those forms which parasitised the intestines could pass out with the faeces, with the possibility of contaminating the food of another host. Those which flourished on mucous membranes could pass to another animal during social or sexual contacts. If the lungs were the site of infection, transmission could occur by droplets of mucus sneezed or coughed out by the host. So much for superficial parasites; but some forms had found a rich source of nutriment in the host's blood. Blood parasites might be transferred to another host if a carnivorous animal ate a herbivorous one; but that posed the problem of the return journey. When, however, the blood-sucking arthropods arrived on the evolutionary scene, they offered a convenient way of transport to another animal. One simple way would be via traces of blood on the arthropod's mouthparts; but, although this still happens occasionally in some species, it is very inefficient, because the traces are obviously tiny and soon dry up, which is harmful for the pathogen. So the "development of a secondary parasitism in the arthropod" which, in the words of an early discoverer, "nurses" the pathogen and allows it to multiply before transmission to another vertebrate, was a most successful innovation, even though it required further modifications to accommodate to an entirely different type of host. The crudest means of transfer would be from the arthropod's gut, either via the faeces (which might be scratched into the wound made at the next blood meal) or possibly by regurgitation (as from the plague flea or perhaps the sandfly vector of leishmaniasis). A more permanent infection of the arthropod would result from the invasion of its body cavity, though initially the only means of escape to another host would be if the arthropod were eaten in the course of grooming, or possibly merely squashed by the teeth of the new host. However, more elaborate means of transmission were to develop when the salivary glands of the arthropod became infected and thus able to transfer the parasite with the next blood meal. In some of these different methods, the microorganism remains (so far as can be seen) generally similar, at least in form; but in others, it undergoes remarkable transformations (notably in the malaria parasite).

This discussion of biological evolution has been somewhat theoretical; but the more recent evolution of arthropod-borne diseases, as they pass from one host to another, has much more practical importance. One essential matter is the degree of specialisation. Some pathogens can be transmitted by a fairly wide range of arthropods (though usually restricted to a class or even a family), but others can be transmitted only by members of a single genus. This may also be true of infection of the major host. It is fairly certain that very many arthropodborne diseases originated as infections of wild animals and the transfer to humans often occurred as our populations grew and expanded into virgin territory. It is still happening, and examples can be given of various stages of the process. In some, the pathogen has not reached the benign state in the wild animals and causes illness and deaths among them; these also severely affect humans when they acquire the infection. A well-known example is yellow fever, an infection of monkeys in the forests of South America and Africa, which 
reaches man by different routes in the two continents. In other examples, the infection has reached a benign state in the wild animals, but is still deadly to humans (e.g. Rhodesian sleeping sickness in East Africa, Chagas' disease in South America and leishmaniasis in the same continent. Malaria has perhaps reached a last stage in the process; it may have begun as an infection of forest primates, but after transfer to our pre-human ancestors, it became strictly a human disease when they left the forests. In contrast, typhus, which is also confined to humans, has probably been so since the time of our earliest ancestors. 


\section{Section 1. The Insect Vectors}

\section{From Speculation to Certainty: The Incrimination of the Disease Carriers}

Today all educated people know the connection between mosquitoes and malaria and may be aware that other tropical diseases are spread by insects. These facts are certainly familiar to doctors who are connected with tropical diseases, as indicated by the emblem of the British Society of Tropical Medicine and Hygiene, which includes a mosquito. The connection was established somewhat gradually, over the 20 years spanning the beginning of this century. Previously, scarcely any physician supposed that such apparently harmless trifles as gnats, fleas or lice could present a threat. Indeed, when the facts were first published, there were some who took a long time to be convinced. On the other hand, there had been, in earlier times, a few who made what now appear to be inspired guesses. Actual proof had to await advances in scientific methodology and technology.

\section{Early Indications Based on Circumstantial Evidence}

One might have supposed that the involvement of insects could have been suspected from their abundance in places or at times when diseases were prevalent; but such correlations were seldom very striking, and in ancient times it was more consistent with medical theory to blame climatic conditions, mysterious miasmas or even stellar conjunctions. For example, some of the earliest suggestions about insect-borne disease were made in relation to malaria, which was familiar to physicians even in classical times because of its prevalence in the Mediterranean region. The most speciously attractive theory was that it was caused by the fetid odour of decaying vegetation arising from marshes (hence the name mal aria or bad air, and the French paludism with its connection with marshes). However, one Roman, the experienced soldier and farmer Lucius Junious Columella (1st century A.D.), took this a little further. In a book on agriculture, he warned against farmhouses situated too near marshes, "which breed insects armed with annoying stings, which attack us in swarms; then, too, they send out plagues of swimming and crawling things, deprived of winter moisture and infected with mud and decaying filth, from which are contracted mysterious diseases which are beyond the understanding of our physicians".

It is, perhaps, straining credulity to suggest this as a significant observation to connect mosquitoes with malaria transmission; but there is no doubt that these insects call attention to themselves by their annoying bites, which might later provide a clue. Since ancient times, Mediterranean peoples have tried to protect themselves from this annoyance, and a recent article by Lindsay and Gibson (1989) traces some early uses of mosquito nets, though they were not actually used as a protection from malaria until the anopheline connection had been discovered. 
The intellectual ferment following the Renaissance in Italy led to renewed speculation about malaria. The 17 th century physician Giovanni Lancisci (1695) in Rome must have been familiar with the disease in the adjacent Campagna; and he wrote a book on the subject: de Noxiis Paludum Effluviis. This repeated the ideas of unhealthy vapours, but also mentioned pollution of mosquitoes in marshes and referred to observations of Leuwenhoek and Swammerdam. After noting the annoyance of their bites, he accuses them of spreading disease and, later in the book, discusses methods of draining the marshes. However, he seems to think that the disease was spread by the mosquitoes polluting sources of water in which they laid their eggs. In any case, for the next two centuries, physicians continued to believe in the transfer by noxious vapours.

I have suggested that it may have been the nuisance of mosquito bites that called attention to them when seeking a carrier of disease, and the same reason could account for early suspicions about houseflies, which also can be very irritating when numerous. Moreover, their unpleasant breeding habits would connect them with the stinks of decay and death. So it is not surprising to find suggestions as early as the 17th century of their transmitting disease: Thus, an early suspicion of houseflies as disease carriers was expressed by the German Jesuit priest and scientist, Athanasius Kircher (1656-1680). In his book on plague, he discusses all kinds of causes of disease and includes this note: (Muscae pestis seminatores) "There can be no doubt that flies feed on the internal excretions of the diseased and dying, then flying away, they deposit their excrements on food in neighbouring dwellings, and people who eat it are infected." He attributes this idea to the 16th century Venetian known as Mercurialis (1577); but I could find no reference to the matter in his book De Pestilentia. Later, the eminent and original British physician Thomas. Sydenham (1624-1689) considered that an abundance of houseflies in the summer was followed by plentiful disease in the autumn. Similar suspicions were held by the American doctor J. Crawford in 1808, who expressed the view that all insects, but expecially houseflies, could act as agents for dispersing disease.

By the 19th century, medicine and science were able to make some definite advances in understanding the aetiology of disease. Rather naturally, the insectborne infections which claimed first attention were those which invaded the temperate zone. Of these, plague and typhus were begining to abate, due to improved hygiene and better housing; but there were two diseases which did not respond in this way: malaria and yellow fever. The first was present in southern Europe, but it always had been and was almost tolerated. It also occurred in parts of the U.S.A.; but more alarming were the sudden deadly epidemics of yellow fever in the eastern and southern cities along the U.S. coast. It was probably these which caught the attention of American physicians, a few of whom speculated intelligently on the causes.

As early as 1807, John Crawford, a doctor practising in Baltimore, wrote: "As to yellow fever, the plague of the country, neither agriculture nor cleanliness have, I fear, had any share in impeding, or the want of them in producing this 
dreadful scourge." Instead, he put forward the suggestion of mosquito involvement. He had wide interests and wrote essays on all kinds of subjects, including entomology; and he mentions those insects (ichneumons) that introduce their eggs into potential insect hosts for their progeny. This probably gave him the notion that mosquitoes might similarly insert their eggs into the human body and cause disease. However, the suggestion did not seem probable to other doctors, and his insistence on it gave him the reputation of a crank, so that he eventually lost his practice.

The next American exponent of insect involvement was Josiah Nott, who had studied medicine in South Carolina and for a while in Paris. Curiously enough, when in practice, he attended the birth of William Gorgas, who was later to be important in controlling malaria and yellow fever in Central America. While Nott (1848) was practising in Mobile, Alabama, he witnessed several epidemics of yellow fever, and these made him abandon the popular miasma theory. He recalled earlier suggestions of the involvement of mosquitoes which seemed more in accord with the observed incidence and spread of the disease; for example, it seemed to be checked by a thick belt of trees. He wrote: "We can well understand how insects wafted by the winds (as often happens with mosquitoes, flying ants and many of the aphids) should haul up on the first tree, house, or any other object offering a resting place; but no one can imagine how a gas or other emanation, entangled or not with water vapour, could be caught in this way." Having made these suggestions, however, he took them no further, other than rejecting the necessity of quarantine, except that ships should not anchor close to the shore.

Another early speculator (cited by Peller 1955) was Louis Beauperthay, a Venezuelan doctor of French origin practising in Caracas. His contribution to the subject (in 1854) was rather ambiguous, mixing sound observations with nonsense. He noted that the Tipulidae puncture the skin with a hollow needle with two lateral saws. Then, he said, they inject a poison like that of a snake, which has the effect of dissolving the blood corpuscles to facilitate sucking them up the hollow needle. He thought that if the insect were interrupted in its feed, some of the poison would be left behind, with grave effects, though normally much would be sucked back with the blood meal. He proceeded to distinguish hazards from different kinds of mosquito, believing that the "Sangudo Bobo", with white striped legs (possibly Aedes aegypti), was the least dangerous. Instead, he accused the "Pyon" of causing scabies, though he had to agree that the lesions were too severe to allow the discovery of the mites, which he knew were always present in that disease.

Some years later, a more detailed case was made for the association of mosquitoes with malaria, albeit by intelligent speculation. In 1883, an English doctor who practised in Washington, with the resounding name of Alfred Freeman Africanus King (1883) published an article in a New York magazine, Popular Science Monthly. In it, he listed 19 reasons for his belief, almost all being associations in time or place of the insect and the disease. Perhaps the weakness 
of some of his reasons (and probably the fact that they were published in a popular magazine) failed to convince other physicians; for example, his arguments were disputed by Walter Reed, who was later to change his mind with regard to yellow fever. King was still obsessed with the idea of marshes, from which the mosquitoes were supposed to bring the infection. However, he boldly insisted that "You can have mosquitoes without malaria ... but you cannot have malaria without ... mosquitoes."

These examples of intelligent speculation might suggest that insect transmission of disease would have appeared so probable as to stimulate further investigation and experimentation to confirm the matter. However, many of the contemporary physicians, being well primed with orthodox views during their training, were very suspicious of unusual new ideas. This is well illustrated by a little book entitled 'What is Malaria?' published in 1871, by a certain Dr. C.F. Oldham, who had served for years as an Assistant Surgeon to H.M. Forces in India and was thus familiar with the disease; indeed, he had suffered from it himself. In the course of 186 pages, he cites a great range of physicians and travellers, from Sir John Pringle and Baron Humbolt to David Livingstone. He set out to examine the suggested causes on the basis of circumstantial evidence. In this way, he is able to discredit the common belief in the foul emanations from decaying vegetation in swamps, rightly pointing out that malarial fevers can exist in quite arid places in the tropics. Again, he can find no confirmation of an association with any particular kind of soil or geological strata. The nearest he comes to considering a pathogen is to mention the American physician J.H. Salisbury, who, in 1866, attributed malaria to the inhalation of algal spores. He is able to discredit this, and dismisses the "germ" theory on the grounds that malaria is not infectious. Finally, he concludes that the cause of malarial fevers is exposure to prolonged heat followed by sudden chilling; and it is remarkable how much anecdotal evidence from respectable authorities he found to support this theory. Moreover, from this explanation, he finds it easy to understand "the intimate, but hitherto mysterious connection between malarious fevers and dysentery, hepatitis, pneumonia, rheumatism and other diseases which are admittedly caused by climatic influences." In short, as he remarks in his Introduction, "after much careful enquiry, I arrived at the conclusion that malaria as a specific poison does not exist".

The very early ideas about the aetiology of malaria have been mentioned by several writers; but less well known is the intelligent speculation about a less dangerous disease, sandfly fever. The first suggestions, which turned out to be well founded, were made as early as 1884 by a Dr. McCarrison (later Sir Robert) an army surgeon serving with the British and Indian forces on the North West Frontier of India (Sinclair 1953). On the epidemiological evidence of the seasonal and locational incidence of the disease, he suspected transmission by sandflies and even attempted some experimental proof. This was unsuccessful, which he attributed (possibly correctly) to the immunity of his Indian volunteers; further work was curtailed when he was moved to another location. 


\section{Experimental Proof of Insect Transmission}

Sir Robert's far-sighted attempts at experimental transmission emphasises the fact that ignorance of the actual pathogen responsible for a disease, though obviously very important for a complete understanding, need not prevent the incrimination of a vector. Sometimes the physicians have infected themselves by bites of a suspected insect, which could be somewhat heroic if the infection was dangerous. In other cases, volunteers were used, occasionally under some degree of pressure or inducement. This clearly raises ethical problems, over which physicians are more scrupulous (or at least, more cautious) today. A good deal depends on the danger of the disease in question.

Human transmission experiments with malaria did not present a very high degree of hazard, because quinine was available for treatment. However, in the years before insect transmission of major diseases was established, most of the infections had no specific drugs for treatment. Yellow fever is a case in point, and some of the first trials with human volunteers were somewhat questionable. They occurred at a time when public conscience in such matters was less sensitive (and less likely to be stirred up by the press!) The doctors in question, Sternberg and Reed, had earlier tried out some anti-toxin trials with unvaccinated children in orphan asylums in the City of Brooklyn. William Bean (1982), in his biography of Walter Reed, comments dryly: "Oddly enough, at a time when the use of orphan children for medical experiments raised no public outcry, anti-vivisectionists were sufficiently well organised to promote a Senate bill forbidding animal experiments and to attack the Army Medical Museum for such practices!"

This raises the matter of transmission experiments with animals, some of which are more or less susceptible to human infections. An exception is malaria, which is specifically a human disease, though oddly enough, some of the earliest valuable information was obtained with a related pathogen, also transmitted to birds by mosquitoes. Rats, which fail to arouse much human sympathy, and guinea pigs, which are convenient laboratory animals, have been used at various times. The former are particularly suitable for plague studies, since rats constitute the primary source of epidemics. The most informative for human diseases are monkeys, because of their close evolutionary relationship, and they have been used for various stages of elucidation of sleeping sickness, malaria, typhus and Chagas' disease. Animal experiments for such purposes are certainly easier to justify than those used in connection with safety tests for cosmetics.

\section{Discovery of Pathogens and Their Association with Some Insects}

Another kind of evidence indicating insect involvement in disease transmission came from studies of the pathogens concerned and speculations as to how they could be transferred to the next host. Obviously, such theorising had to await the concept and the proof of living disease agents; and until the mid-19th century, scarcely any physicians had ever considered this possibility. The "germ" 
theory of disease had, in fact, been vaguely postulated by Marcus Terentius Varro (B.C. 116 to 27) a many-sided scholar, who, in a book on farming, wrote of "minute animals, invisible to the eye, which breed in swamps and reach the body by way of nose or mouth and cause diseases which are difficult to get rid of". This concept was more explicitly defined in the 16th century by Girolamo Fracastoro (1546), who suggested that some diseases were caused by different kinds of rapidly multiplying organisms; and that these were transferred by direct contact, by contaminated clothing, or through the air. Other 16th century Italian naturalists who were attracted by the concept of a contagium vivum were Geronimo Cardan (1541-76) and the anatomist Gabriel Fallopio (1523-62); but the name most frequently cited in connection with the germ theory of disease is probably Athanasius Kircher (1656-80), a German Professor of Hebrew in the Jesuit college in Rome. Among his voluminous writings is Scrutinum Physicomedicorum Pestis, in which he suggested that persons affected with plague breathed out minute infective corpuscles; and these he claimed to have seen by microscopic examination of "putrid" blood from febrile patients. The idea was also rather vaguely developed in connection with malaria by Lancisi (whom I have mentioned) and by Giovanni Rasori (1767-1837, cited 'by Harrison 1978), who taught his students in Pavia that malarial contagia bred in swamps before being in some way conveyed to people to cause fever.

It should be emphasised that these original suggestions carried little weight against most prevailing opinions. The majority of ordinary people would have ascribed epidemics to divine punishment; or in more educated circles perhaps, to inauspicious astrological conjunctions. Rather more experienced physicians tended to blame unfavourable climatic conditions, in accordance with seasonal and geographical occurrence of diseases such as malaria and, to some extent, plague and typhus. Alternatively, noxious miasmas were blamed, arising no doubt from our instinctive aversion to disease and death.

It must be remembered that the writings of early pioneers of the germ theory were often vague and mixed up with other ideas. Fracastoro considered that a foetid miasma was necessary to transform his poisonous corpuscles into living agents. Apart from this, the concept of microorganisms was handicapped by the limitations of the early microscopes, which were scarcely capable of clearly defining bacteria. So there were alternative suggestions of a kind of chemical agent; for example, Jean Pestalozzi, dealing with plague in Marseilles in 1720 , described the infectious cause as a volatile saline fermentive principle. Similar opinions persisted into the next century. Even in 1866, Benjamin Ward Richardson, lecturing to a Congress on Sewage, explained that cholera, typhoid, typhus and diphtheria were due to organic poisons capable of acting as catalytic agents of disease, and it was a common error to suppose that they multiply from a germ, as offspring from parents.

However, it was in the middle of this century that the germ theory became firmly established. In France, Louis Pasteur's discovery that fermentation was dependent on microorganisms, and could be prevented if these were destroyed, led him to conclude that diseases could be due to similar organisms, of which he 
was able to isolate two. Another Frenchman, in pursuit of these organisms, was able to demonstrate them in sheep which had died of anthrax and discovered others in human blood. Meanwhile in Germany, F.G. Henle revived the germ theory of disease, which was finally and conclusively proved by the great Robert Koch.

In his later work, Koch became aware of the difficulty of actually proving the causal links between particular organisms and specific diseases, since observations of innocuous (or even comensal) organisms could be mistaken for pathogens. Accordingly, he enunciated a strict rule for proof, as follows. "It is necessary to isolate the bacilli from the body, to grow them in pure culture until they were freed from any disease product of the animal body which might adhere to them; and, by administrating the isolated bacilli to animals, to reproduce the same morbid condition which, as known, is obtained by inoculation with spontaneously developed [tuberculous] material." These admirable principles ought to have been conclusive, at least for the relatively large bacteria and protozoa which were capable of growing on artificial media, though there were still false claims and "red herrings". However, "Koch's Postulate" actually handicapped the recognition of Rickettsiae and viruses, which could only be cultured in animal tissues (as explained in an admirable article by Victoria Harden in the Journal of the History of Medicine in 1982).

Even when the existence of harmful microorganisms had become widely accepted, however, their transmission seemed to be adequately explained by contagion or infection (though the latter concept was often rather vague). Moreover, there was still a reluctance to abandon the "obvious" causal effects of "chills" or bodily weakness. An excellent example of a man reaching the wrong conclusion after weighing the available evidence is provided by a Mr. W. North, M.A. (1896), who spent 3 years in Italy "enquiring on the spot" as he said, "of the origin, history, distribution and nature of the Malarial Fevers of the Roman Campagna". Significantly, North did not take part in any scientific investigations; but he had available full details of the discoveries of Laveran, though he gave equal attention to the erroneous claims of other Italians, who believed that they had found the causal organism. So, in the end, he was convinced by none, contrasting the clear evidence of the existence of the anthrax germ with these numerous claims. He rightly pointed out that no one could actually find the "malaria germ" in the air, water or soil. Finally, he decided that malaria was a kind of pernicious chill and he warned tourists against rushing about Rome sight-seeing and neglecting proper food and clothing. The copy of this book in the library of the London School of Hygiene and Tropical Medicine is annotated in the hand of Sir Ronald Ross, regretting that it was published before his demonstration of transmission by mosquitoes.

\section{The Elucidation of Particular Diseases}

It is difficult to arrange the discoveries of insect transmission in a logical order. Certainly, it would be right to begin with what is generally considered the first 
definite proof, the demonstration by Patrick Manson in 1877 that certain mosquitoes can act as carriers of a filarial parasite of man, which is generally taken as the "birth of medical entomology". Once the possibility of insect involvement had been established, it was clearly something to be considered in other cases. As the Marquise du Deffand wrote "Il n'y a que le premier pas qui coûte" (specifically refering to the legend that, after his execution, St Denis picked up his head and walked away, though doubtless, as a general observation). However, any attempt to follow the first discoveries with a chronological sequence encounters difficulties, since they are often only partial of even slightly wrong and need further clarification from the work of later investigators. As regards malaria, for example, we would be inclined to name Sir Ronald Ross, but the Italians might prefer Giovanni Grassi and the French would insist on a mention of Alphonse Laveran, who discovered the pathogen. Sir William McGregor (1901), who was a friend and supporter of Ross, put it this way: "Manson was the surveyor, Laveran made the road, Ross built the bridges and laid the rails, while Bignami and Celli supplied the rolling stock." Similar lists could be made for other insect-borne infections which took many years for full comprehension. Working out the details of the transmission of plague and typhus took 10 or a dozen years, while for leishmaniasis (after some early indications) it took several decades.

Despite these difficulties, the matter of timing had to be observed, since the demonstration that one kind of insect could act as a disease vector obviously suggested the possibility for other sorts. A compromise had to be reached, by keeping together similar kinds of insect, so far as possible in chronological order, and with some regard for the importance of the diseases transmitted. Obvious candidates for first place are the mosquitoes, on all three counts. Two groups of higher Diptera (tsetse flies and houseflies), which in different ways attracted early attention, are placed second. These are followed by two quite different types of biting midges (sandflies and blackflies) and finally three other kinds of insect: fleas and lice, belonging to small ectoparasitic orders, and the bloodsucking triatomine bugs, which are unusual members of a mainly vegetarian order. This list demonstrates the major importance of the order Diptera in medical entomology.

\section{Diseases Transmitted by Mosquitoes}

\section{Filariasis}

Because this disease is restricted to tropical countries, it had long escaped the scrutiny of European doctors; furthermore, it is not generally a fatal one nor one which causes alarming epidemics, though it can result in the horrible disfigurement and disablement of elephantiasis. The fact that its mode of transmission was discovered before that of malaria may be due to the fact that the pathogen, a tiny worm, was recognised as a living parasite as soon as it was discovered; whereas the malarial Plasmodium was for a long time seen only in fixed (dead) 
preparations. The minute filarial worms ("microfilariae") were first noticed by a French surgeon in the chylous urine of a female patient from Havana in 1863. Next, they were discovered actually in the blood of an Indian patient by Timothy Lewis (1873) in 1870; and, significantly, unchanged in the same patient 2 years later. He named the parasite Filaria sanguis hominis, and he noticed that the worms were enclosed in transparent sheaths, with no sign of mouth or anus. This suggested that they were the immature forms of a parasite which would eventually grow into an adult; but despite searching, he was unable at first to find such an adult form.

Meanwhile, the microfilariae had been seen in the blood of a patient in Brisbane in 1876 by Joseph Bancroft (cited by Cobbald, 1878). He, too, realised that they were immature forms and began to search for the adults, which.he discovered in 1877 in an elephantiasis lesion of the scrotum of a patient, who also had microfilariae in his blood. He sent specimens to his old teacher, W. Roberts in Manchester, who passed them on to T.S. Cobbold, a leading helminthologist. Cobbold immediately recognised the microfilariae as being identical to those described by Lewis and he published a description of the adult under the name Filaria bancrofti (Cobbald, 1878). Almost simultaneously, Lewis (1877) in India also discovered adults in an elephantiasis patient. By this time, it seemed likely that the worms were responsible for various pathological conditions, especially elephantiasis (Fig. 1.1).

The first steps in understanding the mode of infection of the disease were taken by Patrick Manson, a Scottish physician of good, though not especially distinguished, family in Aberdeenshire. He was one of many North Britons who have contributed to medical entomology. He qualified in medicine in 1865 at the age of 21; and in his biography written by his son-in-law Sir Philip MansonBahr (1963), there is a picture of him at the time, wearing a cutaway suit and trousers of the type favoured by Charlie Chaplin. After a short time as a doctor in an asylum, he was happy to obtain a position in the service of the Chinese Imperial Maritime Customs, first on the island of Formosa (Taiwan) and later on the mainland at Amoy (now Hsiamen). He was not content, however, merely to perform his regular duties dealing with routine complaints of the Chinese employees, and after a short spell of leave in Scotland, he proceeded to London to improve his knowledge of parasitology. In this pursuit he came across the works of Lewis and, on his return to Amoy, he began to look for microfilariae in the blood of his patients. He found some $9 \%$ of them infected, the proportions increasing with age, from 6 to $33 \%$. His subsequent investigations are described in Manson-Bahr's biography and, with further details and corrections, in a paper given by Eli Chernin (1977) at a Washington symposium.

Manson realised, from published work and his own observations, that the adult worms must live in the human lymphatic system; and that, like other similar parasites, the females produced larvae viviparously. The tiny thin embryos would have no difficulty in reaching the blood system; but occasionally, he encountered a prematurely voided egg. These eggs were much wider than the larvae and might easily block certain lymphatics, leading to congestion 


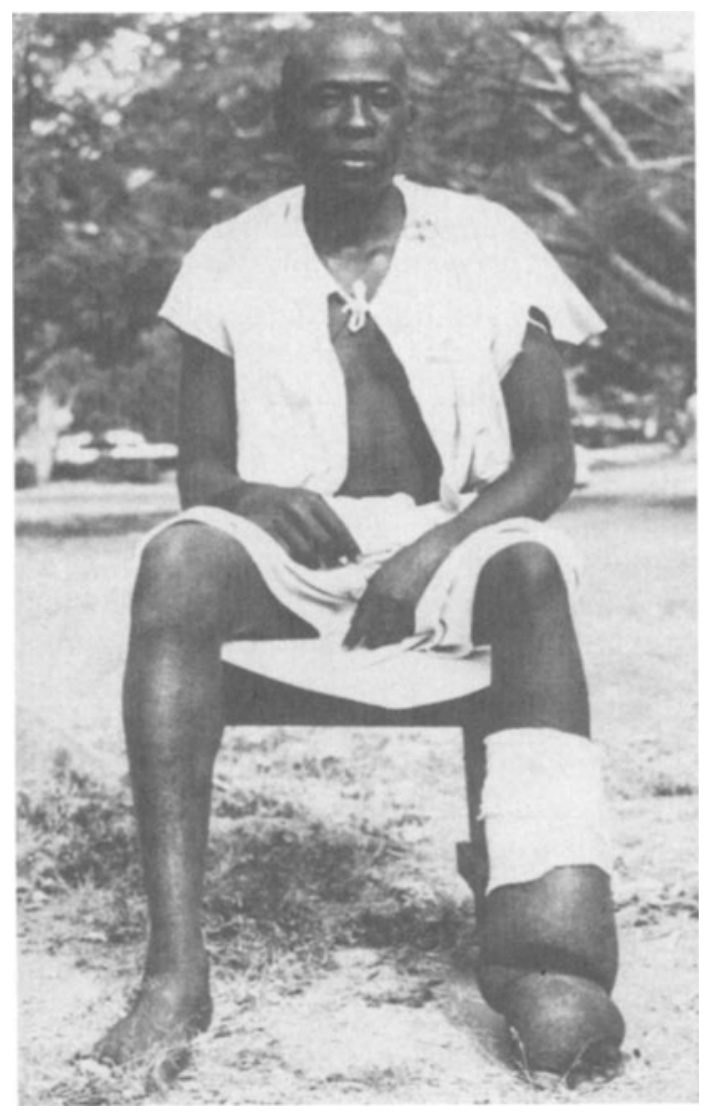

Fig. 1.1. A moderate case of elephantiasis. (Photograph courtesy of WHO)

and, in some cases, elephantiasis. He became curious about the subsequent fate of the microfilariae. Clearly, they could not all develop into adults in the affected human subject, or they would fatally clog the body with their vast numbers. Further development must take place elsewhere. On examining them under the microscope, he noticed that they wriggled about vigorously, as if trying to escape from their transparent sheaths. He then had the surprising (but fruitful) idea of chilling them with ice, which seemed to help them to escape. This suggested to him that their further development must take place away from the warmth of the human body. It could of course, simply be in soil or water; but no doubt he had absorbed information about other invertebrate parasites, which suggested the possibility of another host, a cold-blooded one, probably an insect. He decided against several kinds (bugs, lice, fleas) because they occurred extensively in parts of the world where no filarial disease was present. Instead, he decided that the vector was probably a local mosquito.

The most obvious choice was the common house-haunting mosquito of the tropics, Culex quinquefasciatus. He collected some of these and allowed them to 
feed on his filarially infected gardiner, who agreed to act as a "guinea pig". Afterwards, he dissected the mosquitoes and found that, not only did the worms survive well in the insect's stomach, but many were discarding their sheaths; and when he immersed them in water, they were "quite at home and in no way inconvenienced". This led to what must have seemed an obvious conclusion; that the worms taken up by the mosquito were "nursed" for a while in its stomach; it seemed likely that many of the latter would be drowned when laying their eggs in water, so that when they decomposed, the worms would escape and later infect any one who drank the "filariated water". Other observations (which Chernin points out were made later) confirmed the mosquito as being involved in transmission of the disease. On busy days in the hospital, he was not able to devote time to research in the evenings to take blood from patients, whereas on quieter days he would do so during the day. He noticed that the evening samples from infected patients were more fruitful than the daytime ones. To check this, he trained two Chinese assistants to take the samples, one during the day and the other in the evening, later reversing their roles. This confirmed the nocturnal periodicity of the microfilariae.

It is easy to understand why he became wrongly convinced of this mode of infection, since the only book on natural history available suggested that mosquitoes fed only once, laid their eggs and died; so he could hardly suppose that the worms would undergo development in the mosquito and infect humans with a later bite. Chernin points out that he missed a clue which might have made him reconsider when, after corresponding with Timothy Lewis in India, he began to disect mosquito thoraces as well as their abdomens. He might then have noticed some of the later stages of the worms, which have been seen in one of his own slides recently by Professor Nelson. (This proves that the wild mosquitoes he used must have had an infective meal before they fed on his gardiner.) Meanwhile, he recorded his observations in Reports of the Imperial Maritime Customs and also sent copies to Dr. Cobbold in London for communication to the Linnean Society, of which that gentleman was President. When Cobbold read the paper to a meeting of the Society (Manson by Cobbold 1878), it was sceptically received, especially the disappearance of the microfilariae by day. One or two members even asked facetiously if the little worms had watches and if they knew when to go to bed. The matter was to puzzle Manson for a long time. He had done some research on filariasis of the dog which proved that the microfilariae did not die off during the day; also, investigations of filariae in the mynah bird in Amoy showed that they could anchor themselves to the walls of blood vessels. However, the actual location of the missing larvae was not discovered until 1897, when Manson was in London and making a post-mortem examination of an infected man who had committed suicide at 8 o'clock in the morning. The microfilariae were found to have assembled in the capillaries of the lungs and other blood vessels.

For a long time, Manson continued to believe that transmission of human filariasis occurred through drinking infected water. The truth was finally indicated in 1900, when Low (1900) traced the further progress of the worms 
from the thoracic muscles of the mosquito down the proboscis to the tip, ready to emerge at the next attempt to feed. This was done with the aid of a beautifully clear series of microscope slides of the head of infected insects, sent from Bancroft in Australia and examined at the London School of Hygiene and Tropical Medicine. The final details were completed by Fulleborn in 1908. Yet, even as late as 1922, a Japanese scientist (Kamakama 1922) was casting doubts on transmission by bite and wondering if Manson's original theory of contaminated water was correct!

At the time, Manson's discoveries had little influence on his career. In 1883, he moved to Hong Kong and contributed to other fields of medicine and parasitology. He was largely instrumental in founding a medical college, which developed into the Hong Kong University. In 1889 he returned to Scotland; but after a few years as a country gentleman, he moved to London and a practice near Harley Street. He continued to foster his profession publically, in organising the London School of Tropical Medicine, and later becoming medical adviser to the Colonial Office. While these activities brought him a knighthood and other honours, it is his early proof of insect involvement in spreading tropical diseases which was celebrated in 1977 at the centenary of the Royal Society of Tropical Medicine and Hygiene. Moreover, it was a discovery which influenced his views on the transmission of malaria, which he communicated to Ronald Ross, as we shall see shortly.

As a medical entomologist, I have always been impressed by Manson's unique part in the study of insect transmission of disease. His biography, (Manson-Bahr and Alcock 1927) however, reveals him as a busily working physician and surgeon, devoted to his practice in China; so that time spent on research had to be fitted into his daily programme. Moreover, he made other contributions to parasitology not involving insects, which cannot easily be discussed here.

Further complications in the aetiology of filariasis remained to be unravelled in later decades. The range of "bancroftian" filariasis was found to extend throughout the tropics. In some places, it was transmitted by various anophelines; for example, by An. hyrcanus in China (Feng 1931), and in Freetown, West Africa (Gordon 1932), by An. gambiae and An.funestus. In crowded urban areas, with poor sanitation providing breeding places, Culex quinquefasciatus, the common house-haunting mosquito of the tropics was the main vector. Closely related to this species is the harmless bird-feeding C. pipiens of the temperate region and C. molestus, which appeared to be the vector of filariasis in Egypt (Southgate 1979).

In all cases, however, these mosquitoes fed at night when the microfilariae were present in the blood stream; but a different situation was discovered in the Pacific islands, where day-biting mosquitoes were found to be the vectors. In this part of the world, the parasite had adopted a different rhythm, which had been noted as early as 1896 by a naval surgeon called Thorpe who had observed the microfilariae in the blood stream of patients by day. This was confirmed by others and the matter was thoroughly investigated by Dr. P.H. 


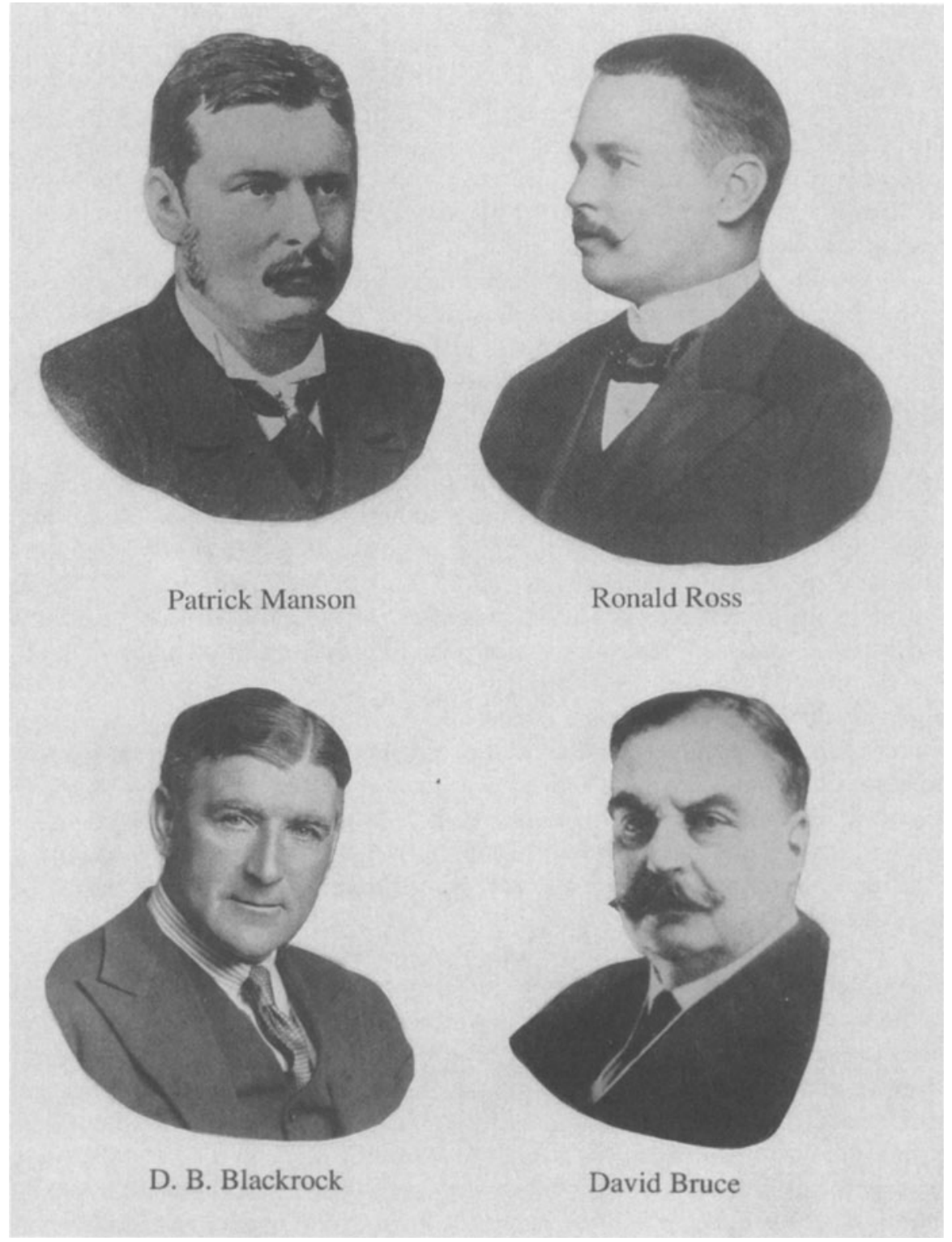

Fig. 1.2. Some British pioneers in the discovery of insect involvement in spreading disease

Bahr (1912) in an extended tour, the results of which he reported to the London School of Tropical Medicine. He discovered that in Fiji and the Gilbert Islands, the microfilariae did not exhibit periodicity and C. quinquefasciatus was certainly not the vector, which was probably Aedes (then Stegomyia) pseudoscutellaris. Other investigators connected with the London School built on these 
findings (Buxton and Hopkins 1927; Manson-Bahr 1963). In particular, Buxton (1928) showed that the non-periodic form of the disease existed only east of longitude $170^{\circ}$, and suggested that this could have come about as follows. When the Polynesians migrated eastwards into the Pacific, they would have brought with them the usual filarial parasites; but even some of the nocturnally periodic forms allow a few microfilariae to be present during the day. In the absence of a night-biting vector mosquito, these would have been selected for by a day-biter and developed into a distinct race.

Recently, Dr. Brian Lawrence (1988) has published an interesting account of the global dispersal of bancroftian fialariasis. He decided that the parasite originally affected an adventurous, sea-going people in South-East Asia and was spread by them to Africa in prehistoric times (probably both the east and west coasts). From the well-established west coast site, the disease was taken northeastwards by pilgrims on their way to Mecca, in the 14th or 15th centuries; and later, to Central America with the slave trade. Another, less dispersed filarial parasite was found in South-East Asia in 1927 by the Dutchman S.L. Brug (1927), who described it as a new species, Filaria malayi. (It was later transferred to another genus, Brugia, named after him.) This can infect some wild animals as well as domestic cats, thus providing a non-human reservoir. Two varieties were found; in one strain, the microfilariae are present in the blood at night as usual, but in the other, they are also there in the day, though there is a small peak of numbers at night.

A search for the vectors was made by Hodgkin $(1937,1938)$ in Malaya, Galliard (1936) Indo-China (Tonkin) and Iyengar (1938) in India (Travancore); all found that species of Mansonia were the chief culprits, though the parasite would develop in a few anophelines which acted as secondary vectors. Mansonia mosquitoes are unusual in that their larvae obtain oxygen from the roots of aquatic plants (especially Pistia sp. and Eichornia sp.) so that they do not need to come to the surface for air.

As in all fields of research, the investigations of host-parasite relations of filarial infections became more sophisticated with the passage of decades. The relations between periodicity of the microfilariae in the blood of the hosts (including man) have been further studied. From being merely accepted as empirical facts, their development as evolutionary adaptions were interpreted by Gillet (1974). Another aspect which might seem to have more practical possibilities was the vector efficiency of the mosquitoes, which was found to vary in different strains. In 1962, for example, W.W. Mcdonald showed that the infectability by a semi-periodic strain of Brugia malayi to Aedes aegypti was controlled by a recessive sex-linked gene. This suggested that it might be possible to produce a strain of a normal vector which was highly refractory to infection, introduce it into the field and induce it to replace the dangerous wild form by modern "genetical control" methods. It has, however, been suggested that such refractoriness may be unstable, due to adaption by the filarial worms (Lawrence and Pester 1967), but Nelson (1978) expressed optimism. Other investigations have sought the causes of refractoriness, which has been related to 
successive stages in the transmission process. The first obstacle to the microfilariae taken up in a blood meal by anopheline vectors (but not culicines) is the armature in the mosquito's pharynx which destroys a proportion of them (Coluzzi and Trabucci 1968). Next the worms have to penetrate the gut wall (Lavoir ierre et al. 1966, 1974), which becomes more difficult with increasing numbers in An. gambiae, but easier with heavy loads in Ae. aegypti. Then there is the passage through the thorax in the last stage of development, which is impeded in the refractory strain of Ae. aegypti; and finally there is the difficulty in invading the next host, since the worms are not injected with the bite, but left on the skin in a tiny pool of liquid. Successful invasion is inhibited if this dries up in conditions of low humidity.

With all these difficulties, it is not surprising that transmission is inefficient. Hairston and de Meillon (1968) in Rangoon, have calculated that over 15,000 bites by infected mosquitoes might be necessary to be successful. While this is difficult to understand in view of the high levels of filariasis in some communities, it does suggest that the maintenance of the parasite in human populations may often be precarious. It would seem that vigorous control measures ought to be able to eradicate the disease, but unfortunately the long life of the adult parasite in man makes this very difficult.

\section{Malaria}

As with filariasis, the first fruitful progress towards the discovery of malaria transmission came from studies of the pathogen. This had been sought fruitlessly during the second half of the 19th century. Thus, in 1866, an American physician, J.H. Salisbury, suspected certain algae (Palmella sp.) common in swampy ground, spores of which he found in the sputum of his malaria patients. This fascinated the Italians, who had classical intimations about the dangers of marshes; and in 1876 Lanzi and Terrigi suggested a species of alga, Monilia penicilata, present in marsh mud; while another Italian, Pietro Balestra (1877), accused an organism described as Alga miasmatica, which he claimed gave off harmful vapour. Later, Lanzi and Terrigi turned their attention to a bacterium, Bacillus bruneum, while two others, Klebs and Tommasi-Crudeli (1878); nominated another species which they called B. malariae. It is possible that this enthusiasm for "discovering" pathogenic bacteria may have followed Pasteur's renowned researches. Patrick Manson evinced more caution in an 1882 paper on leprosy, when he wrote: "The present is the age of bacteria, they are searched for everywhere and in nearly every disease, so they are found everywhere and in every disease." It need hardly be said that these conflicting claims greatly added to the confusion.

The man who was to make the eventual discovery was Charles Louis Alphonse Lavalran, the son of a professor at the Army School of Medicine in Paris. He followed in his father's profession, and after serving as a medical officer in the Franco-Prussian War, spent a few years in his father's former Chair, before joining the staff of the Pasteur Institute in Algeria. His discovery of the 


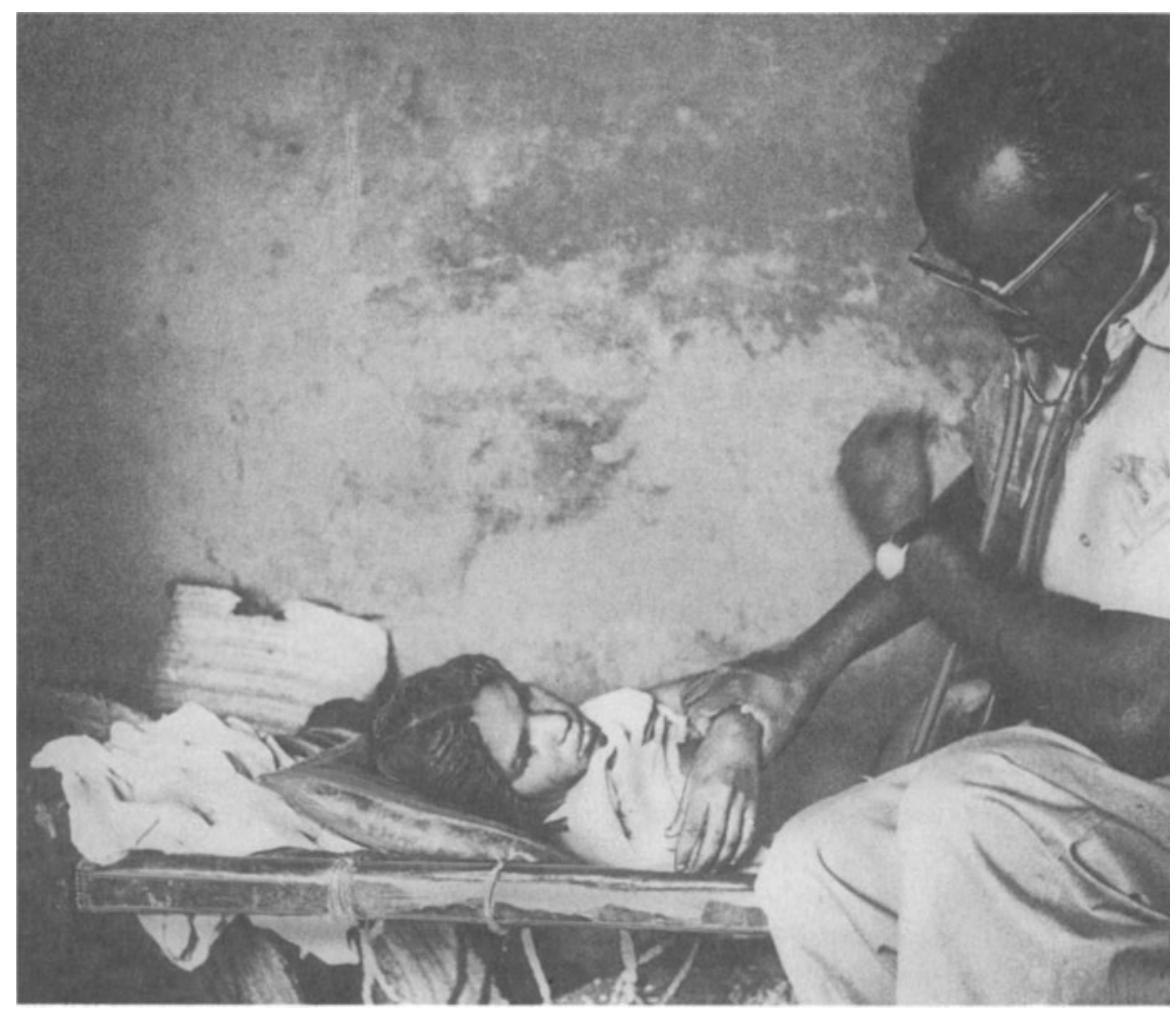

Fig. 1.3. Malaria: an African doctor tends a sick child. (Photograph courtesy of WHO)

malaria pathogen came almost accidentally while examining the blood of a malarial patient in his clinic. It happens that the actual parasites contain black pigment which is the partly digested haemoglobin from the blood cells which they have destroyed. This had been seen long before, first by Heinrich Meckel in 1847 , and then by various other doctors, who definitely associated its presence with malaria. None, however, had recognised the objects as parasites, assuming them to be degenerating blood corpuscles, largely because they had examined killed blood cells on a slide. Laveran, however, also looked at fresh blood smears; and one day he was lucky enough to witness a curious phenomenon. Some of the pigmented bodies became rounded and extruded numerous fine filaments, which waved about actively. The observation was so extraordinary, that he was able to recall the moment of discovery (on November 6th 1880, while examining the blood of a 24-year-old soldien.) This process is known as "exflagellation" and the filaments are actually spermatozoa which, in nature, break off to fertilise female gametes in the mosquito's stomach. Laveran did not know this, but the activity of the flagella convinced him that he was dealing with a live parasite which he assumed to be the cause of malaria. After publishing his discovery (Laveran 1880), he went to Rome, where better-equipped laboratories 
were available as well as eminent malariologists like Ettore Marchiafava and Angelo Celli (1886). They were interested, and discussed the significance of the pigmented objects in some detail, but decided that the evidence for their being live parasites was not convincing. At the same time, Klebs and TommasiCrudeli (1878) were developing their completely erroneous ideas. Using a suction device, they collected their B. malariae from marsh air and used it to "infect" rabbits. Though they knew malaria to be an essentially human disease, they persuaded themselves that the animals developed mild malarial fevers, giving their temperatures and weights, day by day, in many tables.

For some years, Italian malariologists clung to their traditional belief that malaria was somehow conveyed by air or water from marshes. However, when they became converted to Laveran's parasites, they made substantial progress in describing their behaviour. By examining malarial blood, Marchiafava and Celli (1888) were able to describe part of the life cycle. They showed that, after invading a red blood cell, the parasite grew enormously as it consumed this, then divided into numerous progeny, which burst out and invaded other cells. The story was taken further by Golgi (1886 etc) in Pavia, who showed that the release of the parasite progeny was synchronous and that it corresponded in time with the paroxysms of fever. Also, he noted that the timing differed for the parasites responsible for the tertian and quartan types of malaria.

In subsequent decades, there has been speculation about the reason for this synchronisation, and one theory is that, while the fever gives some protection for the patient, the synchronisation may provide some for the parasites (see, for example, Kwiatowski and Greenwood 1989).

Patrick Manson heard of Laveran's discovery in 1890, after his return to Britain, and he was shown the phenomenon of exflagellation by H.G. Plimmer, a London University professor who had been sent specimens from Giovanni Grassi in Rome. Unlike the Italians, who thought that this represented the death throes of the parasite on a microscope slide, Manson immediately assumed that it was a preparation for the next phase of the parasite's life cycle; and, by analogy with his filarial studies, he expected it to be in a blood-sucking insect, probably a mosquito (Manson 1894). To verify his theory, he would have liked to "follow the flagellum" and see if it turned out to be the next stage of the parasite; but to do this, he would have to experiment with mosquitoes, preferably in a locality with malaria patients available. He made some attempts to obtain an adequate grant to go and work in British Guiana, or even experiment with mosquitoes bred in a hothouse at Kew; but I am not sure that he was entirely disappointed when these failed. At the age of 50, after many years abroad, he had commitments at home and was beginning an important stage in his career. So he turned to the idea of vicarious involvement with a disciple working in the tropics. His first choice, in fact, was unfruitful; but when Ronald Ross, on leave from India, came to see him, he was impressed with the younger man, and a valuable relationship begąn.

Ross came from a family with distinguished connections with the Indian Army, in which both his father and uncle had served. His father was keen for 
Ronald to enter the military branch of the Indian Medical Service; but the son was not particularly eager and only just qualified in medicine with the easiest examination of the Apothecaries Society. He did, in fact, join the Indian Medical Service, but made no particular impression at first, apparently enjoying the life of an unattached subaltern. Rather than medicine or the army, his interests were in literature, since he wrote a good deal of poetry and published a couple of novels.

Curiously enough, some of his first publications in the field of medicine were papers attempting to discredit Laveran, since he believed the parasites to be mere artefacts. All this changed after his visit to Manson, who demonstrated exflagellation to him, which completely convinced him. Some of Manson's conviction about insect involvement in malaria transmission was communicated to Ross, who returned to India full of enthusiasm to prove the case. This turned out to be more difficult than expected.

Rather unusually, Ross's superiors in the I.M.S. allowed him some time for his researches; this was probably because Manson had influenced Sir Charles Crosthwaite, Secretary to the India Office, on his behalf. Nevertheless, he was sometimes needed for other duties and moved about from time to time, coming eventually to a crucial point when it was impossible to complete his studies on human malaria. On the one hand, his facilities were meagre and he was isolated from scientific literature; but to balance this, he maintained a long correspondence with Manson, who discussed his findings and offered help and encouragement. Eventually Ross made some significant discoveries. He found that exflagellation occurred much more frequently in blood from a mosquito's stomach (Ross 1897) than in samples from a finger prick. Then he discovered another stage in the parasite's life cycle in the form of round bodies on the outside of the insect's stomach; and he began to suspect that this development occurred more often in one kind of mosquito (Ross 1898). Being ignorant of entomology and without reference books, he was only able to describe the fruitful kind as "dapple winged" (a rough description of the local Anopheles) in contrast to others noted as "grey" or "brindled".

Seeking for the further progress of the parasite, he first investigated Manson's idea that drowned mosquitoes contaminated drinking water; so he gave some "malariated water" to volunteers to drink, but without result. This was in 1895; but in the following year, he wrote to Manson " ... the belief is growing in me that the disease is communicated by the bite of the mosquito. She always injects a small quantity of fluid with her bite-what if the parasite gets into the system in this manner? I shall experiment in this direction and also dissect the head". Later, he found a volunteer who allowed five mosquitoes to bite him 2 days after an infective feed. The result was negative, because he had not allowed enough time for the the parasite to develop inside the insect; but he realised this possibility and also that he might perhaps have used the wrong sort of mosquito (Ross 1923).

At this point, he was moved away from areas where he could work with human malaria, so he reluctantly turned to work on an analogous form of 
malaria in birds. In these, the processes seemed similar; and, most significantly, the round bodies on the outer wall of the insect's stomach divided up into rodlike forms, which he traced to the salivary glands. This strongly indicated the infection by the bite, and he proved it by transmitting the disease from infected to healthy birds. He concluded that this also applied to human malaria and wrote to Manson (Ross 1898) in London to say so.

Meanwhile, some American research on a kind of "bird malaria" had filled the gap between the disappearance of the "flagellae" and the development of "oocysts" on the outside of the mosquito's stomach. Encouraged by Dr. W.S. Thayler of the Johns Hopkins Medical School in Baltimore, two research students, E.L.Opie and W.G. MacCallum, sought for clues from studies of a haematozooan parasite of crows. They found that the flagella were, in fact, spermatozoa, which proceeded to fertilize female gametes in the mosquito's stomach, and their offspring burrowed through the wall to form the oocysts. Soon after this, MacCallum actually observed the process of fertilization in human malarial parasites (MacCallum 1897).

By this time workers in Italy had made quite considerable progress. They had been busy since Laveran's visit in 1882, and had long discarded the classical ideas about malaria originating in "putrid swamp water". By 1896, Amico Bignami (1898), having reviewed the evidence on transmission in a letter to the Lancet, began to be convinced of infection by a mosquito, noting that the great German bacteriologist Robert Koch had inclined to this opinion (though he tended to believe in inheritance of the pathogen in the insect). In November 1898, Giacomo Grassi and his colleagues (Grassi and Bastianelli 1898) definitely concluded that infection was acquired by the bite of a mosquito; and the same year, Bignami had conducted some trials which he believed proved the point, by transmitting malaria to volunteers by some anophelines captured in an endemic area (Bignami 1898).

There were, however, some defects in these Italian publications, and Harrison (1978) suggests that the authors had rushed into print to forestall Koch, who was becoming involved in the problem and who had been lionised on a recent visit to Italy. The artificial infection trial suffered from the defect that the volunteers were all Italians and could, conceivably have been infected previous to the experiment. However, final proof of the transmission by anophelines was provided by a crucial experiment devised by Manson (1900). Two British physicians, C.W. Sambon and C. Low, together with the wellknown entomological artist of the British Museum, Terzi, agreed to spend 3 months in the highly malarious Roman Campagna during the transmission season, but avoiding bites by keeping inside a mosquito-proof hut after sunset. None acquired the disease. In contrast, some mosquitoes collected in the area were sent to London and allowed to bite Manson's son Patrick Thorburn, who eventually developed typical tertian malaria. This clinched the theory of transmission and opened the possibility of reducing malaria by vector control.

Unfortunately, the competition for public acclaim as the discoverers of the "cause" of malaria resulted in a protracted and rather unsavoury quarrel, mainly 


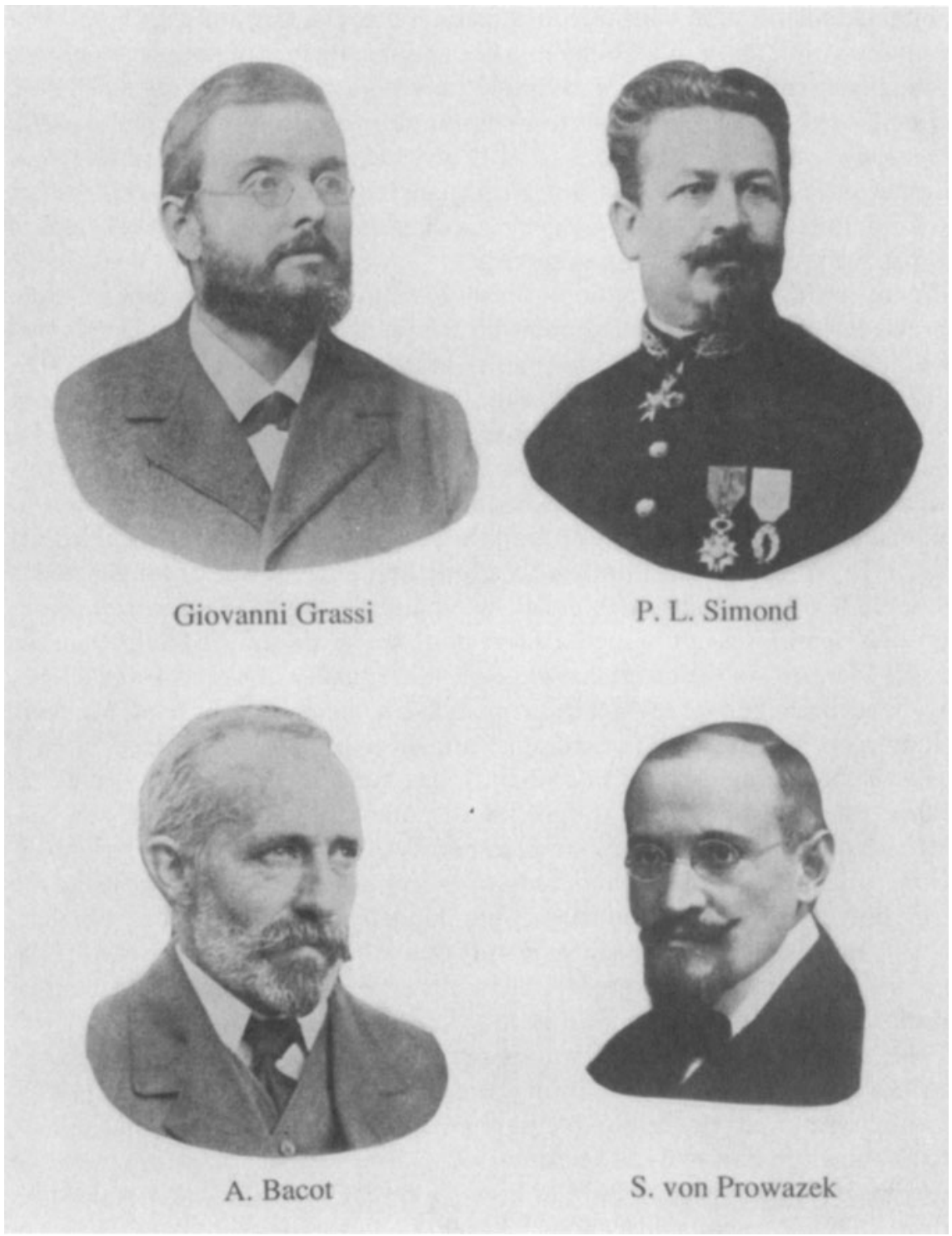

Fig. 1.4. Some European pioneers in the discovery of insect transmission of disease

between Ross and Grassi. The Italians had given scant acknowledgement of the work of Ross or MacCallum in their publications and Ross was infuriated, calling them "brigands". Other British scientists and the American G.F. Nuttall also censured the Italians, though in more restrained terms; and Koch was trenchantly scathing in a letter to Ross (though his own publications seem to me to be notably free from references to other workers). Grassi, for his part, 
maintained his position with vigorous counter attacks. Certainly, he had taken the investigation forward, notably in more specifically incriminating Anopheles, having better entomological information than was available to Ross. Koch, too, had narrowed the vectors down to house-haunting species, naming Anopheles maculipennis and Culex pipiens, in both of which he claimed to have found parasites developing (evidently not Plasmodium in the latter). The whole affair was a prime example of odium academicum, thankfully absent from most cases of the discovery of insect vectors of disease.

In reviewing the contributions of Sir Ronald Ross, one becomes a little depressed at the querulous discontent he exhibited in later life. He complained about inadequate financial rewards and cited the case of the award of $£ 30,000$ to Jenner for introducing small pox vaccine; but the latter was obviously present in England early in the century; whereas malaria was a disease of "natives" and a few hardy travellers and traders. Although one may sympathise with Ross in this matter and to some extent with his resentment of the Italians, it is less easy to condone his evident jealousy regarding the suggestion that Manson guided his work in India, though he admitted to a long and detailed correspondence. $\mathrm{He}$ wrote 110 letters to Manson about the work and received 55 letters back. After Manson's death, Ross published a short book under the title 'Memories of Sir Patrick Manson', in which he insisted on the originality of his own work. That may have been fair enough; but it included some denigration of Manson, including his filarial discoveries, despite numerous assertions of friendship.

By the beginning of the 20th century, it had become generally accepted that malaria was transmitted by anopheline mosquitoes; and already it was suspected that only certain kinds were responsible. In the following decades, it became evident that, of the hundreds of different species of Anopheles in the world, only a very small proportion were important malaria vectors. Furthermore, in any given locality, there were only one or two dangerous species. These facts were gradually discovered in the course of practical efforts to control malaria in different places.

There remained, however, a curious anomaly which was not cleared up until the 1930s. The story of its elucidation is excellently told by L.W. Hackett (1937), who himself played a considerable part in its solution. It seemed that even a species known to be a malaria vector was not always dangerous; there might be places were it transmitted freely and others where it seemed to be harmless. As early as 1899 the Italian malariologist Angelo Celli (1900) pointed out that there were some parts of Italy where Anopheles maculipennis, which had been confirmed as a vector, was very plentiful but did not cause appreciable amounts of the disease as it did in other areas. This phenomenon was later confirmed and extended and known as "anophelism without malaria" (Rouban'd 1920; Wesenberg-Lund 1921).

The first suggestion to account for this was based on changes in the environment which might tend to isolate people from bites of the mosquito. It was pointed out that during recent decades there had been great improvements in rural housing, especially in northern Europe; and it seemed obvious that a 
clean, whitewashed cottage would be less attractive to mosquitoes than a dark, cobweb-infested hovel. Instead, the mosquitoes would probably prefer to visit barns and stables and feed on the animals. In addition to this, more intense farming practices would have led to extensive drainage, which would reduce breeding places for the mosquitoes. Then finally, there was strong medical opinion that the resistance of well-fed people to disease would be greater than that of impoverished peasants.

Unfortunately for this theory (which was likely to appeal to northern malariologists like Col. S.P. James (1920), the location of the phenomenon did not always correspond with the theory. Malaria had been a long time dying out in East Anglia and was still prevalent in parts of The Netherlands and northern Germany, whereas it had vanished from southern Germany, France and parts of Italy.

As an alternative theory, malariologists sought for changes in individual species of anophelines in different localities which might affect their capacity to transmit the disease. Thus, D'Hérelle (1932) studying malaria in the Nile delta, noticed an unusually low prevalence, which he associated with the possibility that the anophelines were feeding on honey from the abundant clover in the region. This idea was soon discredited by observations elsewhere. Another theory involving lower infectability of the vectors was proposed by Alessandrini (1925), who postulated local conditions selecting out a more robust strain of mosquito which might be more resistant to infection by the Plasmodium. In complete contrast, the veteran malariologist Grassi (1922) (perhaps noting the association of malaria with coastal districts) suggested that anophilines which had survived breeding in brackish water might be more robust and live longer, thus being able to transmit the disease more often.

These theories were at least up to date; but there were still a few who could not quite abandon notions pre-dating the discovery of insect transmission of disease. Even as late as 1930, a Dr. Wolter (1930) of Hamburg, having studied malaria in Russia, came to the conclusion that an environmental factor in the soil, perhaps the water table, was involved. This was supported by the Italian engineer Bellincioni (1934), who related the rise and fall of malaria with soil water levels.

Of the various hypotheses proposed, an attractive but misleading one was put forward by the French entomologist, Roubaud (1928). After careful examination of the anatomy of the anopheline vector, he claimed that there was a difference in the mouth parts of the cattle-feeding forms. Their maxillae (rapierlike piercing organs) had more teeth than those of the same species found in human dwellings. He concluded that a strain had been selected which had more powerful piercing mouthparts to feed on the tough hides of the animals. Unfortunately, he was wrong on two counts. Later investigators could find no consistent differences in the mosquitoes which fed on man or beast (De Buen 1935), moreover, there was no evidence of selection for a change in feeding habits. Nevertheless, the matter of feeding preference was recognised to be vital and it began to seem likely that there were pre-existing strains or races within 
the species An. maculipennis with different habits, though indistinguishable anatomically.

Another important difference in habits was discovered by the Dutch malariologists Swellengrebel et al. 1928, who showed that there were two distinct types of the vector in The Netherlands. One form retreated in the autumn to hibernate in a cool empty building; the other entered a human dwelling and continued to feed at intervals during the winter. It was these non-hibernating forms which were responsible for the spring malaria incidence in that country. One further observation was that the hibernating form tended to have longer wings than the other kind. Further illumination on this problem came from some neglected observations of a retired Italian health inspector called Falleroni (1924). Being interested in mosquitoes, he noticed that the eggs of An. maculipennis were marked with black and white patterns; and, most significantly, these were consistent, and there were two different types. He named these after two of his friends: Dr. Messea and Dr. Labrancha. Falleroni's observations were published in 1924, but no one realised their significance until Martini, Missiroli and Hackett (Martini et al. 1931) re-examined the mosquito populations of dwellings and compared them with those in barns and stables. They found very significant correlations, indicating the existence of two different races within the species An. maculipennis in both Italy and Germany. In the next few years, more such races were discovered and named atroparvus (the short-winged Dutch form), sacharovi (first called elutus), melanoon and typicus; these were added to messeae and labranchiae (Hackett and Missiroli 1935). Experiments in which atroparvus was crossed with the other forms revealed varying degrees of sterility, indicating greater divergence genetically (De Buck et al. 1934). Most distinct were messeae and atroparvus; the closest were atroparvus and labranchiae. The distribution of the different forms throughout Europe was worked out.

The importance of the prevalence of the different forms was found to be dependent on their feeding preferences. All of them were found to feed readily on cattle and other animals, but, apart from sacharovi and labranchiae, they were reluctant to feed on man. Those two were more or less indifferent, so that their choice depended on the relative availability of man and farm animals; but wherever they occurred, they were likely to be serious malaria vectors. As for the other types, they were normally harmless except where man was the only source of blood meals. That situation had sometimes occurred in the past before stock breeding had become common; therefore malaria from this cause tended to die out as farming prospered with plentiful domestic animals. One other fact emerged from these studies: the dangerous sacharovi and labranchiae bred most freely in brackish water, which explained the prevalence of malaria in coastal districts. The short-winged atroparvus also preferred brackish water, and because of its hibernating habits, was also a moderate vector.

The various races of An. maculipennis are now regarded as six distinct species, on the grounds of various levels of genetic incompatability. I have dealt with the story of their discovery at some length, partly because of the interesting meanderings of research which led to the truth, but also because they represent 
the first well-established example of sibling species, which are closely allied forms difficult or impossible to distinguish from one another by morphological criteria. Their existence is important because only certain members of the groups may be serious vectors. This is often due to their difference in habits, notably (as in the case of the maculipennis complex) differing propensities for biting humans. Recent research has also revealed some immunological factors in some biting insects which can affect their vector capacity by preventing establishment of parasites in them. Another important possible difference in members of a complex is varying liability to develop insecticide resistance.

In recent decades, examples of sibling species have been found in several kinds of insect. As regards anophelines, by the time the maculipennis complex had been fully established, there was already evidence of similar groups in other "species". An. sundaicus was being separated from An. ludlowi, while An. melas and later An. merus were being distinguished from An. gambiae. Subsequently, the latter was shown to embrace other closely allied species: An. arabiensis, An. quadriannulatus and An. bwambae. Other anopheline species now known to be complexes include An. balabacensis, An. minimus, An. farauti and An. culifacies.

Davidson's (1977) early work on revealing the An. gambiae complex depended on simple crossing tests to show genetic incompatability between colonies. Later, more sophisticated techniques were employed: differences in banding of polytene chromosomes, variation in heterochromatin of mitotic chromosomes visualised by different banding methods, electrophoretic patterns of enzyme systems and species-specific DNA probes. The results are not merely interesting to explain local variations in malaria incidence, but they are important for planning effective control measures.

\section{Yellow Fever}

Yellow fever is a highly dangerous disease endemic in the Neotropics and in Africa, where it probably originated. Almost certainly, various European explorers must have suffered from it during past centuries; but for a long time, it was not clearly differentiated from other tropical diseases, especially malaria. This was partly due to the absence of competent physicians in the tropics, so that the specific signs and symptoms of yellow fever were not recognised. Moreover, there was a general tendency to ascribe a common cause to all "putrid" diseases, believing that local conditions of heat and humidity could produce their effects. An excellent account of the confusion is given by H.R. Carter in 'The Early History of Yellow Fever' (1931).

Though both malaria and yellow fever had evil reputations, they differed in their morbidity and epidemiology in ways that affected Europeans and Americans (Fig. 1.5). Both were deadly to expatriates in the tropics, but this was not because white people were more susceptible to them. The natives in endemic areas inevitably became infected, but if they did not die as infants, they acquired a degree of immunity. 


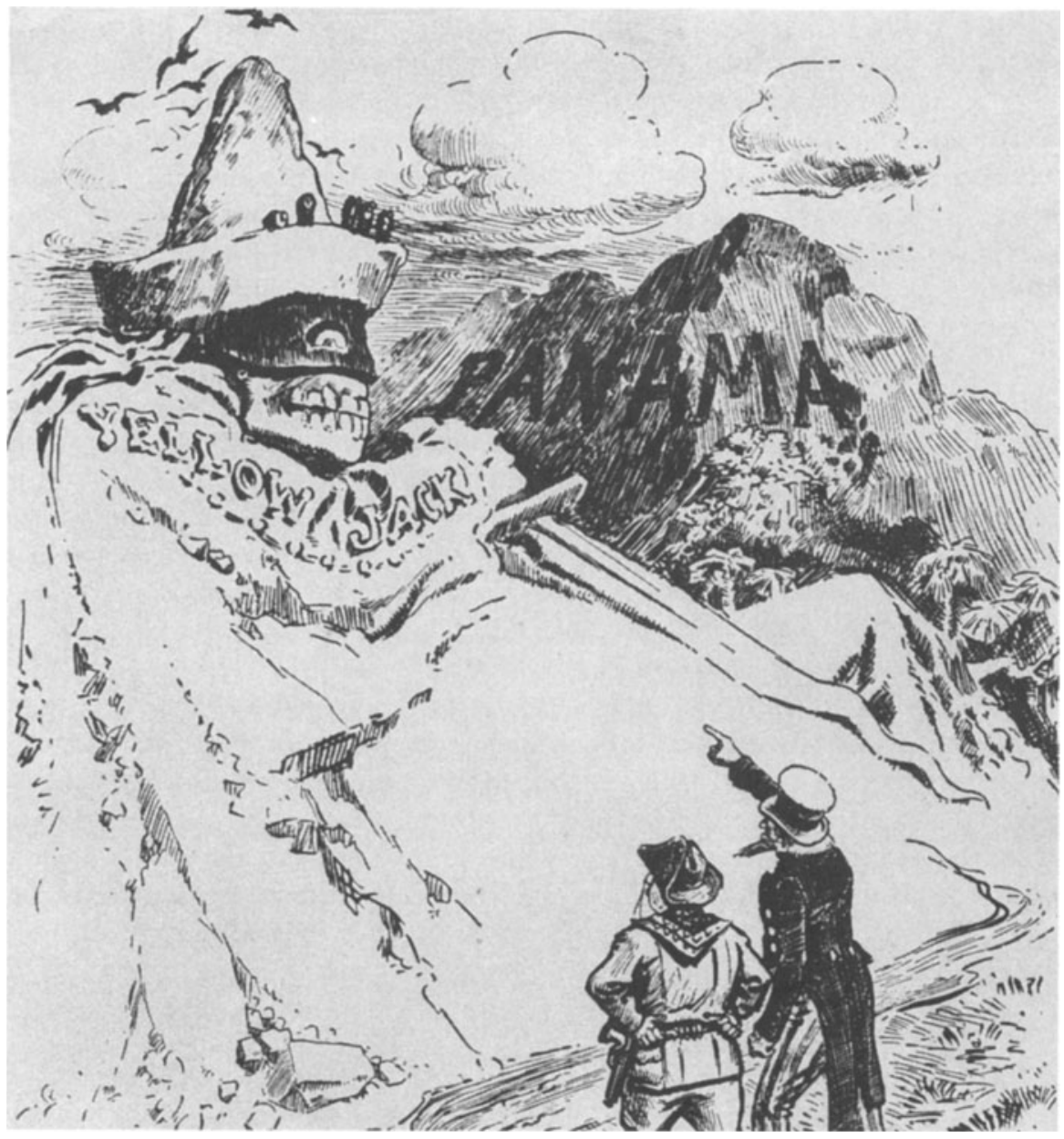

Fig. 1.5. "Uncle Sam" emphasises the danger of yellow fever to Theodore Roosevelt

Malaria does not provide complete and lasting immunity, but a kind of tolerance described as "premunition", which may fade in areas where the disease fluctuates. Northerners entering the tropics as adults were, of course, fully susceptible; but they usually relied on quinine, so that they did not die from early attacks but could develop the deadly blackwater fever. This was a recognised hazard which colonial administrators faced stoically, while merchants felt somewhat compensated by less competitive trade.

In contrast, yellow fever was believed to be slightly less dangerous to children than to susceptible adults, for whom it could be rapidly fatal. Those who recovered, however, were totally immune for life and suffered no ill effects. Consequently, local epidemics tended to die out as the inhabitants died or became immune, though after some years another generation of susceptibles 
would appear and be vulnerable to a new epidemic. However, the natives in yellow fever regions seldom lived in very large communities, so that spectacular epidemics were rare; but in the New World tropics, cities grew up with numerous immigrants from Europe, all, of course, susceptible, so that there were obvious, terrible epidemics. On the other hand, in Africa, which was the only part of the Old World where yellow fever existed, there were few large accumulations of expatriates, so that cases of this disease tended to be sporadic rather than epidemic.

The yellow fever epidemics in the southern cities of the U.S.A. and the Caribbean were frightening, because not only was the mortality of the susceptible cases high (20 to $70 \%$ ), but the onset and course were rapid. No curative drug was available and the physicians were powerless. Moreover, the cause was unknown, though a belief in transmission by fomites persisted, in spite of the evidence of an ingenious Dr. Ffirth (1804), published in a doctoral thesis for the University of Pennsylvania. In this remarkable document, he carefully distinguished contagious diseases, such as measles, venereal infections, vaccinia and small pox, from infectious ones, like typhus, dysentery and "hospital or jail fevers". Then, turning his attention to yellow fever, he undertook some truly heroic experiments, sleeping in the beds of yellow fever patients, injecting their vomit and swallowing some, putting bile, sweat or urine of these people into pockets of his skin, and inhaling vapour of the vomit. In no case did he contract the disease.

In later years of the century, there were the sporadic suggestions of mosquito involvement which I have mentioned, but none as accurate as that of Carlos Finlay; the son of a Scottish doctor and a Parisienne, born in Cuba and educated in France, he took a medical degree in Philadelphia and then practised in Cuba. In 1879 he was invited to join a commission to study yellow fever and soon became convinced that the common house-haunting mosquito Aedes aegypti (then called Culex fasciatus) was involved. His papers give epidemiological evidence and entomological data from Réamur, as well as his own observations (Finlay 1886). Confidently, he began to try transmitting the disease by feeding these mosquitoes on patients and then on newly arrived soldiers, who were persuaded (? ordered) to volunteer. The details of their subsequent condition often record slight fevers (up to $101^{\circ} \mathrm{F}$ ), from which he concluded that they had got mild infections of yellow fever. This, in fact, could not have been due to the bites, since the virus needs about 12 days to become infective in the insect, while Finlay had used them soon after the first meal, believing that passage of the infection would be on contaminated mouthparts. In support of his claim, he suggested that 48 of the 67 cases had acquired immunity to the disease (Finlay 1886).

These trials were conducted over the period 1881 to 1898 . In that year, the brief Spanish-American War aroused increased interest in yellow fever in the U.S.A. The Army set up a medical board headed by Major Walter Reed (Bean 1982), including James Carroll, Jesse Lazear and Aristides Agramonte (Fig. 1.6). They were soon in contact with Finlay, but at first Reed could not believe his 


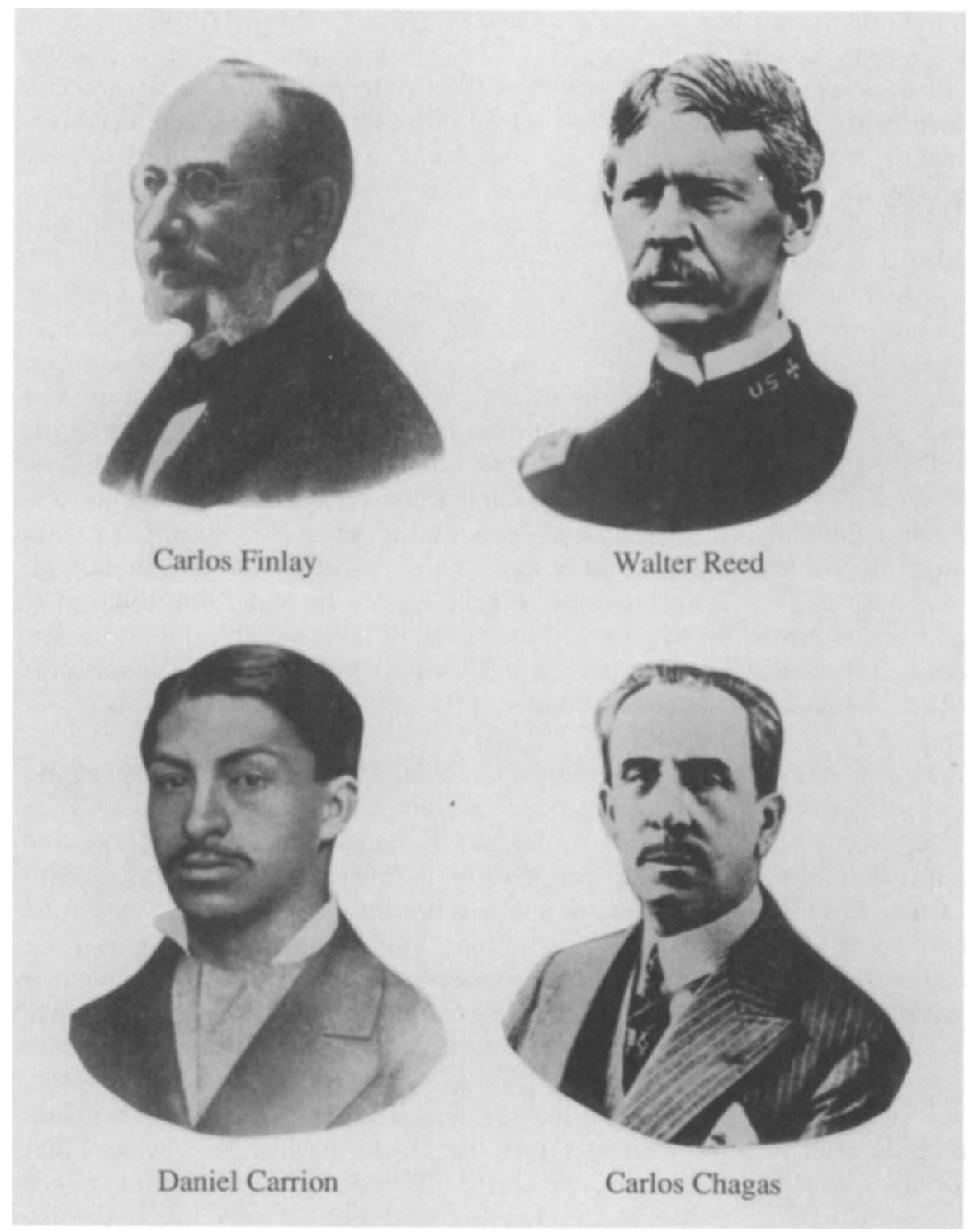

Fig. 1.6. Some American pioneers of the discovery of insect involvement in spreading disease

mosquito theory, pointing out that the blood travels up the mosquito's mouthparts not downwards, presumably not considering the insect's saliva. However, they decided to re-examine Finlay's theories by trials, using a colony of the suspected mosquitoes supplied by him. Incidentally, they found that the eggs would survive drying and the larvae would emerge when they were once again 
immersed in water. As is well known, these experiments supported Finlay's theory; but they were not entirely satisfactory. Lazear, who volunteered to take the test, acquired the disease, became gravely ill and died; unfortunately, he had visited a hospital soon after the bite, which involved the possibility of his having acquired the infection there. Then Carroll recorded an accidental bite, without certain identification of the mosquito before he, too, got the disease, from which he recovered. However, the evidence was more convincing in the case of a civilian clerk who later volunteered and was kept isolated except for the infective bites which gave him yellow fever, from which he, too, recovered. Reed then claimed that the mode of transmission had been proved (giving due credit to Finlay); but doubts remained and many physicians were loath to abandon the traditional sterilisation of fomites.

Reed therefore decided that he needed further proof, using non-immune volunteers. He was easily able to obtain these from the numerous Spanish immigrants, who were in any case aware of the considerable risk of getting the disease naturally. If, however, they recovered from it (and Reed offered the best of medical and nursing attention) they would be immune for life and, with a certificate of immunity, they could command much higher wages, not to mention a reward of $\$ 250$ from the Army Board. Eventually then, experimental transmission trials by Reed and his colleagues proved the involvement of mosquitoes (Reed et al. 1901).

All these experimental infections were, fortunately, light; indeed, many of Reed's volunteers were soldiers anxious to obtain immunity and the $\$ 250$ ! This unfortunately gave Reed and William Gorgas of the Health Department the unlucky idea that artificial infection by mosquito could produce mild disease and confer immunity, by analogy with small pox vaccination. Accordingly, Dr. James Guiteras of the Commission began attempts to test this theory. After some failures to transmit the disease, he found a batch of 11 mosquitoes which produced a mild infection in one man and proceeded to allow them to bite a further seven more persons. Six of them developed severe infections and three of them died, including a young nurse, which predictably aroused serious public concern.

No more such trials were feasible, nor indeed necessary. Despite the sad deaths, the information obtained was invaluable and, in the circumstances justifiable. It revolutionised the attitude to prevention of the appalling disease, showing that fomite disinfection was unnecessary and many of the quarantine procedures also. All that was needed to stop the spread of the disease was to prevent the biting of a particular kind of mosquito.

As with the elucidation of malaria transmission, I will conclude with some later discoveries which have greatly enlarged our understanding of the aetiology of yellow fever. At first, it seemed to be a solely human disease spread by the urban mosquito, Aedes aegypti. Indeed, in 1906, Marchoux and Simond (1906) showed that certain other mosquito species could not transmit. It is true that in 1911 at a conference in Bogata, a certain Dr. Franco (1911) had suggested that there might be other vectors and perhaps other hosts; but for many years this 
warning was disregarded, largely because of the very successful quenching of epidemics in Central American cities by attacks on Aedes aegypti. Indeed, in 1925, it seemed that the disease had been conquered.

In the next few years, however, a series of inexplicable epidemics occurred in South America; some in rural areas and one in Rio de Janeiro which had been free for years. The first suggestion was the existence of endemic yellow fever in rural areas infested with Aedes aegypti, a partial explanation which could be (and was) finally dealt with by greatly extending the usual control measures into rural areas. Later, however, it was noticed (in 1932 to 1938) that some outbreaks were occurring in places without Aedes aegypti (Soper 1938). The explanation for this emerged from a long series of researches by American and British scientists in South America and Africa, after it had been established that the pathogen responsible was identical in the two zones.

The investigations began when a team sponsored by the Rockefeller International Health foundation went to Africa to study the disease there in 1925 . They fairly soon made the valuable discovery that the disease could be maintained in rhesus monkeys, which a Dr. Stokes had brought with him from England when he came to join them. They managed to start a permanent strain of the pathogen in these monkeys, both by blood transfusion and by bite transmission (Stokes et al. 1920). (Sadly, Stokes caught the disease and died.) Then in 1928, J. Bauer a Swede, found that some other African mosquitoes besides Aedes aegypti could transmit the infection; and this was followed by similar findings in South America (Davies and Shannon 1929).

Nevertheless, this was not considered very significant, since yellow fever was still firmly associated with Ae. aegypti. Soon, however, came unexpected jungle epidemics and these were supplemented by rural surveys by two new techniques. Thus, by 1931 it was possible to test for yellow fever antibodies in human blood (indicating recovery from an attack) by a test involving mice. Also, a postmortem test on liver specimens made confirmation of recent deaths from the disease more certain. These two techniques, used widely in South America and East Africa, revealed a wide incidence of the disease in unsuspected ("silent") epidemics.

The next problem was to discover the vector and the reservoir of the virus. Monkeys, which were known to be very susceptible, were obvious suspects as the reservoir; but painstaking research was needed to discover the vectors (Strode 1951). Both parts of the puzzle were finally discovered by an American team in Colombia and a British one in East Africa in the early 1940s. Each confirmed the existence of "jungle yellow fever" persisting in forest monkeys and spread among them by mosquitoes inhabiting the forest canopy. The disease was passed on to men in different ways in the two continents. In South America, the infected mosquitoes were brought down when a tree was felled by forest workmen, and sometimes bit them. In Africa, it was the monkeys which came down to ground level when raiding plantations, where they were liable to be bitten by a different species of mosquito, which also fed on man. In both cases, there was a possibility that men infected in the forests could travel into towns 
before the disease became evident and there infect Aedes aegypti, which might start an urban epidemic. These findings finally destroyed the hope that yellow fever could be totally eradicated from the world, since the forest reservoir could scarcely be extinguished.

It will be noticed that, unlike malaria and filariasis, the investigation of the transmission of yellow fever was not assisted by studies on the pathogen, which was not identified for many years. Indeed, a false trial was first laid by Sanurelli an Italian professor working in Brazil, who claimed to have discovered that the pathogen was a bacterium (B. icteroides), which he suggested might be acquired by inhalation. Also, he claimed that protection could be obtained by an antiserum and some trials were reported allegedly demonstrating this. The claim was investigated by a board of medical advisers sent to Havana and they published a report supporting it in 1899. In accepting this theory, they overlooked some awkward facts. For example, a prisoner in solitary confinement had acquired the disease without contacting a single case. Then a doctor of the Marine Hospital, Henry Rose Carter, who later became an authority (Carter 1931), demonstrated that about 2 weeks always elapsed before an individual could pass on the infection. To counter this, it was suggested that the organism remained dormant in the soil, an unlikely circumstance. Neither Reed and his colleagues nor General Sternberg believed that B. icteroides was the pathogen and declared that its presence in a proportion of yellow fever patients was incidental. Moreover, James Carroll, the English member of the group, claimed to have passed the actual pathogen through a Berkefeld filter, which should have excluded bacteria; and F.G. Novy of the University of Michigan suggested that "like the germ of measles, smallpox, hydrophobia etc., it belongs to a group of organisms smaller than bacteria and as yet unknown, awaiting discovery".

Unfortunately, this correct assumption was temporarily discarded some 10 years later by the claims of an unusual Japanese bacteriologist named Hideyo Noguchi, based in New York. A dedicated worker, he had studied the pathogens of rabies, poliomyelitis, syphilis and (most successfully) Chagas' disease. As part of a Rockefeller-sponsored team investigating yellow fever in Guayaquil (Ecuador), he produced another "red herring" by accusing a spirochaete, Leptospira icteroides, of being the pathogen (Noguchi 1912). (The similarity in the name is due to the Latin word ictericus, meaning jaundiced.) This organism causes Weil's disease, a kind of jaundice with some effects resembling those of yellow fever. It could have been present in some of the yellow fever patients incidentally, since it was known to exist in rats (a common reservoir) in Guayaquil. Noguchi, who had worked extensively on spirochaetes, was convinced that he had found the cause of yellow fever and used a strain of the organism to produce a vaccine. With this he "immunised" many people in the city and claimed that this had reduced the incidence of the disease among them, though his statistics were later found to be quite unsound. Such was his reputation that his claims were accepted by many authorities, though disputed by others, notably Agramonte, a survivor of Reed's group, and Labredo, a Cuban member of the Yellow Fever Commission. 
During the early 1920s, a group of Rockefeller scientists in West Africa sought to find L. icteroides in yellow fever patients without success. Noguchi himself came over to confirm his theories, but eventually succumbed to the disease despite having "immunised" himself. Soon afterwards, the Rockefeller group were able to isolate the pathogen and definitely establish it as a virus.

\section{Dengue}

The disease known as dengue has been known for a very long time as occurring in many hot countries. Though very rarely fatal, it causes fever with extreme pains and stiffness in the joints, which explains the common name of "breakbone fever". There is no specific remedy for it other than what physicians call symptomatic treatment.

The first suggestion that the infection was transmitted by a mosquito was made by $\mathrm{H}$. Graham in 1903 after observing cases in the Lebanon. He suspected the common house mosquito, Culex quinquefasciatus, and claimed to have prevented the disease from spreading through families in a few cases, by fumigating their houses (with chlorine gas!) Then, he induced four young men to sleep under nets into which he introduced batches of mosquitoes collected from houses with cases of dengue, and three of them contracted dengue. It is possible that he included some Aedes aegypti in the batches, as these were later found to be the actual vectors. While examining the blood of patients, he claimed to have found the pathogen, stating that it resembled Plasmodium, which is probably what he saw. This suggested pathogen was discredited by later workers especially Ashburn and Craig (1907), who were able to transmit the infection with blood passed through a filter which excluded organisms larger than 0.05 microns; so they concluded that it was a kind of virus. (Later studies, when the science of virology was further advanced, showed that four related viruses were involved, designated dengue 1, 2, 3 and 4.)

Meanwhile, and apparently unknown to Ashburn and Craig, T.L. Bancroft in Australia had made progress in identifying the vector of dengue, which had arrived in the country in 1885 . He decided that it was not transferred by simple propinquity of the sufferers and suspected an insect vector. Observing a case where some people became infected after a day visit to an endemic locality, he looked for a day-biting insect, and thus suspected "Stegomyia fasciata" (Aedes aegypti). He proceeded to try some experimental transmissions, which were successful in two tests in which volunteers were bitten 10 and 12 days after feeding on a patient. Two other trials, made 15 and 17 days after the infective feeds, were negative. Bancroft's work, published in 1906, was fully confirmed by Cleland and Bradley in 1918.

It might be thought that these investigations had settled the matter, but doubts persisted into the 1920s, with suggestions that dengue was merely a form of malaria (Ingram-Jones 1923), or perhaps sandfly fever (Chandler 1925) (later shown to be a distinct disease), or at least spread by sandflies (Sudler 1927; Cardamitis 1929). Finally, however, the transmission by Aedes aegypti and some 
other members of the sub-genus Stegomyia was established (Schule 1926; Blanc and Caminopetros 1928). It is generally an inter-human disease, but in 1931, it was found to exist as a zoonosis among monkeys in South East Asia (Simmons 1934).

\section{Haemorrhagic Dengue}

In the rainy season of 1953-54, a serious febrile haemorrhagic epidemic occurred in the Philippines, among children of Asian origin, and was often fatal. Studies by Hammon et al. (1956) revealed the presence of two dengue-like viruses in their blood and were designated dengue 3 and 4 to distinguish them from the two already established. The vector was soon identified as Ae. aegypti, from the urban nature of the disease, and Ae. albopicutis added later. The reason for its great virulence seems to be that it follows super-infection of serotype 2 after previous infection with another type, producing a shock syndrome. This might explain the concentration of cases among indigenous people. If so, there is presumably a threat of the haemorrhagic complication appearing in any country where dengue viruses already exist, especially since previous vaccination producing antibodies against one or other of the serotypes might be dangerous. Such dengue-endemic and dengue-receptive areas of the world may include no less than 61 countries, inhabited by 1500 million people. Cases of classical dengue must occur in millions, though the great majority are not reported (Halstead 1982). In Thailand, it is estimated that there are 100 cases of ordinary dengue for each haemorrhagic case. In fact, epidemics of this dangerous disease have occurred in parts of eastern Asia from East Pakistan to Taiwan and south to Singapore and most recently into the West Indies. The spread of classical dengue in the past was limited by the short flight range of the main vector, Ae. aegypti; but now this is greatly increased by extensive travel by air. Between 1956 and 1980 there appear to have been some 350,000 cases with nearly 12,000 deaths. Naturally, the disease has attracted very considerable attention and at a symposium on the subject held at a Congress of Tropical Medicine and Malaria held at Rio de Janeiro, there were many contributions which were later published in the Bulletin of the WHO. Also there were discussions at meetings of the WHO Regional Office for the Western Pacific in 1962 and 1969 recorded in useful reports. Most of the contributions dealt with clinical and epidemiological matters and problems of virology.

\section{Miscellaneous Mosquito-Borne Arboviruses (WHO 1967a)}

As we have noted, yellow fever and dengue were recognised as specific diseases and their vectors identified well before their respective pathogens were properly understood. The existence of pathogens smaller than those visible under light microscopes had been recognised since the tobacco mosaic disease had been ascribed to such an agent in 1898; but the great numbers and varieties of viruses remained unsuspected until the extensive research in the late 1920s and sub- 
sequent decades. It is now evident that there is a very large number of viruses capable of causing diseases, ranging from dangerously virulent down to virtually innocuous (a concept readily accepted by the layman, who accounts for various minor ailments accordingly!)

We are concerned here with "arboviruses" a term short for "arthropodborne viruses", of which some 30 were known by 1930, and many more have since been identified. As a class, they are not always easy to define with accuracy, since most definitions involve exceptions. Transmission to animals is almost always via the bite of a blood-sucking arthropod, but there are some cases of transmission through the milk, urine or even the placenta of an infected animal. Again, many of those which cause human diseases exist separately as zoonoses, and transmission to humans is accidental, often representing a "dead-end" for the virus. Yet, as we have noted, inter-human infections can occur, either via a different arthropod (especially, a mosquito) or through infected human secretions.

In the early days, there were difficulties in identifying these diseases with any certainty. General features could be helpful: the clinical syndromes, the level of morbidity and the age group affected. The pathological effects were of three kinds: the most benign consisted merely of fever, rashes and joint pains; while the pains were often severe, the outcome was very seldom fatal (e.g. dengue and sandfly fever). Other diseases were haemorrhagic, causing bleeding from mucous membranes and other effects, leading occasionally to fatal shock. The third type caused symptoms of encephalitis with effects resembling those of poliomyelitis. The earliest of the arboviruses to be recognised as such (apart from yellow fever and dengue) were Murray Valley fever and Japanese encephalitis, both in about 1925. Characterisation was difficult and, apart from clinical features, depended on effects in laboratory animals. Viruses obtained from fatal cases could be injected into mice (to which they were generally fatal) and subsequently injected intracerebrally into laboratory animals (rabbits, guinea pigs, monkeys or sheep). Various viruses produced characteristic patterns of virulence in these different animals; in addition, a variant of the mouse protection test developed for yellow fever was able to distinguish certain allied kinds of virus. Thus, if a patient recovering from disease $\mathrm{X}$ did not protect the mouse from virus $\mathrm{Y}$, the two could be considered distinct. In subsequent decades, virus identification was facilitated by more sophisticated techniques, such as haemaglutination-inhibition and complement-fixation tests. In this way, viruses could not only be distinguished, but certain affinities between some of them began to be recognised. Three main groups were observed, first designated A, B and (less common) C. These groups did not correspond closely with morphological differences (when these were eventually revealed), but were found to be empirically convenient. Subsequently, viruses were to be classified in families, the major ones being Togoviridae (containing those in the $\mathrm{A}$ group), Bunyaviridae ( $\mathrm{B}$ and $\mathrm{C}$ groups) and smaller numbers in Obiviridae and Rhasdoviridae. However, I do not think that these groupings relate more helpfully to the type of vector involved, nor even to the symptomology. 
The vectors and reservoirs involved were, at first, generally suggested by epidemiological evidence in the particular environment of the disease. Actual proof was liable to be delayed until virological technique was adequate (for example, to extract and identify virus from mosquitoes). In the alarming and mysterious outbreak of encephalitis in St. Louis in the U.S.A. in 1933, Dr. L.L. Lumsden (1958) was sent to investigate its aetiology. Most physicians believed that the infection was spread directly from person to person, like poliomyelitis, or transmitted via milk or water supplies. Lumsden, however, after carefully reviewing all the evidence, (e.g. distribution of cases in space and time) concluded that a mosquito (probably Culex tarsalis) was involved. Considerable support for this theory was provided in the same year, when Kelser (1933) demonstrated transmission of Western Equine Encephalitis to guinea pigs through bites of infected Aedes aegypti; but the transmission of St Louis virus was not actually proved until 1941 (Hammon et al. 1941). Meanwhile, a Japanese worker had claimed in 1937 to have transmitted the Japanese virus through the bites of Culex pipiens pallens; but this could not be confirmed by others, until Hammon confirmed its transmission by C. tritaeniorhynchus (Hammon et al. 1949).

During the 1950s, further evidence of mosquito involvement was provided by the isolation of various viruses from wild mosquitoes (Alexander and Murray 1958 ) and, in some cases, transmission was demonstrated (as for Murray Valley encephalitis, in 1956) (Roseboom and McLean 1956). Subsequent research showed that the quantity varied in different species and that some viruses (such as yellow fever and dengue) could infect only a small range of mosquito species, while others could infect a wide range. After being taken up, the virus could multiply in the insect, which would remain infective for life. Various small vertebrates were found to act as reservoirs of the various viruses, but birds were most important and small mammals next. In some cases the viruses from zoonoses might be harmless to humans, because the mosquito vectors very seldom fed on people. However, the virus might be diverted to another vertebrate host, such as pigs or chickens, and from such new reservoirs pass to man via a different vector.

By 1960, a much clearer view of the status of arboviruses had been obtained (WHO 1967a), with a recognition of their liability to change and evolve, as discussed by the late Dr. C.E. Gordon Smith at a meeting of the Royal Society of Tropical Medicine and Hygiene (Proceedings Vol. 54, p. 113). He pointed out the unequal distribution of known arboviral infections, by far the majority being in the tropics. Of the 87 kinds recognised in 1957, the numbers in different areas were as follows: Neotropics, 27; Ethiopian Tropics, 24; Oriental Tropics, 15; (total tropical, 66); Nearctic, 9, Palearctic, 12; (total, 21). At the same meeting, Dr. P.F. Mattingly, gave an impressive paper on the ecological and evolutionary aspects of the arboviruses transmitted by mosquitoes, which constitute the majority (about $75 \%$ ), with some $20 \%$ spread by ticks (mainly ixodids) and a few by sandflies of the genus Phlebotomus. He suggested that the arboviruses originated in avian hosts and mosquitoes of the genus Culex. 
The following are a few of the better-known arboviruses spread by mosquitoes, beginning with those identified before the Second World War. As their numbers increased, it was found convenient to distinguish them by capital letters, thus: yellow fever $=\mathrm{YF}$ etc.

Japanese Encephalitis (JE). This disease has occurred widely in eastern Asia for many years and was known to cause dangerous illness as long ago as 1871 . More recently, quite large epidemics have occurred; for example, in 1948 there were 4757 cases in Japan with 2620 deaths, and in Korea in 1958 some 5700 cases with 1322 deaths. It has been most intensively studied in Japan, where the virus was isolated in 1925 .

Later, the main vector was identified as Culex tritaeniorhynchus, which breeds in rice fields, marshes and clear water round fields. While this is responsible in the area from the eastern U.S.S.R. down to Malaya, the vector in India is apparently $C$. vishnui. The wild hosts are believed to be birds, though certain bats have been shown to maintain the virus for long periods. Domestic pigs are important reservoirs, since they not only occur close to man, but can act as amplifiers of the virus; thus, a pig can be infected by a single mosquito, but it can reinfect hundreds of mosquitoes (WHO 1962a).

Australian X Disease, Later Known as Murray Valley Encephalitis (MVE). In 1917 and 1918 a mysterious epidemic of encephalitis occurred in the southeastern states of Australia, which particularly affected children, with a high $(40 \%)$ mortality. There have been some later outbreaks, for example in 1951; but though the disease is potentially dangerous, the numbers involved were few. (There were 40 cases among a population of 150,000 at risk.) The virus was identified as such in 1925, and from general local observations, the vector was suspected to be Culex annulirostris, which breeds in shallow fresh water pools over a wide area. The maintenance hosts appear to be birds in the northern tropical regions from which the infection may be brought down south by migrating water fowl.

The next few arboviruses have caused moderately serious epidemics in the Americas, especially in the U.S.A., though they have been identified in other parts of the world. In 1954, Dr. F.F. Ferguson published a detailed review of all the useful information on the American incidence. He mentioned that up to that time, there had been 27,784 cases in the U.S.A., though relatively few had been actually identified as arboviruses. All of them had been found to be infectious to horses, to different degrees, but often fatal; but although some (like VEE) were mainly veterinary problems, SLE was mainly a human disease.

St Louis Encephalitis (SLE). This virus appears to be confined to the U.S.A. The first recognised cases occurred in Paris, Illinois in 1932 and in the following year there was a serious epidemic in St Louis County, Missouri, with 1100 cases and 200 deaths. Probably it had been endemic in the area without recognition. Later outbreaks of the disease were identified in California and Washington 
State. The vectors are domestic mosquitoes, mainly Culex tarsalis and $C$. pipiens, with a reservoir in wild birds. From these, it could be brought to humans via domestic poultry.

Western Equine Encephalitis (WEE). As the name implies, this is mainly a disease of horses, to which it can be fatal; but it can also attack humans, the first case being recorded in 1938, 5 years after the virus had been isolated from a horse. The vector is also $C$. tarsalis, with a probable reservoir in wild birds.

Eastern Equine Encephalitis (EEE). This virus, identified in 1933, also attacks horses and (rather infrequently) humans, the first human case being recorded also in 1938. Apart from in the Eastern states of the U.S.A., it has also been recorded in the Philippines and, rather surprisingly, in Czechoslovakia. The natural reservoir is wild birds, especially the ringed pheasant in the U.S.A., and it is transmitted by culicines, especially $C$. melanura. The vector seldom bites man, which explains the infrequent human cases.

Venezuelan Equine Encephalitis (VEE). This has been responsible for serious epidemics among equines in South American countries, often with fatal results. It was identified in 1938. Curiously, though being quite dangerous to laboratory workers, it seldom attacks people in the field. The vectors are probably Mansonia titillans and species of Aedes with the usual reservoir in wild birds.

During the 1950s and 1960s, a considerable number of additional arboviruses were identified, mainly in tropical regions, especially Africa. No doubt these were endemic infections which had not been previously noticed, presumably because of their relatively localised distribution; moreover, they would have been less noticeable than many other dangerous tropical diseases. They were extensively studied by workers at the Yellow Fever Institute at Entebbe, in Uganda. After the epidemiology of yellow fever in East Africa (as described earlier) had been elucidated, attention was turned to other viruses which occurred from time to time. Some of them were isolated from people who were suffering from symptoms suggesting viral origin, initially thought to be due to dengue. Laboratory tests, however, proved otherwise (and dengue seemed to be absent from the region). Viruses were obtained not only from humans, but some also from monkeys and mosquitoes. Culicines were mainly, but not exclusively, involved. The ecology of some species which were important in maintaining the reservoir (monkeys and birds) were studied from a platform high up in the forest canopy, by W.H.R. Lumsden, A.J. Haddow and others. Considerable investigations were often necessary to connect a virus with a particular disease (if any) or to match isolations from mosquitoes with humans, or vice versa. An interesting account of these problems is given by Gillett (who was involved) in his book Mosquitoes (Gillett 1971). He pointed out that most of the viruses first discovered were named after the locality in which they were found; but later ones, which were responsible for painful diseases, were named after the vernacular equivalent of the common English name for dengue: "breakbone" 
(e.g. Chikungunga and O'nyong nyong). The dates of isolation of some of these East African viruses are as follows: Rift Valley, 1931; Bwamba fever, 1937; West Nile, 1937; Ntaly, 1943; Uganda S, 1947; Zika, 1947; Chikungunga, 1955; O'nyong nyong, 1960. The most important of these, responsible for epidemics among humans, are the last two. (Chikungunga has affected some 40,000 casesf).)

\section{Diseases Spread by Higher Diptera}

The next insect-borne diseases to be elucidated were those spread by tsetse flies and houseflies. These appear to be very different insects, mainly because of the blood-sucking by the tsetse flies. However, this is not so extraordinary if we consider the same habit in the stable fly, which closely resembles the housefly, so that people often complain that the latter has bitten them. All three belong to the same family, which can be described as being one of the "higher" forms of Diptera, because they are the most advanced evolutionarily. With the houseflytransmitted diseases, I have included those spread by other non-biting flies, the eye flies.

\section{Sleeping Sickness}

The West African disease causes a gradual relapse into a comatose condition, which usually ends in death if untreated, and was noted by visitors to Africa in quite early times (Scott 1939). Perhaps the first was an Arab who, in 1373, described the illness and death of a native king who lived near the Niger. A 1742 account by a British naval surgeon has been quoted as follows: "The Sleeping Distemper, common among Negroes, gives no other notice than a want of appetite two or three days before; their sleeps are sound and sense of feeling very little; for pulling, drubbing or whipping will scarce stir up sense or power enough to move, and the moment you stop beating them they fall down again into a state of insensibility. ... Young people are more subject to it than old, and the judgement is generally pronounced death, the prognosis seldom failing. If now and then, one of them recovers, he generally loses what little reason he had and turns idiot." In 1803, a colonial surgeon called Winterbottom gave a further description, adding the characteristic sign of enlarged glands in the neck. This disease, described as "Negro lethargy" was also noted in slaves transported from West Africa and attributed to unhappiness and homesickness. However, physicians who saw the disease in West Africa made vague suggestions relating their sufferings to vegetable poisoning, smoking cannabis or sunstroke. Clues to the aetiology of this disease were finally provided by discoveries in the veterinary field which led to the elucidation of a related disease of imported horses and cattle, known as nagana. It is arguable that nagana had almost as much effect in retarding civilization in Africa, since the inhabitants were denied the milk of cattle, their meat and that of pigs, the mobility and ploughing potential of horses 
and oxen and the manure of all of them. Moreover, European penetration of the interior was delayed for centuries for lack of horse transport.

The interaction of Europeans and Africans is a very complex subject; because both tsetse and trypanosomiasis are involved, it is discussed in Buxton's (1955) great monograph on the subject. The modern vogue for self-depreciation by white men rightly deplores the horror of the slave trade. While it should be remembered that slavery was the fate of those captured in African tribal raids, it was magnified by the Arabs and later the Europeans. On the other hand, there are many benefits introduced by the colonists, (as by the Romans in Europe): civilized amenities and pacification of the land, thus preventing tribal wars. However, as Nash (1969) pointed out, these well-intentioned actions brought some harmful consequences, notably in regard to trypanosomiasis. Before the Europeans came, most Africans lived in large communities, often protected by a walled town for safety against raiders. The surrounding land was cleared and used for growing crops, which rendered it unsuitable for tsetse. After tribal raids were curtailed, the "people tended to move out of the defended towns with their exhausted farmlands and to form small hamlets in tsetse-infested bush", thus becoming more exposed to infection. Ford (1971), too, illustrated another aspect of European penetration, pointing out that colonialism diminished the power of the chiefs and the priests, upsetting established patterns of life. Moreover, the attraction of relatively well-paid labour on plantations increased the dispersion of Africans, which tended to spread the infection. A final effect of civilized contacts was the growth of large cities, surrounded by "shanty town" suburbs. Against these harmful effects can be set our efforts to discover and prevent various tropical diseases, including trypanosomiasis.

As usual, the evidence which was eventually to reveal the aetiology of sleeping sickness came from several different sources; notably from epidemiological studies and from investigations of the pathogen. For a large part of the 19th century, however, the two kinds of information were pursued separately. Trypanosomes parasitic in the blood of animals were first discovered in the trout by a German professor working in Berne in 1841, and soon afterwards by other workers, in frogs and other amphibia. In 1879, Timothy Lewis (whom I have mentioned p. 14) found them in the blood of healthy Indian rats (Lloyd et al. 1933), and in 1880, Griffith Evans $(1881,1882)$ saw them in the blood of horses and camels suffering from the fatal disease "surra". Although he imagined this infection to be acquired by their drinking infected water, he made the significant observation that it might also be conveyed when biting flies, interrupted in their feed, moved quickly to another beast.

So much was known when David Bruce began his investigations into nagana and sleeping sickness. A recent paper by Dr. A.J. Duggan (1987), summarises accounts of the life and work of this remarkably able man. In 1887, at the age of 33, as a member of the Royal Army Medical Corps, he discovered the causal organism of Malta fever, after 4 years study on the island. The LieutenantGovèrnor of Malta, who had subsequently become Governor of Natal and Zululand, arranged for Bruce to come out to South Africa to investigate nagana 
in 1894. Within a few weeks of arrival, he had discovered the parasite in the blood of infected animals, describing it as a haematozoan. Then came a 7-month interval in his studies because, like Ronald Ross, he was subject to army duties and was recalled to Natal. On return to Zululand, he continued intensive work, assisted by his wife, who made excellent illustrations of the parasites, which he now identified as a trypanosome. Transfusion trials with dogs and horses proved it to be responsible for nagana. Identification of the vector was facilitated by the fact that there were well-known native traditions accusing the fly, which had been reported by earlier travellers, such as James Bruce in 1813 and Captain (later Sir) William Harris in 1839. The descriptions of the biting flies were somewhat vague, but Livingstone had no doubt that they were tsetse flies at the time of his first African journey in the 1850s. In the fascinating account of his travels, he mentions them several times, stating that on one occasion his party lost 43 fine oxen, following their bites, even though "not a score of flies" had been seen to attack the herd. He gave a fair description of Glossina morsitans, a figure of which is given on the front page of his "Missionary Travels and Researches in S. Africa' (1857). Of the bite, he wrote: "The poison does not seem to be injected by a sting, or by ova placed beneath the skin, for, when one is allowed to feed upon the hand, it is seen to insert the middle prong of three portions into which the proboscis divides, somewhat deeply into the true skin. ... The previously shrunken belly swells up and, if left undisturbed, the fly quietly departs when it is full." Later, after a description of the disease symptoms, he adds: "These symptoms seem to indicate what is probably the case, a poison in the blood, the germ of which enters when the proboscis is inserted to draw blood. The poison germ, contained in a bulb at the root of the proboscis, seems capable, though very minute in quantity, of reproducing itself. . .." Some 10 years later, Dr. (later Sir) John Kirk (1864) provided further information from his own travels and those of others. He corrected one error of Livingstone, stating that dissection of the mouthparts of the fly revealed no poison gland. The puzzling potency of so small an injection of saliva producing such a fatal effect in large animals made some people sceptical about the dangers of tsetse flies; though, as early as 1897, J.J. Drysdale suggested the possibility of a living pathogen.

Bruce, therefore, had little difficulty in identifying the vector of nagana. $\mathrm{He}$ confirmed it by sending dogs and oxen into known "fly belts" and soon found trypanosomes in their blood, followed by the disease. His results were published in two reports (Bruce 1895, 1896), the second giving an account of the unusual life history of these insects which, unlike other insects, do not lay eggs; instead, the female retains the larva in a kind of ovary until it is fully grown. It is then deposited on the ground in a selected place (which varies with the species) and the grub immediately burrows into the soil and pupates. These discoveries drew the attention of entomologists to tsetse flies, and a few years later E.E. Austin's (1903) excellent monograph was published by the Natural History Museum. This summarised both the biological information available and (with extracts) the observations of travellers and naturalists. It provided details of the anatomy 
of the more important species, and their identification was facilitated by the beautiful coloured illustrations of them by the Italian artist Terzi, who worked in the Museum.

The involvement of tsetse flies with sleeping sickness was not easily apparent because the more common West African form of the disease is slow to take effect and may take many months between the infective bite and the final comatose stage. This type of sleeping sickness was endemic, but there had been no alarming epidemics. However, at the end of the 19th century, the disease had travelled eastwards to Uganda, possibly because of the movements of infected Africans with European explorers and adventurers. For example, in 1887, Henry Stanley led an expedition with numerous bearers and their wives from the Congo across to Upper Egypt, to the relief of Emin Pasha (who was besieged by the Mahdi), and some of these Africans settled in the area. In any case, at the turn of the century, there was a terrible outbreak in the region of Lake Victoria, which eventually caused the deaths of two-thirds of the local population (about 300,000 ). This appalling epidemic attracted the attention of the British, and the Royal Society sent out experts to Uganda to investigate the disease. About the same time, the Liverpool School of Tropical Medicine sent Everett Dutton to study it in Gambia. There, the colonial surgeon A.M. Ford showed him parasites in the blood of an African patient, which Dutton (Dutton and Forde 1902) recognised as trypanosomes. However, the connection with "negro lethargy" was not immediately recognised, though the parasite was connected with "trypanosomal fever", which occasionally infected Europeans and had been seen in a case in England. Meanwhile, Sir Aldo Castellani in Uganda had discovered trypanosomes in the cerebrospinal fluid of sleeping sickness victims (Castellani 1903) and showed them to Bruce, who suspected the tsetse fly, from his experience with nagana. Soon afterwards this was proved in a joint investigation with Nabarro and Greig in 1903 (Bruce et al. 1903).

While this investigation seemed to be conclusive, there were still anomalies which caused some foreign workers to express doubts. It had to be admitted that sleeping sickness did not occur in parts of the world where tsetses did not exist, yet there was not always a good correlation between the incidence of the disease and numbers of tsetses. Koch (1907), for example, discovered tsetse-free areas where the women were infected and suggested that their husbands became infected while away hunting and passed it to them in sexual intercourse. Then, in a Report of a French Mission to study the disease in the Congo, Mesnil (1908) mentioned other examples of places where there was disease, though tsetses were rare. His conclusion was that there might be other blood-sucking insects (such as Stegomyia or Simulium) which could pass the infection via contaminated moutharts if interrupted in a feed on an infected person. In general, however, he agreed that the main vector was Glossina.

For a long time, Bruce himself thought that transmission by tsetses was passed in the same way, without development in the insect. This, indeed, can occasionally occur; but usually there is a cyclical development in the fly, as suggested by Kleine in 1909. Bruce and his colleagues (1911) re-examined the 
matter and confirmed this, while the full cycle was elucidated by Muriel Robertson in 1913.

Meanwhile, parasitological investigations had sorted out various kinds of trypanosome in the blood of wild "game" animals (T. vivax, T. congolense and T. brucei). The kind responsible for the "classical" West African sleeping sickness was known as T. gambiense (Fig. 1.7).

In 1910, Stephens and Fantham discovered a different kind of trypanosome in a human case in East Africa, which they named T. rhodesiense. Two years later, its transmission by G. morsitans was demonstrated by Kinghorn and York (1912). It rather strongly resembled T. brucei, which causes nagana in animals but which is harmless to man; and there were some who suggested that this was merely a strain that had become adapted to humans (Carpenter 1920-21). By 1924, however, Brumpt's investigations pointed to it being a distinct species, and this is now accepted. This pathogen causes quite a different sort of disease, being much more acute and being relatively rapidly fatal if not treated. Although more dangerous in this respect than the "Gambian" form of the disease, the "Rhodesian" type has always been rarer and has occurred in scat-

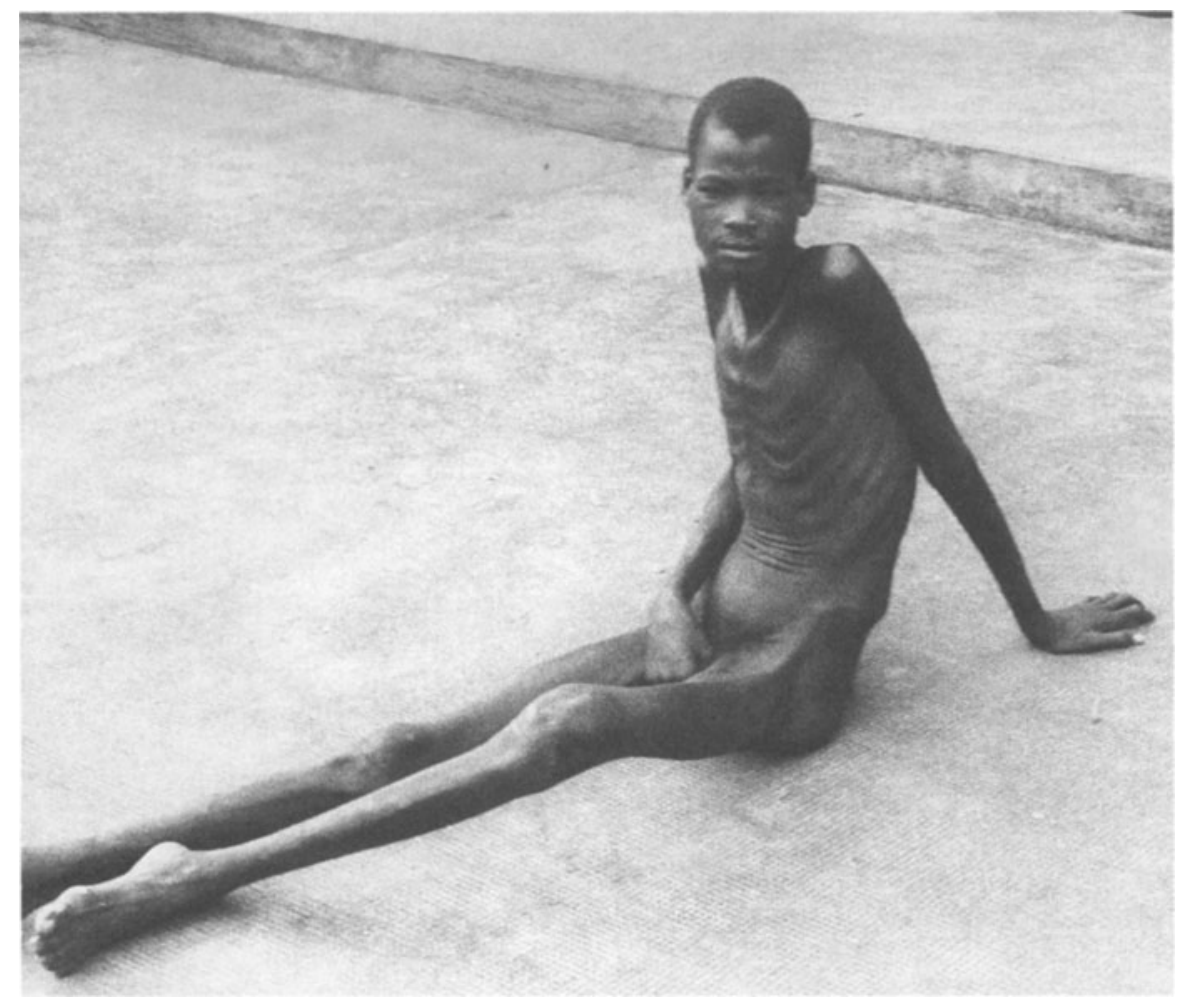

Fig. 1.7. An African in the late stage of Gambian sleeping sickness. (Photograph courtesy of WHO) 
tered locations in East Africa. It always seemed unlikely to be transmitted directly from man to man by tsetse flies, because infected people were soon acutely ill and likely to be lying in their huts. The acuteness of the illness suggested a pathogen ill-adapted to humans, since it is clearly a disadvantage to kill one host before transferring to another. This indicated a zoonosis, occasionally transmitted to humans; and since men were more often infected than women, it seemed likely that they had been infected from game animals while out hunting. This was not actually confirmed until 1936, when Corson (1936) transmitted $T$. gambiense from a human case to sheep and continued cyclical transmissions between G. morsitans and various animals. Then, 22 years later, Heish et al. (1958) proved an actual isolate from a wild bush buck, which was infective to man.

Further studies on the infection process revealed several important facts relating to both nagana and sleeping sickness. The trypanosome species responsible for these diseases were to be found either in the front of the insect's alimentary canal or in the mid-gut. Those to be found in the front (rather quaintly described as the "anterior station") had either remained there or had reached the site after a complex cycle elsewhere. Rather naturally, the species which had remained there, $T$. vivax, was most frequently found, and the next most common was $T$. congolense in the mid-gut. These two were responsible for nagana, as was also one of those which had made the complex cycle, T. brucei. Two other species which had made the journey, T. gambiense and $T$. rhodesiense, were the ones responsible for sleeping sickness.

Association of the disease with the vicinity of water courses led to the identification of the main vectors in West Africa: Glossina palpalis and $G$. tachinoides. In many regions, there is frequent association between these flies and people who come to collect water, bathe, or merely to cross fords of rivers and streams. Hence, there were seen to be many opportunities for these tsetse flies to bite people repeatedly and thus transfer the infection, which is almost exclusively a human disease. No other host has been definitely established, though there are certain suggestions that pigs or dogs might be involved.

\section{Diseases Spread by Houseflies}

Non-biting insects are capable of transmitting infections if they have habits which may transfer pathogens from septic matter to human foodstuffs, or even from sores to mucous membranes. Virtually always there are other pathways of infection, so there is not an exclusive connection like that of malaria and anopheline mosquitoes. Nevertheless, various insects are potentially capable of such transmission and once, many years ago, I visited a childrens ward in a hospital where German cockroaches (Blattella germanica) were spreading enteric disease by alternating between soiled babies' napkins soaking in buckets and exposed food, but such opportunities for the pathogens are fortunately rare and much more often the danger has been from the common housefly. 
Apart from the unpleasant habits of these constant companions of man, they tended to draw attention to themselves (like mosquitoes) by the nuisance they caused. Yet a few people had a good word for them; for example, the 18th century minor poet, William Oldys, who wrote: "Busy, curious thirsty fly/Drink with me and drink as I." A rather more bizarre idea was quoted in a book by Sir John Lubbock (1871) (later Lord Avebury) of a statement made in the House of Commons: "The fly keeps the warm air pure and wholesome by its swift and zigzag flight." Sir John had no illusions on the matter, however, mentioning the fly's habit of laying eggs in decomposing matter and wounds, so that it was anything but pure. He also called attention to its probable involvement in spreading opthalmia in Egypt by its "constant attention to bleary eyes". Others, too, had opinions on this subject; for example, certain remarks of Dr. William Budd in 1862, who was convinced of their involvement in opthalmia transmission. This was also supported by Laveran (1880), speaking of the disease in Biskra, Algeria, he remarked on the eyelids of indigenous children being covered with flies, to which they passively submitted, and which he believed would carry the infection to others. (He also thought that this could happen with oriental sore.) Houseflies were accused of transmitting opthalmia by Koch (1883) in 1883, after a visit to Egypt (though he was more concerned with fomites) and also by the American Dr. Lucian Howe (1888), speaking at a Congress of Ophthalmology in Wiesbaden in 1888. Among other early writers who strongly suspected flies of transmitting such infections were Braum (1882), Demetriades (1894) and German (1896), all cited by Abel (1899).

Hewitt (1914), who recorded these observations, corresponded with Dr. Andrew in Khartoum, who agreed with them and pointed out that ophthalmia was less common in the Sudan than in Egypt, as were also the flies. Dr. MacCallan of the Egyptian Department of Health, gave his opinion that, while flies were responsible for much ophthalmia, they were less involved in transmitting trachoma, which he thought was more often effected by fingers, soiled clothing etc. Hewitt also obtained specimens of the offending insects, which he identified as the common housefly, Musca domestica. We must take his word for this, but not forget that in hot dry countries there is an even more irritating species liable to visit human eyes, closely allied to the housefly and resembling it except in minor details, called $M$. sorbens, which has similarly been accused with spreading ophthalmic infections.

Flies and Enteric Diseases. It will be observed that, apart from the vague generalisations of Mercurialis and Sydenham, the earliest accusations of flies spreading disease concerned ophthalmic infections. Later physicians, however, turned their attention to enteric diseases, an obvious possibility because of the habits of flies, which are liable to visit infected human faeces and later contaminate foodstuffs. This possibility became evident after the pathogens responsible were identified; and an early suggestion of dissemination of cholera germs by flies was made by Nicholas in an 1873 letter to the Lancet, describing his observations in a Malta hospital in 1849 where "large numbers of these 
voracious creatures, present in great numbers and having equal access to the dejections and the food of the patients, gorged themselves indiscriminately and then disgorged themselves on the food and drinking vessels". He also noted that H.M.S. Superb, like others of the Mediterranean fleet, suffered a great deal with cholera when in port, where flies were plentiful, but after a time at sea, when the insects disappeared, the disease subsided. Military camps in hot countries during the 19th century were also prone to suffer from cholera. Sir John Moore (1893), as Surgeon General to the British Forces in India, after 20 years service in that country, strongly deprecated the siting of latrines, and sometimes hospital tents, close to the cooking areas. He contended that the germs of cholera (and possibly other diseases) "would be conveyed to the soldiers' food by flies"; and he quoted some tests in which extracts of fly guts had caused cholera in guinea pigs. If such conditions could exist in peace time, they were likely to be exacerbated during wars. In 1871, the American doctor Leidy (1872) declared his belief that the spread of gangrene infections in wounds during the American Civil War was largely due to flies. Later, Reed (1899); having observed conditions during the 1898 Spanish-American War, attributed the numerous cases of enteric infections to flies. Similar suggestions were made by Tooth (1906) and others during the Boer War.

However, one did not need to go to army camps to find epidemics of enteric disease in the early years of this century; moreover, suspicion was soon falling on houseflies. A Dr. Fraser (Fraser and Nash 1902, cited by Howard 1911) referring to an epidemic of diarrhoea in Portsmouth, stated “... the occupants told me that they had suffered from a plague of flies and that every article of food was covered at once with them. . . I repeat that to this, and this alone, I attribute the diarrhoea in the Goldsmith Avenue District". This was in 1902; and in the next year, Dr. Nash of Southend-on-Sea pointed out the association of the disease with warm weather and likewise considered houseflies to be the chief carrier of it. There were certainly opportunities for flies to visit exposed human faeces at this time; for example, a Local Government Board Report (Sweeting 1909) recorded that in the borough of Rotherham there were no less than 2248 privy middens as compared to 8500 water closets. Another similar report (Yohnstone 1909) on a typhoid epidemic in Orınsby in 1909 stated that 1301 houses had privy middens and 1296 had pail closets. Previously, in 1898, the privy middens were nine times as common as the pail closets, so that some minor improvement was being made; however, the installation of water closets was strongly urged. Even more backward were parts of the U.S.A. at this time. In 1910 Stiles published a survey of conditions in certain southern states and found that $55 \%$ of farms had no privy at all $(35 \%$ of white and $76 \%$ of black dwellings). Facilities in other parts of the world were described in a series of papers by Major F. Smith (1903), R.A.M.C., who compared the human defaecation habits and general arrangements in South and West Africa, India, Malaya and England. These ranged from using the shelter of a bush or the open, a latrine trench or pit, the sea, or a river, a privy midden, a pail and finally a water closet. The last mentioned was by no means universal in England, as I have noted; and 
the collection of "night soil" from privies was often done with a half-open cart, with buckets and a kind of ladle to empty out the contents of the pit. In all these cases, there was frequent exposure of faeces, which could be visited by flies.

All this evidence finally induced scientists to seek for further proof of the role of houseflies as vectors of disease, which was necessary because both of the most strongly suspected diseases could be spread by other means. Ophthalmic infections could be spread by human fingers or by shared towels. As for enteric diseases, there was the possibility of contamination of water supplies by leakage from drains, as in the case of the well-known pump in Soho, which Dr. John Snow showed in 1854 was distributing cholera to households using its water. Another important method of spread was from the fingers of infected people, especially those preparing food, some of whom could carry infection without being much affected. There was the famous case of "Typhoid Mary", a cook in New York, who in 1906 was found to have caused at least ten outbreaks of that disease, including three deaths. Another reason for needing more exacting scientific investigation was sometimes an over-enthusiasm for attributing to flies the spread of a whole range of unlikely diseases, such as plague, syphilis and sleeping sickness.

In Britain, a systematic attack on the problem was begun in the early years of this century, by Graham-Smith in Professor Nuttall's department at Cambridge and by C. Gordon Hewitt at Manchester University. To begin with, both made a careful survey of the literature, which was fairly substantial. Among the many names, it is interesting to find some who contributed to the elucidation of other insect-borne diseases: A. Laveran in 1880, G. Grassi in 1883, A. Celli in 1888, W. Reed in 1899, A. Castellani in 1907, E. Roubaud in 1908, A.W. Bacot in 1911 and S.T. Darling in 1912.

A survey by Nuttall and Jepson in 1909 considered no less than 15 diseases, including yaws, plague and tuberculosis, as well as the more probable enteric and ophthalmic infections. There were two main kinds of evidence to evaluate. Flies could be caught and examined for pathogenic bacteria, which were not infrequently found. However, the significance of this depended a great deal on the circumstances of the capture. For example, Yersin (1894) collected some flies in a room where he had made post-mortem examinations of animals dead of plague, and from them was able to transmit the disease to some laboratory animals; but this was scarcely proof that flies were normal vectors of plague. On the other hand, the facts that Tizzoni and Cattani (1886) cultured cholera vibrios from flies taken in a hospital ward and that Tsuzuki (1904) did the same with flies caught in a cholera house, while Flicker and Hamilton independently isolated B. typhosus from flies taken in houses with typhoid patients, seem decidedly important. Moreover, before the First World War, there were various records of pathogenic bacteria being detected in flies captured in the general environment of cities, for example: Salmonella spp., Staphylococcus spp. and Streptococcus spp. (see list in West 1951).

Of lesser significance were experiments in which flies were artificially fed on bacterial sources to see whether the organisms survived in their intestines. Many 
such were positive; but this merely indicated the possibility of transmission. The British investigators I have mentioned continued these experiments and also improved the technique. The results of the Cambridge group were published in a series of reports to the Local Government Board between 1909 and 1913. Then most of the important data were collected together in Graham-Smith's book (1914). 'Flies in Relation to Disease (Part 1: Non-Blood-Sucking Flies)'. In the same year (1914) Hewitt published his monograph on 'The House Fly', which contained his own and other results of tests as well as general biological information. (At the time, he had left Manchester and become Dominion Entomologist for Canada, at Ottawa) Another very useful book on these lines was 'The House Fly, Disease Carrier; an Account of its Dangerous Activities and Means of Destroying It', published by the American L.O. Howard in 1911.

The general conclusions which emerged from these substantial works were as follows. Flies taken in dining halls or kitchens could be found to contain various kinds of bacteria. In the laboratory, flies fed on syrups containing pathogenic or other bacteria were killed later at intervals and the legs, heads, crops and guts examined for the presence of the microorganisms. It was found that non-spore-bearing bacteria could survive up to $18 \mathrm{~h}$ (though often less) on the legs; but, more significantly, in much greater numbers for up to 18 days in the intestines. In addition, some eggs of intestinal parasitic worms could be ingested by the flies, but only those less than $0.05 \mathrm{~mm}$ in diameter. As regards transmission possibilities, the hazard from direct contamination from the legs or feet was therefore less serious than that from defaecation by the fly, since the organisms could survive longer in the gut. Another method of contamination was the regurgitation by the fly, a common habit, of what was called the "vomit drops". Other significant information from British and foreign investigators concerned flies bred from infected material. It was found that some pathogens, such as typhoid bacteria, did not survive well among the natural microflora in the guts of the maggots and therefore were scarce after metamorphosis to the adult. Hence, the habits of the adult flies constituted the danger.

Apart from the mass of experimental results which continued to accumulate, there were some important epidemiological data which strengthened the case for transmission of enteric diseases by flies. In particular, the records of such infections in Manchester for the years from 1904 to 1909 provided comparisons from infant mortality from this cause and the numbers of houseflies; the curves were found to fit closely. Similar evidence was cited by Ainsworth in 1909, who noted a close correspondence in the peaks of fly prevalence and enteric disease in Poona. However, though his conclusions of cause and effect were supported by others, Morrison (1915) later decided that the correlation did not prove the flies totally responsible, though they might have contributed.

So far, we have only been able to judge the involvement of flies in disease transmission by three kinds of evidence. First, there are the habits of the insects, which certainly allow them to pick up pathogens, and next there are the laboratory tests, which show that they can ingest pathogens and excrete or regurgitate them in viable condition. Finally, there is the correlation between 
outbreaks of disease and fly prevalence. None of these, however, is conclusive, since flies might well be common under conditions which favour other means of transmission; and, while they can acquire the pathogens, this does not prove that they transmit them to an important degree. However, by 1919, Sir Andrew Balfour was sufficiently convinced to incriminate flies in a lecture on the hygienic problems of Egypt, neatly summarising the matter as follows: " . . careless contact cases, carriers (chiefly cooks), drains, dirty drinking water, dust of dried dejecta and the repulsive regurgitation and filthy feet of faecal-feeding flies". Modern views appear in the excellent book 'Flies and Disease' (1973) by Greenberg, who reviews the evidence for flies acting as vectors of no less than 19 diseases. In my opinion, this evidence is restricted to the three kinds just mentioned, except for two types: enteric and ophthalmic infections. Not only are the indications stronger, but there are important demonstrations that fly control can actually reduce these infections. Probably the first of such experiments was conducted by Armstrong (1914) in the city of New York in 1914. He chose two areas which were reasonably comparable in population (about 3500) as well as ethnic and economic status. In one of these areas, all feasible means of fly control were undertaken by the authorities, such as regular refuse removal and larvicidal treatment of all manure and privies with iron sulphate. Extra dustbins with lids were provided for householders, who were urged to screen windows and cover foodstuffs. After 8 weeks, there was a reduction in diarrhoeal disease to 20 cases in the treated area, compared with 60 in the control zone, while noncommunicable diseases remained similar.

This modest, but praiseworthy trial could scarcely be improved upon until a more radical method of fly control became available with the introduction of DDT. Its powerful effect on fly prevalence was first noted in extensive residual spraying in anti-malarial campaign. Thus, Vine, in 1947, describing the operations in Greece, remarked that the reduction in numbers of flies in Athens was a matter for comment; and as a result of the nationwide spraying, reports of dysentery had been reduced from 1511 in 1945 to 254 in 1946. In 1948, Viswanathan and Rao $(1947,1948)$ reported similar results in two Indian states in which anti-malarial DDT spraying had reduced deaths from diarrhoeal disease by approximately $50 \%$. Other similar records of this beneficial sideeffect of DDT spraying were published by Hemphill in 1948 in the U.S.A., Corbo in 1951 in Italy and Gabaldon in 1956 in Venezuela (cited by Greenberg 1973).

As regards DDT spraying operations directed specifically against flies, the most carefully controlled trial was that of Watt and Lindsay (1948), working in southern Texas from 1948 to 1950 . Fly control was obtained in five out of nine small towns with generally low standards of hygiene and endemic enteric infections. They recorded fly density by the "Scudder grill" (Scudder 1947) (a wooden grill on which resting flies could be counted at intervals). Also, they recorded Shigella infections in rectal swabs of infants, which they found correlated well with reported diarrhoeal disease and infant mortality. They obtained good fly control for about 18 months, after which DDT treatments 
were stopped in the test towns and switched to the control group, with a reversal of fly density and also of enteric Shigella infections; this seemed to prove that the flies acted as vectors. Other impressive results of insecticidal control of flies were as follows. Weir (Weir et al. 1952) in Egypt, claimed to have reduced infant deaths from diarrhoea from 227/1000 in 1949 to $115 / 1000$ in 1950. Barinskii in the U.S.S.R. made similar claims in 1952, as did West (1953) in a WHO report after visiting several countries in the Eastern Mediterranean in 1953. It is interesting to note that these good results were all obtained in hot, dry areas, while some results from northern U.S.S.R. were less convincing (Sorin and Rundvist 1956; Uvarova 1958 edited by Greenberg, 1973). This may, perhaps, be explained by an interesting paper by Teschner in 1958, which provided evidence that flies in the northern temperate zone are less attracted to human faeces. It is known that Musca domestica, though a world-wide species, is polymorphic, with a tropical race sometimes described as M.d. nebulo, an intermediate form, M.d. vicina, as well as the type form, M.d. domestica. These appear to have slightly different habits, though it is not easy to decide whether this is innate, or due to environment; but in any case, it may be that flies in cool temperate climates are less coprophilous than those in hot places.

While these results appear to have established the importance of houseflies as vectors of Shigella, the case was much less impressive for certain other infections. Thus, Watt and DeCapto (1950) could discern no improvement in Salmonella infections in the treated towns, while Paffenbarger and Watt (1953) could find no difference in poliomyelitis cases, though there was a correlation between paralytic cases and contacts with other sufferers. These findings do not preclude some involvement of flies, which have been proved to carry the pathogens of both diseases; but often, other mechanisms of transmission must be more important. In all cases, a low level of hygiene seemed to be critical and in one investigation this was demonstrated (Stewart et al. 1955). Indeed, it is not difficult to imagine the route of enteric pathogens in the villages described by Higgins and Floyd (1955), where: "The toilet of the anus after defecation is probably important [for transmission].... The general practice among the poorer economic class is to clean the anus with the hand using water when available, or a stick or stone when water is not at hand. No paper or other type of tissue is used. The mother sometimes cleans the buttocks of her infant with a rag or the sleeve of her costume, and the clothes of the child and the mother often become grossly soiled with faeces". It is therefore scarcely surprising that investigations in Georgia, U.S.A. (Stewart et al. 1955) and Venezuela (Zinsser 1934) both found enteric infections lowest in villages which had a plentiful supply of water, even if not of high quality. With Salmonella infections, a close correspondánce was found between the rates and types of pathogen in humans and domestic animals, especially chickens (Stewart and De Capto 1953). While there was some possibility of transference from animal faeces by flies, there were doubts whether they could transmit sufficient numbers of the pathogen to infect people (Greenberg et al. 1963, 1964). An alternative source was the fingers of housewives disemboweling chickens for food. 
Ophthalmic and Cutaneous Infections. After a lapse of some decades, investigations of fly involvement in spreading ophthalmic infections were seriously resumed after the Second World War. As I have mentioned, the related species $M$. sorbens is now considered a probable vector. It breeds readily in exposed faeces, including human dejecta, which in some places are often deposited in the open. While, however, these flies may pick up pathogens of enteric diseases, they very seldom enter dwellings and thus seldom visit kitchens to contaminate food. On the other hand, they are particularly annoying in their attention to faces, especially the eyes; and these visits are tolerated by local children who become apathetic and apparently indifferent to them (Fig. 1.8). This happens in countries with low standards of hygiene and hot, dry climates favourable for fly breeding, for example in the southern Mediterranean, the Near East and southern Asia. Several investigations in these places have compared the seasonal prevalence of M. domestica and M. sorbens. In Egypt (Hafez and Altia 1958), the former predominated in late winter and early spring, while $M$. sorbens was more common in summer and autumn. In Morocco, according to Gaud et al. (1950) M. domestica is most common throughout the year, while $M$. sorbens rises to $30 \%$ of the fly population only in the autumn. They emphasise, however, that this does not reflect their relative importance as vectors of eye infections, since $M$. sorbens is much more prone to visit infected eyes. Several other investigators also believed $M$. sorbens to be the main culprit. Various pathogens have been found in eyes suffering from conjunctivitis, especially staphylococci, streptococci and haemolytic micrococci. There have been at least two trials in which fly control apparently reduced such infections.

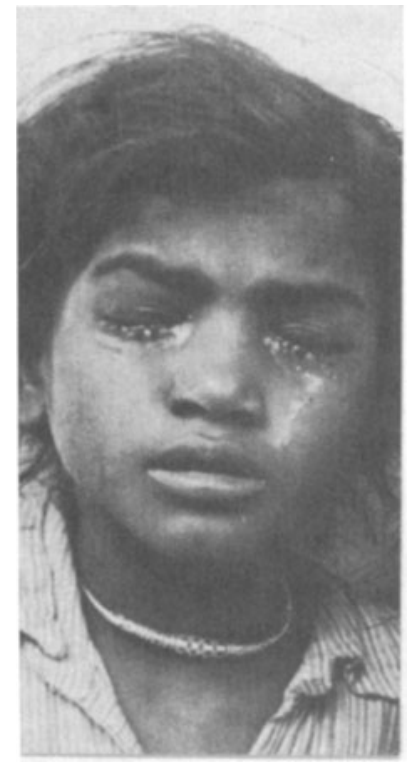

Fig. 1.8. An Indian girl suffering from an opthalmic infection often spread by flies. (Courtesy of WHO) 
Sukhova (1953 cited by Greenberg 1973) in Turkmenia claimed a reduction to $20 \%$ of the former level by this means, while in Morocco, Ponghis (1957) obtained a significant reduction in several villages, while Gaud et al. (1950) also in Morocco, thought that control of M. sorbens had produced a reduction in disease.

There is, therefore, good evidence of fly transmission of bacterial conjunctivitis, but the authorities (Siniscal 1955) are less convinced about the spread of trachoma (which involves a virus) by this means. In either case, the infections can be spread by human fingers or shared towels; and it must be remembered that regular cleansing of children's faces would prevent exposure of the septic matter and also reduce the attractiveness of the flies to such excretions.

\section{Diseases Spread by Eye Flies}

Apart from the housefly and Musca sorbens, there are other flies, only distantly related to them, which are even more irritating in their habit of alighting on the faces of men and animals, seeking lachrymal fluid from their eyes. They also visit sores, ulcers and small wounds to drink the blood, or serous exudate; and, as with the muscid flies, this involves a risk of transmitting disease. These "eye flies" belong to the genera Siphunculina and Hippelates, of the family chloropidae. They are very small black flies, unlike other members of the family, which are light-coloured and unimportant, except for the flit fly and the gout fly, which are pests of cereals. Siphunculina is an Old World genus, while Hippelates occurs in the Western Hemisphere.

Siphunculina funicola. Quite early in this century, observant physicians in India noticed that outbreaks of severe conjunctivitis usually coincided with the seasonal prevalence of this fly (Graham-Smith 1930). Thus, Patterson in 1908 mentioned the myriads of gnat-like flies ("mango flies") "that swarm on exposed sores and are probably active agents in the dissemination of the infection". Moreover, he stated that "innoculation from man to man failed on healthy skin; but if a slight abrasion was allowed partially to heal and material from an ulcer was placed on it, a typical lesion developed". This suggestion was reinforced by Ayyar who, in 1917, noted the abundance of the fly in warm weather after the monsoon began, in India, Ceylon and Java. He remarked on the attraction of the eyes of Indian children for the fly, which might cause the sore eyes which the natives attributed to their eating too many mangoes. Further suspicions were expressed by W. Patton (1921) in Madras, who emphasised the risk to children, since the fly "settles on the inner canthus and sucks up fluid there; that it may transmit bacteria in this way can be easily understood". In the same year, Fox (1921), in Assam, accused the fly of spreading Naga sore or Cachar boil, epidemics of which were associated with "a plague of small flies . . which swarm on the sores and mechanically convey infective material. Dr. Hall Wright has actually infected himself with Naga sore through the agency of these flies". Senior-White (1923) and Syddiq (1938) also suspected the flies of spreading 
yaws. The former, who dissected the mouthparts, believed that the insects scarified delicate tissues round wounds and sores to obtain exudate; but Roy (1928) decided that they merely poked their proboscides under scabs.

Hippelates spp. In the U.S.A., the Coachella Valley in California has for many years been notorious for swarms of these flies, which Herms described in 1926 as a "most persistent little creature, buzzing about the head, settling momentarily on one's clothing, darting frequently at the eyes and the ears. Drops of blood on the skin, open wounds, sores, mucous membranes and so forth are particularly attractive to the flies". Apart from the nuisance caused, the fly was accused of spreading a conjunctival infection known as "pink eye", which afflicted agricultural workers and others (Anon. 1929). In 1929, some 15,000 schoolchildren were noted as suffering from the infection. Several flies of this genus occur in the U.S.A. but the worst species was $H$. pusio, which occurred in various southern states, including Alabama, Georgia and Florida.

A related species, $H$. pallipes (formerly known as $H$. flavipes or Oscina pallipes) has been incriminated as a vector of yaws. Apparently the earliest suggestion was made by L. Nicholls (1912) in the West Indian island of St. Lucia. He studied the condition of patients who were segregated in a "yaws asylum", noted the avidity with which these flies gathered on their lesions and wrote: "The persistence of these little flies is extraordinary; they must be brushed off by actually touching them and will immediately return. If undisturbed, they will engorge with pus, blood, serum or sebaceous secretion...", and he concluded that they must pass on the infection. Then, 24 years later, he published further evidence indicating the fly's association with yaws (Nicholls 1936). About this time, the matter was being extensively investigated by Kumm (Kumm and Turner 1936) in Jamaica. He confirmed the association of the flies with the disease and showed that they could transmit the pathogen (Treponema pertenue) to rabbits after feeding on a human yaws lesion. The spirochaete did not persist in the flies for more than $48 \mathrm{~h}$ and was therefore transmitted mechanically (probably by, "vomit drops") without cyclical development in the insect.

\section{Diseases Transmitted by Biting Midges}

\section{Sandfly-borne Diseases}

Sandfly Fever. Compared with most of the infections I have mentioned, the subject of the transmission of the diseases involving sandflies is much less straightforward. To begin with, the common name "sandflies" is sometimes used for biting midges of the genus Culicoides which, though annoying, are unimportant as regards human disease. More correctly, sandflies belong to a fairly small group of insects which are not represented in Britain, though related to the harmless "moth flies" which occasionally invade our houses. 
The plebotomine sandflies can transmit several diseases, none quite as serious as malaria or yellow fever, but unpleasant and dangerous enough. Of these, the infection known as bartonellosis and, even more, the different forms of leishmaniasis, have proved very difficult to study, so that discoveries of their aetiology began rather late and extended over many years. (Accordingly, these will be discussed later p. 57.)

The acute but non-fatal sandfly fever, however, involved little confusion, and its mode of transmission was discovered relatively early. As I mentioned earlier, the first suggestion of sandfly involvement was made by Sir Robert McCarrison in 1884 (Sinclair 1953). It is doubtful whether his work was known to the Austrian doctors in Herzgovinia and Dalmatia who were studying a febrile condition affecting troops stationed there, 20 years later. The first of them to suggest transmission by sandflies was a Dr. Taussig, in 1905, from the distribution of the infections and the fact that they seemed to originate in the evenings. At that time of day, a small insect known locally as "papadatschi" was very troublesome, which aroused his suspicions. He published a very rough description and (incorrectly) called it Simulium reptans. After this, a Commission under a Dr. R. Doerr came to investigate the matter thoroughly and eventually published the findings in a small book in 1909. Clinical details were described by K. Franz, aetiology by Doerr and epidemiology by Taussig. Transfusion experiments with filtered blood had indicated that the pathogen was a virus. The vector suspected was Phlebotomus papatasii and some transmission experiments were carried out. To eliminate the possibility of local infection, flies fed on patients were sent to Vienna to feed on volunteers. Despite the difficulty of ensuring survival of these tiny flies on their journey (by boat and train!), enough arrived alive to feed on eight people, five of whom developed the typical fever. This seemed conclusive, and the disease is sometimes known as papataci fever.

Bartonellosis or Carrion's Disease. Bartonellosis is another disease transmitted by sandflies, though it has provided some complex problems in aetiology. Like Chagas' disease, it occurs in South America, but in a more restricted area in the Andean Cordilleras of Peru, Ecuador and Colombia. In these regions, moreover, it occurs only within altitudes between 1000 and $2500 \mathrm{~m}$, and it is normally contracted only during the hours of twilight. According to Charles Townsend (1914), an American who went to Peru in 1913 to become the government entomologist, the disease had once been more widespread among the indigenous Indians; and he quoted Augustin de Zarate, a Spaniard writing in 1545. Myron Schultz (1968), however, who gives an excellent account of the history of the infection, is inclined to doubt stories of epidemics among the Incas and he has similar reservations about an epidemic affecting a Spanish expedition led by Pizarro along the coast of Peru in 1524. Although the horrible effects of that disease resemble some of those of bartonellosis, Schultz points out that the location of the Spanish epidemic on a low-lying coastal plain is outside the endemic area and has never shown signs of the disease since. The first undeniable account of the infection dates from the mid-19th century, when the western 
part of South America was being exploited for guano to make gunpowder and fertilizers. These developments led to the construction of railways into the interior and a series of epidemics struck the workmen involved, especially those on a line intended for the town of Oroya, which gave its name to a fever which is the first effect of the disease.

Again like Chagas' disease, bartonellosis produces two different pathological effects. The initial fever can be slight in some cases, but in sensitive individuals it is often accompanied by a super-infection of Salmonella and can then result in mortality of about $40 \%$. After 2 to 8 weeks, the survivors are afflicted with multiple erruptions of large wart-like tumours all over the body, causing pain and irritation, though seldom death. Because, however, these conditions are so different, and because the eruptions can occur after a very mild early fever, they were regarded as quite separate infections; the former was called Oroya fever and the latter, verruga peruana.

The first demonstration that the two were manifestations of the same infection was accidentally provided by a young Peruvian doctor, Daniel Carrion. He was studying the nature of verruga peruana and, needing to discover early indications of the disease, he innoculated himself with material taken from a patient. Three weeks later, he developed a severe attack of Oroya fever which finally proved fatal 18 days later. Before he died in 1885, however, he became convinced that the two conditions were due to a single cause. This was readily accepted by Peruvian physicians, who urged that his name be given to the disease, in recognition for his heroic action.

The causative organism, a bacterium, was first described by a Peruvian doctor, Alberto Barton (1909). Unfortunately, however, he had initially accused a certain coliform bacterium, which rendered many sceptical of his second claim. Eventually, however, that was confirmed by members of an expedition from Harvard who came to study the disease in 1913 (Strong RP quoted by Schultz 1968). They found ample proof of the organism in cases of Oroya fever and it became known as Bartonella bacilliformis; but unfortunately, they could not find it in lesions of verugia peruana. Therefore, Carrion's claim of the identity of the two conditions was discounted for many years until being confirmed by the work of Noguchi $(1927,1928)$ a Japanese working in New York.

The possibility of an arthropod vector of the disease was suggested as early as 1911 by the eminent entomologist S.T. Darling, who mentioned mosquitoes or ticks. The search was taken up by C.H. Townsend (1914) soon after his arrival in Peru. At first, he suspected transmission by a tick, from some resemblance to Rocky Mountain Spotted fever; but this hypothesis was unfruitful. Then, a lead was provided when he heard that the railway workers were convinced that infection occurred in the evenings. He began to search at dusk and almost at once noticed sandflies biting. Further evidence of their distribution and habits compared with that of the disease was compatáble with the theory of their being the vectors. This was strengthened by an occasion when one of his assistants developed verruga after being bitten by the flies when he and another assistant escaped without being bitten. An attempt at experimental 
transmission made with a British seaman volunteer was inconclusive because, though he developed a fever, he left the country before a proper diagnosis of his condition could be made. In any case, Townsend was sufficiently convinced to name the sandfly species concerned Phlebotomus verrucarum.

So far, the evidence against the sandflies was only circumstantial. However, in 1928 R.C. Shannon (1929) was sent to Peru to collect material for Noguchi at the Rockefeller Institute. Of 25 species of arthropods in the collection, the only ones positive for the pathogen were two species of Phlebotomus (Noguchi et al. 1929). Further studies were made by M. Hertig (1942), who was a member of the 1937 Harvard Expedition and who went back to Peru for more work on the subject. Finally, Carrion's self-inoculation experiment was repeated by Kuezynski-Goddard (1937), who developed the disease after a 17-day interval; though, fortunately, he did not die.

Leishmaniasis. Describing the unravelling of the aetiology of the various forms of leishmaniasis has proved more difficult than for other insect-borne diseases; this is due to the protean manifestations of the disease and the many inconsistent results of some of the early experiments designed to confirm indications based on epidemiology. Research on the matter continued for more than half a century and there are still some questions under examination now. The subject is quite complicated and any one really interested should consult one of the detailed reviews available. (e.g. Adler and Theodor (1957); Lewis (1974); Lainson and Shaw (1978) Williams and Coelho 1978)).

Even the discovery of the pathogenic forms of the organism responsible was somewhat confused. It began as early as 1884, when D.D. Cunningham (1884), an army surgeon in India, described parasites in the tissues of patients suffering from Delhi boil; this must have been the organism in question, later described as Leishmania tropica. (This Dr. Cunningham subsequently described, for the first time, several other parasites of medical importance and he also designed a laboratory in Calcutta which was later used by Ronald Ross for his experiments on bird malaria. Manson-Bahr (1963) reproduces a photograph of him in an article on malaria. (It is the only one which I have seen depicting a scientific worthy with a friendly dog to share the picture!)

Then, between 1898 and 1902, two Russian doctors working in Turkestan observed similar organisms in people with "Sart sore"; one of them even suggested that transmission might be by mosquitoes (Hoare 1938). These reports, however, escaped notice, and the next progress was in 1903, when the parasites of the more dangerous visceral form of the disease (Leishmania donovani) were discovered independently by two men. W.B. Leishman (1903, 1904) (later Sir William) an army surgeon in Calcutta, was making a postmortem examination of a young soldier who had died of a long illness known locally as "dum dum fever". He discovered parasitic inclusions resembling trypanosomes and published a note suspecting Indian trypanosomiasis. However, by the next year, he noticed some peculiarities and claimed to have found the cause of the visceral disease generally known as kala azar. Meanwhile, in 
1903, another army doctor in Madras C. Donovan (1903), noticed unusual parasites in the blood cells of men who seemed to have died of pernicious malaria. At first, he thought he had discovered the missing link in the Plasmodium cycle, but he soon realised that this was something new and similar to the forms found by Leishman. His original suspicions of malaria were perhaps justified, because the parasites were also protozoan and because at one time kala azar was thought to be an acute form of malaria. Indeed, Ronald Ross spent some time working on this assumption and, when he realised his error, suggested that the new parasite be named Leishmania donovani. A few years later, Nicolle (1909), in Algeria, claimed that a different species was responsible for the disease in children, to be named $L$. infantum. Then, soon after the original discoveries, Rogers (1904) succeeded in culturing the parasite and from the appearance of the leptomonad stage, which resembled certain insect parasites, suggested that the human disease might be spread by an insect vector.

There followed a long series of attempts to find the insect responsible. In 1911, Wenyon reviewed the situation, rejecting a number of candidates (for example, Patton in India, who made claims for bed bugs, in which the parasites were able to develop). Wenyon himself had found some forms similar to the Leishmania bodies in sandflies from Aleppo, where oriental sore was prevalent; but he cautioned that they might be merely insect parasites. However, he attempted to determine if they were the pathogen by infecting himself with L. tropica from a sore and proceeded to Malta, where he proposed to try to infect the local sandflies by feeding them on his lesion. Unfortunately, the project failed, due to accidental destruction of that sore. A few years later, a Major Mackie (1915) of the Indian Medical Service made a few tentative experiments, from which he concluded that sandflies were the most probable vectors of kala azar.

Proof, however, turned out to be extraordinarily difficult, though investigations continued for over a quarter of a century. In 1921, Sergent and his colleagues (1921) crushed a large number of sandflies, thought to be infected, into saline, and injected some of this into 23 volunteers, one of whom developed an infection. A few years later, Adler and Theodor (1925) dissected no less than 3624 sandflies of the species Phlebotomus papatasii (the one shown earlier to transmit sandfly fever) which were caught in Jericho, where oriental sore was prevalent. They found four of these to be infected with organisms which were later proved to be $L$. tropica, and these were injected into three volunteers who developed typical lesions. This seemed to have identified the local vector, though other species of sandfly were responsible elsewhere. In India, for example, Sinton (1922) showed that the distribution of oriental sore corresponded closely with that of $P$. sergenti, and it began to seem probable that the infection was transmitted by sandflies. However, positive proof was elusive. Adler and Theodore, working in Palestine, were able to infect P. papatasii from sores; but despite many trials (1925-1929), they were not able to transmit the infection via the bites of the insects. Eventually in 1941 (Adler and Tser 1941), they were successful in further laboratory experiments; but it was still not clear whether 
natural infections came from bites or through flies being crushed on the skin and the pathogen scratched into a wound.

Meanwhile, similar work had been in progress in connection with kala azar in India by various members of the Kala Azar Commission. In 1922, Sinton showed that the distribution of the disease corresponded with $P$. argentipes, and soon afterwards Knowles et al. (1924) succeeded in infecting this species by feeding some of them on patients, which was confirmed later by Christophers et al. (1925). Subsequently, there were many attempts to transmit the infection by sandfly bites without success, though it could be shown that the foregut of the insects was full of the pathogen. Proof did not come until many years after the first suggestion that the sandflies were vectors. It followed a lead by Smith et al. (1940), who showed that transmission to animals could be facilitated if the insects were fed on raisins after their infective meal, instead of repeated blood meals. This seemed to lead to a proliferation of the pathogen, with possible blockage of the gut (as with plague-infected fleas) which increased the chances of transmission. Some final tests confirming human transmission were made by Swaminath et al. in 1942.

In the New World, diseases due to Leishmania include the relatively mild cutaneous form in Central America due to L. mexicana, the horribly disfiguring muco-cutaneous lesions caused by L. braziliensis in the forests of South America called "espundia" and the self-healing cutaneous form known as "uta" which occurs high in the Andes. Investigations into their aetiology began later than analogous ones in the Old World, arising from suggestions based on observations of local biting habits of the vectors, in the 1940s and 1950s. The sandflies responsible were allocated to a distinct genus: Lutzomyia, and actual transmission experiments have been made successfully with a few species. Since infection did not, in some cases, require blood to be taken during the bites, there was a possibility of infection occurring by crushing the insects and scratching the wound, though this may occur only rarely.

With the exception of $L$. donovani, vector of kala azar, the other forms of Leishmania can infect other animals, and most exist as zoonoses which accidentally transfer to man from wild animals. For example, the American forms exist in wild forest animals, especially rodents. Some other diseases can form reservoirs in domestic animals; for example, dogs which can carry infections of $L$. infantum etc. Recent work has shown that many species and sub-species of Phlebotomus and Lutzomyia can act as vectors of Leishmania; Killick-Kendrick (Killick-Kendrick 1978, 1979) has listed as many as 52.

\section{Disease Transmitted by Blackflies}

Onchocerciasis. This disease resembles sleeping sickness (and, to some extent, Chagas' disease) in that the most serious effects are long delayed, so that for a long time they were not connected with the original signs and symptoms. Naturally, this made it difficult to discover the original infecting agent. The disease is caused by a filarial worm, the adults of which are several inches long 
and lie curled up under nodules on the body (Fig. 1.9). These produce vast numbers of microfilariae which mainly inhabit the skin. One visible effect of infection is the coarsening of the skin with crinkling produced by this invasion and there is intense itching; this condition has long been known as "craw craw". Eventually, after a long interval, some of the microfilariae may enter the eyes and their presence, live or dead, causes various pathological effects, leading in some cases to eventual blindness.

Early signs of the disease were noticed by European doctors long before it was connected with blindness. In 1875, an Irish naval surgeon, John O'Neil (1875) of the brig Decoy, published his observations of "craw craw" among West African blacks. He noted a similarity to scabies in the skin condition and the itching, but found sulphur applications useless. Using a scalpel, he sliced off thin sections of affected skin and under the microscope noticed tiny wriggling worms, which he described and depicted. The adult worms were not described until 1893, by the German helminthologist Leucart, from specimens taken from

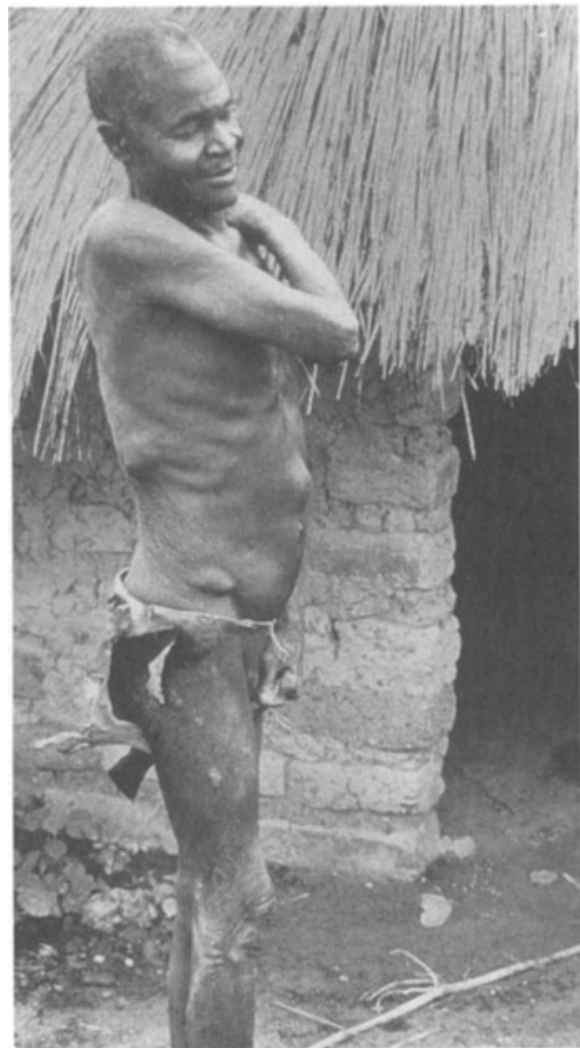

a

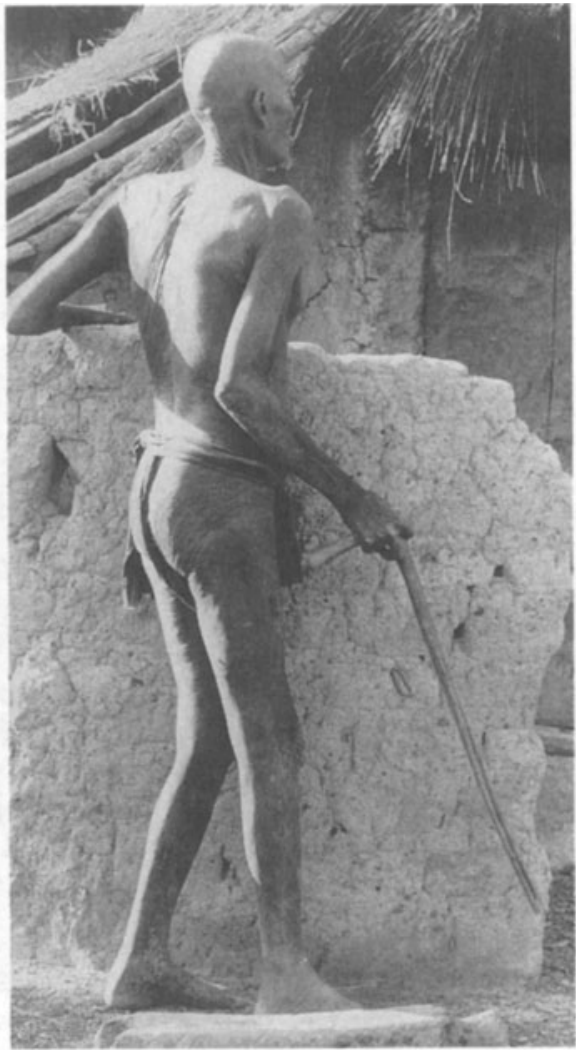

b

Fig. 1.9. Two effects of infection with Onchocerciasis: left the body nodules due to the adult stage; right a blind African. (Photographs courtesy of WHO) 
nodules of natives of the Gold Coast. He called the parasite Filaria volvulus; but it was later transferred to the genus Onchocerca, which includes similar parasites of veterinary importance.

The full significance of the human infection and its liability to cause eventual blindness was not recognised, nor was the mode of transmission discovered for many years. A highly significant clue was provided by F.W. Dry (1921) working in Kenya, who in 1921 reported the existence of a skin complaint which the local natives ascribed to frequent bites of a small black biting fly, Simulium neavei. Moreover, they also believed that, while not fatal, the disease involved a risk of blindness and could last as long as 30 years. By this time, disease transmission by insects was well authenticated; and, in the French Congo, Blanchard and Laigret (1924) began to search for an arthropod vector, but without reaching a conclusion. They noted that both Simulium flies and Ornithodoros ticks readily took up microfilariae during feeds on an infected person (though bed bugs did not) and they suggested that ticks might provide an aid for diagnosis of the infection.

The final definitive solution of the transmission problem was provided by D.S. Blacklock (1925), a Scottish doctor who had become Professor of Tropical Medicine and Director of a laboratory in Sierra Leone, attached to the Liverpool School of Tropical Medicine. He sought the vector from 1923 to 1925, finding it by no means easy. He mentioned no less than 23 kinds of arthropod which had been suspected, but from his own observations he favoured the blackflies of the genus Simulium. (I have no idea if he knew of Dry's work)! These tiny biting flies have aquatic larvae which cling to rocks and trailing vegetation in well-oxygenated streams and rivers. They appear in vast numbers and tend to bite any exposed skin, especially below the waist. The main African species is well named S. damnosum.

Blacklock allowed some of these flies to feed on infected men, and in subsequent dissections found the larvae surviving well in the insects' stomachs. In further work, he traced the development of the larvae and followed them to the thoracic muscles and then to the proboscis. Finally, he induced the infective stages to emerge from the tip of the proboscis by applying it to monkey serum on a slide (though plain saline would not cause this). Moreover, he found that they would also emerge when the proboscis was placed against a monkey's skin. In separate tests, he made punctures of the nodules on infected men and released the eggs and the microfilariae.

Blacklock's two papers were generally considered satisfactory proof of the mode of transmission; they led American workers to identify their own vectors of the disease, after a visit of a group to West Africa to inspect the situation there in 1931. One further discovery of interest was not made until 1950. In East Africa, the disease was known to be spread by another species of blackfly: Simulium neavei; but no one could find the larvae. Eventually, they were found to attach themselves to the carapaces of fresh water Crustacea, especially crabs of the genus Potamonautes. Though interesting, this discovery did not alter the means of control, which involves application of larvicide to streams and rivers. 
Subsequent investigations of the aetiology of onchocerciasis in West Africa revealed that "Simulium damnosum" is actually a complex of numerous species and sub-species, very often only distinguishable by banding patterns of the larval chromosomes. The various forms are adapted to different ecological conditions, some being associated with savannah country, others with forests. Most of them are able to transmit the disease, but as a rough generalisation, the savannah types appear to be the most dangerous in producing blindness. There is less definite information about $S$. neavei in East Africa, but this, too, is a complex of at least three species.

Onchocerciasis was discovered in Central America in 1915, though it is less widespread than in Africa. The mode of transmission and the biology of the blackflies responsible are more or less similar.

\section{Diseases Transmitted by Insects Other than Diptera}

\section{Plague}

The diseases discussed so far mainly affect hot countries; and even though malaria once penetrated as far north as Britain, most Europeans would consider it a tropical disease. Few, however, can be ignorant of plague which, as the "Black Death", killed some 25 million people, or a quarter of the population of Europe in the 14th century. Even earlier, in the reign of Justinian (6th century), there was a terrible epidemic in southern Europe and there is some evidence that the plague of the Philistines mentioned in the Bible (I Samuel v. 9) was bubonic plague. These ancient epidemics have been the subject of some considerable controversy, summarised by Stickler (1900), Hirst (1953), Pollitzer (1954) and myself (Busvine 1976). In more modern times, the evidence is uncontrovertible; e.g. the "Plague of London", witnessed by Pepys and Defoe.

There was, of course, no shortage of speculation about the cause of the disease, ranging from divine justice for human sins, or dire astrological conjunctions, to unhealthy emanations from the soil. Those who believed in supernatural causes resorted to prayer, or occasionally to incantations; but probably most people suspected plague to be contagious. In the 15th century, those Italian doctors brave enough to treat plague patients wore a special dress covering the whole body. Over the head was a hood with a beak filled with fragrant herbs through which they drew breath, and the eyes were covered with glass discs. (The resulting bizarre appearance of this headdress resembled certain Venetian carnival masks).

So far as the authorities were concerned, the obvious action was to isolate the victims when plague broke out, either by evacuating them to hospital (in the more humane communities) or by confining them in their houses with their, as yet, uninfected relatives. The most sensible measures were based on the experience of previous outbreaks, though when confronted with sudden major epidemics, the authorities were liable to commit drastic and callous actions. Some 
of the worst examples of this occurred during the severe and unexpected outbreak in Marseilles in 1720, graphically described by Gaffarel and Duranty (1911).

By the 19th century, plague was gradually receding from Europe, though British physicians were concerned with an epidemic in Malta in 1813-14. Other European doctors were involved in Egypt in 1834, with renewed interest in problems of transmission. Actual experiments were done with condemned prisoners innoculated with blood from victims, or made to sleep in their bedding. Two brave French doctors, Bulard (1839) and Clot-Bey (1840), themselves took part in risky experiments; but the matter was not settled.

The first discoveries regarding the aetiology of plague concerned the pathogen. A final pandemic had arisen in Central China and reached the coast about 1870, where it fluctuated for a while, infecting Canton and Hong Kong before spreading round the tropical world, being especially serious in India. Again the cause was being sought, but this time with the advantage that disease organisms had been shown to exist by Pasteur, Koch and others. By 1894, the plague bacillus was found in almost simultaneously by two research workers in Hong Kong. Shibasaburo Kitasoto (1856-1931), a Japanese bacteriologist who had studied under Koch in Berlin, and Alexandre Yersin (1863-1963), a Swiss who had worked at the Pasteur Institute in Paris. Both discovered the bacillus in tissues of plague victims. Kitasoto's (1894) announcement was slightly earlier, but Yersin's (1894) description was clearer and his name has been attached to the pathogen: Yersinia pestis.

It was not, however, immediately evident that rats and fleas were involved in transmission. Some confusion may have been caused by a variety of plague in which the lungs become heavily infected and the victim coughs out bacteria, thus causing droplet infection. The first such case recognised as plague in Europe was that of Child in 1897; but this form is rare in most bubonic epidemics. The involvement of rats might have been suspected from preliminary epizootics among them, killing large numbers; it has been pointed out that such "rat falls" were well known in the Orient. Sir Harold Scott (1939), for example, quoted a Chinese poem by Shih Taonan (1765-1792), who himself died of plague, beginning:

Dead rats to the East/Dead rats to the West/A few days following death of the rats/Men pass away like falling walls/.........

The coming of the devil of plague/Suddenly makes the lamp dim/Then it is blown out/Leaving man, ghost, and corpse in the darkened room.

A few years ago, a certain O. Neustatter (1941) published in an art journal several reproductions of pictures depicting plague, pointed between the 13th and 18th centuries, which include what appear to be numerous rats or mice. However, early European writers made no special mention of rat deaths, though they mention the deaths of domestic animals and birds in time of plague. Certainly, no contemporary physicians suspected rats until the end of the 19th century, when the plague was being investigated in India by commissions of 
various nations (British, German, Russian, Austrian and Egyptian). Although their efforts were conscientious and occasionally very dangerous, so that one Austrian caught the disease and died, the problem turned out to be very difficult to solve.

The involvement of rats eventually came to the notice of the scientists in 1897, when Yersin and Roux (1897) reached the conclusion that plague was primarily a disease of rats which could infect humans; and moreover, they decided that the best way of dealing with it was to destroy the rats. About the same time, that medical polymath Robert Koch expressed the same opinion following a short visit to India. Meanwhile, M. Ogata (1897), who was working in Tokyo, proposed that the disease was transmitted by blood-sucking insects, such as mosquitoes or fleas; and he provided evidence by crushing some fleas which had fed on infected rats and injected an infusion into some mice, one of which died of plague. The idea was further developed by the Frenchman P.L. Simond (1898), who had worked at the Pasteur Institute in Marseilles under Metchnikoff before going to the Far East in 1986, where he witnessed the epidemic in Yunan before leaving for Bombay. Having seen the dead rats accompanying the China epidemic, he, too, was convinced of their involvement. Then, having found organisms like plague bacilli in the stomachs of fleas which had fed on infected rats, he began some experiments trying to transmit the disease by feeding fleas on infected rats and then on healthy ones. Four trials were successful and two failed (perhaps because he added some cat fleas to supplement the rather few rat fleas available, and the former are poor vectors). Nevertheless, he was convinced of the role of fleas in transmission and presumed that they would carry the infection to man. Some far-seeing individuals were convinced, such as Koch, Manson and Haffkine, but many still doubted the theory.

As Balfour (1925) pointed out, the German Plague Commission of 1899 and the first British Commission of 1901 both "poured cold water on the theory"; but an Australian physician, J.A. Thompson, who had witnessed plague in Sydney, was convinced that "plague in rats always preceded plague in human beings and that infection was transferred from rat to rat and from rat to man by the flea and in no other way". Proof, however, was lacking, and in the next few years, various attempts were made to repeat Simond's transmission experiments, mostly unsuccessful. Tidswell failed in Australia in 1990 and again in 1903; so did Kolle in Germany. On the other hand, Gauthier and Raybaud (1903) in Marseilles succeeded several times in 1902-3; but the Swiss Galli-Valerio repudiated Simond's theory on the grounds that rat fleas very rarely bite man, and further failures to transmit plague even between rats were published by Kister and Schumacher in Hamburg. Eventually, however, the truth was established by the extensive work of the British Plague Commission in India $(1906,1907,1910)$ published as a series of lengthy reports. Not only was the involvement of rats confirmed, but the black rat Rattus rattus (then called Mus rattus) was found to be the culprit. Plague also occurred in the brown rat, $R$. norwegicus ("Mus decumanus") but the timing of their epidemics did not 
correspond to those in humans. Moreover, that rat was not native to India and was absent in the interior, so that it could not have been responsible for epidemics there. As regards the flea vector, suspicion fell on Xenopsylla cheopis ("Pulex cheopis"), which W.G. Liston of the British Commission had found to be most prevalent in plague houses.

There remained the problem of the exact mode of transmission. Some suspected the bite of the flea, others its infective faeces. The latter was disproved by N.H. Swellengrebel et al. (1928), in Java, who managed to transmit the disease to rats by feeding infected fleas on them through muslin. Finally, in 1914, Bacot and Martin showed that the plague bacilli multiplied in the insect's foregut and in some cases, this became blocked by a mass of them, so that subsequent attempts to feed by the flea would dislodge packets of bacilli into the wound.

The first species of flea incriminated as a plague vector was, as mentioned, $X$. cheopis, which was noticed to be particularly prone to this blocking effect by Bacot and Martin (1914), later confirmed by other workers (Hirst 1923; Goulding 1983). Other factors, of course, were found to be involved in the transmission of plague from rat to man (Wheeler and Douglas 1941) for example, the vector fleas had to have an appetite for human blood, and seek out people soon after leaving a rat dead from plague. This eliminated some rodent fleas which were, nevertheless, important for maintaining rodent plague by ratto-rat transmission. Naturally, suspicion fell upon other species of the genus Xenopsylla, which were liable to be found on plague-infected rats. A detailed description of $X$. cheopis had been published by Rothschild in 1903 and by 1914 , he had provided a simple key to distinguish the other important species: $X$. astia and $X$. braziliensis. Subsequently, the relative importance of these three species was gradually determined. All the evidence tended to confirm the major role of $X$. cheopis, which probably originated in the Nile Valley, but being very adaptable has spread widely in all continents. $X$. astia, on the other hand, is largely confined to Southern Asia and the Arabian peninsula (Hirst 1923a). Within this region, Fabian Hirst (1926); who worked on the problem for many years, pointed out that the distribution of plague epidemics in India and Ceylon corresponded largely to areas where $X$. cheopis was most common, while places where $X$. astia was predominant were free of plague. Its lower efficiency as a vector (later confirmed by Webster (Webster and Chitse 1930) in India) seemed to be due to its less robust nature. It was more difficult to rear in the laboratory than $X$. cheopis, required feeding more often and lived less long. Moreover, it was somewhat less ready to feed on man.

Investigations of $X$. braziliensis showed it to be a potentially dangerous vector; but it was found to be less widely distributed than $X$. cheopis, being largely restricted to Central Africa, some parts of India and South America. In most places it was prevalent in rural areas; for example, it was commonly found in African huts with thatched roofs and much less common on rats in earth burrows (Roberts 1936; Vincke and Derignat 1937). Of particular importance was the nature of rat and flea infestation of very large granaries and warehouses at ports, where $X$. cheopis was found to be especially prevalent. In Colombo, for 
example, Hirst found both this flea and the rats to be present in large numbers, while $X$. astia was less common and $X$. braziliensis was virtually absent. Because of its obvious importance, the bionomics of $X$. cheopis was the subject of numerous laboratory studies in the inter-war years. Fortunately, it is a very easy flea to breed in captivity.

By the early years of the 20th century, therefore, the main features of the aetiology of bubonic plague had been discovered. There remained certain problems concerning the origin of the Asian epidemics and also the changed nature of the world distribution, following the great expansion in international trade in recent decades. Both concerned unsuspected reservoirs of plague among wild rodents. It might have been suspected that the black rat was not a permanent reservoir of the disease, for it succumbed so easily that epizootics tended to be short and sharp. Natural reservoir animals either have a degree of immunity, or else have extensive populations among which the disease can wander about as depletion of susceptible animals by death or acquired immunity quenches local epizootics.

An important reservoir, and possibly the source of early human epidemics via black rats, was discovered to be certain wild rodents in the south-eastern Asian steppes. In particular, ground-living marmots (or tarbagans) were found to be one source. They were hunted by Mongolian tribes for their meat or fur and sporadically caused the disease, usually due to infection while skinning a sick animal, since their fleas seldom attacked man. A peculiar characteristic of plague contracted this way was that the infection tended to develop into the pneumonic form and spread further infections directly by droplet inhalation. As a result, localised epidemics occurred among small rural communities, but these were not identified as plague until 1905 . The source was traced to the tarbagans by 1911 and this was finally proved when Yersinia pestis was recovered from naturally infected dead animals in 1923.

The earliest plague epidemics which had reached Europe had travelled slowly overland by caravan; but in the 19th century, trade had expanded enormously in volume and speed with inter-continental shipping. Plague had travelled with this, carried by black rats and their fleas in the holds. At distant ports, infected rats might come ashore to the docks or their fleas might be brought in with the cargoes. In this way, local rats would become infected, resulting in a bubonic plague epidemic. Several such epidemics occurred around the turn of the century in the ports of California, South Africa and South America. The infected rats occasionally transferred the infection to some adventurous wild rodents around the periphery of these ports and in this way, rural reservoirs of plague became established in the interior of these countries.

In subsequent decades, the location of these reservoirs came to be defined. Thus, in what was probably the original home of the disease, there were a series of loci stretching across Central Asia, from the Caspian Sea to Manchuria. In South Africa, there were patches ranging from the Orange Free State to 
Bechuanaland, and another one in Tanzania. In South America, there were several in the north-east of Brazil and, on the Pacific side, in Peru. In the U.S.A., there were numerous foci in California and another series east of the Rocky Mountains, stretching from Oregon down to New Mexico. The small mammal reservoir hosts were identified; they were mainly rodents (tarbagans, sisels, marmots and jerboas in the Old World, ground squirrels, prairie dogs etc. in the New World). Various species of flea were shown to be their specific vectors. Extensive epidemiological research was done by Karl Meyer, D.H.S. Davis, N. Kalabukov, B.K. Fenyuk and Wu Lien-teh, among others (Pollitzer 1954). The permanence of these rural reservoirs was found to depend on the plague resistance of the rodents and their bionomics. The foci could not persist among those very susceptible to the disease, except perhaps by meandering about in a large dense population of them. In some cases, the disease could lie dormant over winter while the host hibernated, and then re-emerge next season; and the pathogen could also persist for long periods in the fleas in cold conditions.

On the whole, such permanent reservoirs did not lead directly to many human cases. Over the period 1920 to 1976 there were only 120 cases in the U.S.A. This was because the wild rodent fleas were reluctant to bite humans, though a few hunters became infected while skinning the animals. More important was the fact that plague might be re-introduced to the urban rat population, reversing the early transfer. Therefore such reservoirs demanded attention, especially if expanding populations of people invaded wild territory and set up camps etc/with rat pests. Following the lead of Ricardo Jorge, a Portugese scientist, such reservoirs have been described as "sylvatic" plague, with an unfortunate association with forests, since they mostly occur in open country. Hirst has made a plea for calling it "campestral" plague; but early usage is hard to overcome. Perhaps the best term is "wild rodent plague".

Despite the unwelcome discovery of rather intractable foci of wild rodent plague, the incidence of human plague has been steadily declining throughout the century. In India, for example, the numbers of cases annually recorded over the period from 1900 to 1957 fell from 183 to 1.8 per 100,000 (Seal 1969). Similar improvements in recent decades have been noted in other countries, such as Madagascar (Mercier et al. 1952, 1953) and (up to 1940) Viet Nam (Burnett 1960). Moreover, the global incidence reported to WHO (1981) also shows a slight decline from 1967, as follows:

$\begin{array}{rrrrrrrrrrrr}1967 & 1969 & 1971 & 1973 & 1975 & 1977 & 1979 & 1981 & 1983 & 1985 & 1987 & 1989 \\ 6000 & 4550 & 4420 & 680 & 1480 & 1350 & 880 & 200 & 1067 & 1346 & 1043 & 750\end{array}$

This generally satisfactory situation probably reflects improved sanitation and better medical services. When, however, these are interrupted by warfare, the disease can surge back, if we are to judge from the data for Viet Nam. In this respect, plague responds to warfare in the tropics as typhus does in the temperate region. 


\section{Louse-Borne Typhus}

While plague can be considered a disease of hot countries which has often invaded the temperate zone, typhus is especially dangerous in cold conditions and occurs in the tropics only at high altitudes. However, in contrast to the voluminous early works on plague, few historical accounts of typhus can be recognised with certainty. It did not stand out so starkly because it was prevalent in conditions conducive to other diseases, caused by bad sanitation and insufficient food. It was a disease of besieging armies, beleaguered cities and prisons. Under these circumstances, specific diseases were not often distinguishable with certainty, nor were intelligent and dispassionate physicians often available. So, up to the middle of the 19th century, typhus was liable to be confused with relapsing fever or even typhoid. The causal organism was not identified until some years after the mode of transmission had been discovered, so that clues from that source were not available.

By the mid-18th century, Sir John Pringle, who wrote 'Diseases in the Army in Camp and Barracks' (1753), was convinced that hospital and jail fevers were identical. He put the cause down to "filth and impurity and poisonous effluvia or sores, mortification, dysenterie and other septic excrements". A little nearer the mark, James Lind, in 1763, pointed out that patients from a ship infected with typhus "had never changed their clothes, from the time they were pressed in June to the 22nd October, when they came into hospital. The unclean rags they had lain in for about four months were sufficient to have bred infection".

According to Zdrodovski and Golinevitch (1960), it was a Russian, Gregor Minkh, who in 1878 first suggested that typhus was spread by blood-sucking insects. However, the most fruitful deductions were made by Charles Nicolle and his team working in the Pasteur Institute in Tunis. They noted the suggestions of louse involvement by two French doctors reporting on an epidemic of typhus in France in 1892-3, which accorded with their own observations in North Africa, where the louse-infested natives were more frequently attacked than the Europeans. To obtain experimental proof, they managed to infect monkeys; and, by 1910 they were beginning to transmit the infection from infected to healthy monkeys by using human lice which had fed on the former (Nicolle 1910).

The type of pathogen was first seen by a young American, Howard Ricketts, who noticed some minute organisms in the blood of patients suffering from Rocky Mountain spotted fever (see p. 83) He described them as minute bacteria, but noted that they could not be cultured on artificial media. Subsequently, he went to Mexico to work on typhus, but very soon contracted the disease and died. The problem was then pursued by a Brazilian, Henriques da Rocha-Lima, and an Austrian, von Prowazek. In 1914, they studied typhus in Turkish prison camps and later in Hamburg among Russian prisoners of war. Both contracted the disease and the Austrian died, but Rocha-Lima (1916) observed the pathogens and named them Rickettsia prowazeki in honour of the two who had died in the course of their work on the disease. 
Nevertheless, not everyone was convinced at this stage. For example, the eminent parasitologist Brumpt (1918) fed on himself some 50 lice containing Rickettsia without contracting typhus; in the U.S.A. a certain Dr. Plotz working at the Mount Vernon Hospital claimed to have found the pathogen in the blood of patients in the form of a bacillus, B. typhi exanthematicum. His views were supported by four other men; but five others confirmed Rocha-Lima. Strong and his colleagues (1920), in their book on the Servian epidemic, discuss this controversy without reaching definite conclusions. Possibly the confusion was due to the existence of a harmless form of Rickettsia occurring in lice: $R$. pediculi; but as Rocha-Lima pointed out, it can be distinguished from the pathogenic $R$. prowazecki, because it does not invade the gut cells of the insect and kill it as does the dangerous kind. By 1921, Hindle had sorted out the various species of Rickettsia and generally confirmed Rocha-Lima (Hindle 1921).

Meanwhile, in 1916, E. Weil and A. Felix had developed a useful (though non-specific) way of diagnosing serious rickettsial infections. In later years, the complement-fixation test was adapted for detecting these pathogens and subsequently, a whole battery of sophisticated serological techniques. Nevertheless, the Weil-Felix reaction remained important for a very considerable time. It was based on a strain of the bacterium Proteus (known later as OX19), which Felix had isolated from the urine of a patient with typhus in Poland. He discovered that it was agglutinated by the patient's serum; and more importantly, by serum of other typhus patients, a reaction described as the Weil-Felix reaction. An interesting sidelight on this was given by T.E. Woodward (1981) in a paper discussing the historical background to rickettsial diseases. It concerns the ingenuity of two Polish doctors during World War II, who used killed suspension of Proteus OX19 in numerous patients in certain villages to build up an immune reaction to typhus. The German health authorities were persuaded that this was evidence of active transmission of louse-borne typhus and kept well away from the villages, which were thus spared many of the hardships of the occupation.

Despite the advances in knowledge of the pathogen, there were still some problems regarding transmission by lice. Despite the strong indications of their involvement (apparently, not necessarily by their bites) there seemed to be cases of infection in sanitary personnel protected from lice, so that questions of possible droplet infection (analogous to pneumonic plague) were raised. The clue to this problem had actually been indicated by Nicolle and his colleagues (1914), when they showed that fresh faeces from a louse fed on a typhus patient could transmit the disease to guinea pigs. Further work by Arkwright and Bacot (published in 1923, after both had acquired the infection from which Bacot died) proved that louse bites were indeed not the mechanism, but it was the faeces which were infective and remained so for long after they had dried to a powder. Typhus therefore could be acquired by infected louse faeces scratched into an abrasion, contacting a mucus membranes, or by being inhaled. They were therefore very dangerous to both nurses and research workers, and killed another of the latter, a German named Schüssler. 
The discovery of the aetiology of typhus came just before the appalling epidemics of the First World War. Fortunately, typhus was absent on the Western Front, though lice were common among the troops of both sides. Yet many men there suffered from the less lethal disease known as trench fever. It is possible that this disease was identical with another, known in Central Europe as Wolhynian fever; but this will never be known with certainty, because both diseases died out completely after the war. It was established, however, that both are due to a species of Rickettsia (Topler 1916) and it was suspected that they were spread by lice. To test this theory, Davies and Weldon (1917) collected some lice from patients and fed them on themselves, subsequently developing trench fever. However, their experiments were criticised for not being adequately controlled and were repeated by two other investigators with conflicting results. Finally, however, two substantial groups looked into the problem; one was a joint team of the Medical Research Council workers and the American Red Cross (Strong et al. 1918), while the other was sponsored by a Committee chaired by Sir David Bruce (Byam et al. 1918). The former was based in France near the B.E.F. so as to have patients readily available, and the other worked in Hampstead. Both relied on plenty of volunteers for experimental infections. Eventually, transmission by lice was fully confirmed, by the same vehicle of infected faeces (as with typhus).

\section{The Brill-Zinsser Disease}

In 1910, a Dr. N.E. Brill reported on what seemed to be a new disease among immigrant Jews arriving in New York from eastern Europe. It resembled a mild form of typhus with a mortality of only about 5\%. Curiously, it could occur among people without the usual vector, body lice; however, it could spread through groups with such infestations. Moreover, cross-immunity tests showed that the pathogen was the dangerous $R$. prowazeki. Later, in 1934, Zinsser reviewed the records of 538 cases of this disease and concluded that it was a recrudescence of the pathogen after it had lain dormant for many years.

\section{Louse-Borne Relapsing Fever}

I have mentioned the 19th century confusion between typhus and relapsing fever, both of which are promoted by conditions of widespread lousiness. Even when differences in signs and symptoms were noted, it was thought that both were varying degrees of the same infection. However, in 1844, a Scottish doctor, William Henderson (1844), who had extensive experience of the two, declared that they were distinct; but even when this was accepted, it was rather naturally believed that they were spread by contagion in unhygienic conditions. The spirochaetes which cause the disease were discovered by Otto Obermeyer (1873), who demonstrated them to the Berlin Medical Society in 1873. Further progress was hampered by the difficulty of culturing these organisms in vitro, 
which was not achieved until 1912, by H. Noguchi in New York. Meanwhile, a step forward was made when Robert Koch and H.V. Carter independently showed that monkeys could be infected.

There remained the problem of transmission, for which clues might have been provided by the discoveries of insect vectors of other diseases at the turn of the century. The first conjectures, however, led down a blind alley. Thus, in 1897, the Russian J. Tictin, observing an epidemic in Odessa, noted that it was especially prevalent among sailors in bug-infested lodgings. On examining the blood in the stomachs of these bed bugs, he found the spirochaetes and was able to infect monkeys from this source, thus indicating bugs as the vector. Similar conclusions were reached by a Pole, Justin Karlinski (1902), from observations of epidemics in the Balkans. However, repeated unsuccessful attempts to transmit infection by bugs were made by C. Christie (1902) in India and by A. Breinl et al. (1906) in Liverpool; nor have any later experiments shown that these insects are regular vectors of any disease. Suspicion turned to lice from the observations of Percival Mackie (1907) of the Indian Medical Service concerning an epidemic in a children's home in Bombay. He noticed that the boys were more often infected than the girls and that the former were more often infested with body lice, whereas both sexes suffered equally from bed bugs. The final proofs emerged from French workers in Pasteur Institutes in North Africa. In Algeria, E. Sergent and H. Foley (1910) carefully assessed the possible roles of ticks, mosquitoes, fleas, lice and bugs, concluding that lice were the most probable. Then Nicolle and his colleagues (1913) in Tunis attempted to transmit the disease to monkeys via lice. Their results were inconclusive until it was found that the spirochaetes invade the body cavity of the louse, only to be released when the cuticle is burst. This could easily happen during personal de-lousing activities, especially in such people as often bit the lice to death! The organisms could then enter the human body through a scratch or be rubbed into a mucus membrane; and two experimental infections of volunteers showed this to be possible (Neil 1917).

\section{Flea-Borne Murine Typhus}

In the meantime, other cases of typhus-like fever with a low mortality rate were observed in the U.S.A., Mexico and a few other countries. They were considered to be "endemic" typhus; or, if affecting people without lice, to be Brill's disease. However, there were some differences in pathological features; and a unique character was an enlargement of the scrotum in guinea pigs into which the pathogen had been injected. By 1929, Maxcy, on epidemiological grounds, postulated a non-human reservoir, probably rats or mice; and he suggested that the vector to man was a flea, mite or tick. Finally, in 1931, the specific pathogen was isolated from rats (Mooser et al. 1931, 1932) and also from rat fleas (Dyer et al. 1931), which confirmed this theory.

The pathogen, which was named $R$. mooseri, is a natural infection of rodents which can occasionally be transmitted to humans. It is clearly a less virulent 
pathogen, since, apart from its less malignant effect on man, it does not kill either the rodents or their ectoparasites.

The mode of transmission is not absolutely certain. Even as late as 1978, Traub suggested that it is "unique among the major arthropod-borne diseases, as far as the extent of our ignorance about fundamental information on the ecology of the infection is concerned". Many small mammals and their ectoparasites can be infected and transmission to man could involve the crushed bodies of the vectors or the urine or faeces of the mammals. However, it seems clear that domestic rodents (especially rats) and their fleas (especially Xenopsylla cheopis) are virtually always involved in most outbreaks of human cases. Transmission is probably via the infected faeces of the fleas, as in typhus. Control of these two agents has been successful in dealing with the disease.

\section{Chagas' Disease}

Although few British people know anything about Chagas' disease, it is endemic in large parts of South and Central America, affecting about 24 million people out of perhaps 65 million at risk. A possible interesting link with England is the supposition that Charles Darwin showed signs of having perhaps acquired the disease during land excursions from the "Beagle" (thus Adler 1965; but see also Woodruff 1965). There are certain unique features in the discovery of the aetiology of this disease. The trypanosomal pathogen was found in the insect vector prior to the identification of the human infection, and both were due to one man, a young Brazilian parasitologist, Carlos Chagas. In his account of the discovery, Kean (1977) describes how the disease was formally named after Chagas at a meeting of eminent parasitologists, after they had heard his paper read by Oswaldo Cruz in 1909. Cruz himself was an outstanding scientist and organiser, who attracted many outstanding workers to the institute subsequently named after him. Chagas joined this Institute in Rio de Janeiro in 1903, the same year, as Minter (1978) has pointed out, that Bruce and his colleagues published the definitive account of African trypanosomiasis.

Chagas began his studies by working on malaria and in 1907-8 was attempting to control an epidemic in a rural locality, which had halted construction of a railway line. There, one of the engineers showed him specimens of some blood-sucking bugs which afflicted many rural dwellers; they were called barberios or "barbers" from their habit of biting sleepers on the face. Chagas decided to dissect some and he found certain trypanosomes in the gut, which suggested to him that these might alternate with a vertebrate host, since he had already found similar organisms in the blood of marmosets. He therefore sent some of the bugs to the Institute in Rio, where the Director, Dr. Oswaldo Cruz allowed them to feed on a healthy marmoset. Returning after 20 or 30 days, Chagas examined the blood of the animal and found it to contain many trypanosomes differing from those already known; and he named them Trypanosoma cruzi in honour of his supervisor. Experimental infections of various 
animals showed them to be pathogenic to different degrees, but especially dangerous to marmosets and guinea pigs.

Knowing that the blood-sucking bugs infested rural dwellings and fed on the inhabitants, Chagas suspected them to be carriers of a peculiar endemic disease from which some children died and others experienced heart and bowel defects in later life (Fig. 1.10). On investigation, he found trypanosomes in the blood of children and also in a domestic cat. It may be of interest that the first human case he identified was a 2-year-old girl, whose subsequent history is known (Lewinsohn 1979). Many years later, in 1962, she was medically examined and found to be still harbouring T. cruzi, though apparently without serious symptoms. Chagas published his findings in three papers in 1909 (Chagas 1909, 1912); and he identified the bugs as belonging to the family Reduviidae, a sub-family of which, the Triatominae, feed on the blood of birds and mammals. A few species in South and Central America have adopted the habit of infesting rural dwellings and attacking the occupants and their domestic animals. Chagas identified the species he was investigating as Conorhinus megistus (now known as Panstrongylus megistus). He continued his investigations of the disease and in 1912 he found the first wild animal (an armadillo) carrying the trypanosomes, from which he correctly deduced that the disease was a zoonosis, occasionally passed to man.

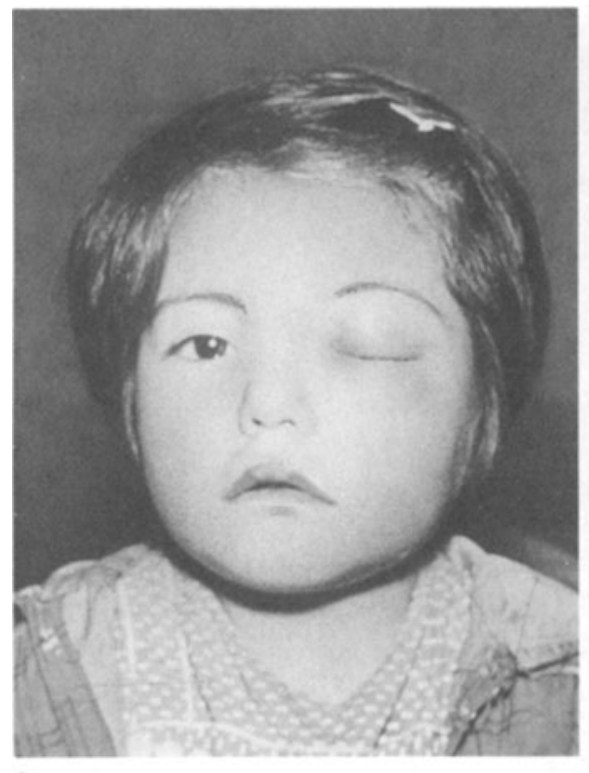

a

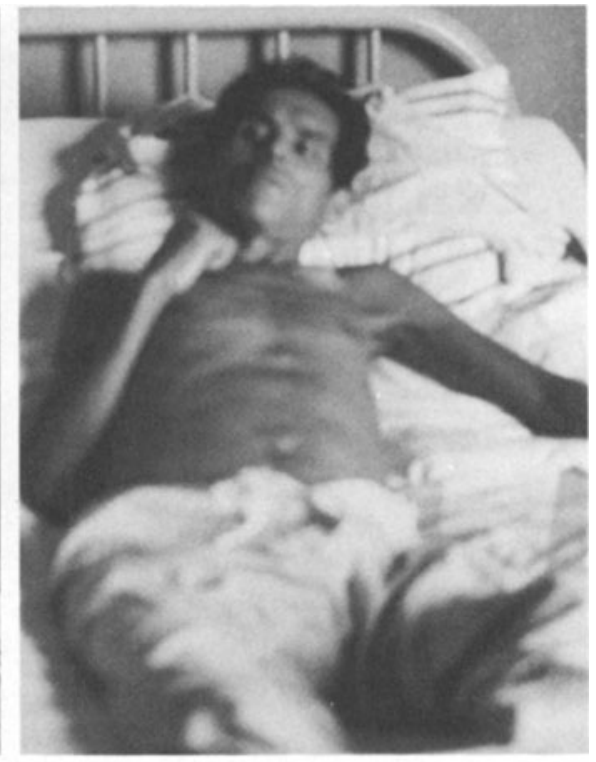

b

Fig. 1.10. Two stages in Chagas' disease. Left A girl with an oedermic eyelid indicating an early stage in the disease. Right A case of dangerous heart disease in mid-life, following repeated infections with the disease. Both printed from colour transparencies. Left courtesy of Prof. D.J. Bradley from the collection of the former Ross Institute. Right from a photograph taken by the author in Venezuela in 1973 
These discoveries brought Chagas ready recognition, honours and awards, not only in Brazil but abroad; Robert Koch, for example, was much impressed. Unfortunately, however, he made certain errors of detail in the life cycle of the parasite and he also assumed that the infection passed via the insect's bite. Doubt was thrown on this by some of Brumpt's investigations; published in 1915, with various biting insects and other species of trypanosome. He showed that the Chagas' disease pathogen developed in bed bugs as well as in triatomids, and that the faeces of both insects were infective when applied to mucous membranes. Thus, he suggested that the infection might come via the faeces of the triatomids when they fed on sleeping people, noting that their habits had earned them the name "kissing bugs" from feeding near the lips.

During the next 10 years, various sceptics (notably Kraus et al. 1915, 1925a, b, c), disputed Chagas' conclusions, which fell into desuetude until they were rediscovered in the 1930s. There was still some doubt about the mode of transmission, but Brumpt's suspicion of infective faeces was confirmed by Dias (1932), Cardoso (1938) and himself (Brumpt 1939).

In recent years, new methods of diagnosis have been developed: by serological immunodiagnosis, and by xenodiagnosis (i.e. the detection of trypanosomes after feeding a triatomine on a suspected patient). For up-to-date information on the more recent entomological aspects of Chagas' disease, the reader should consult the excellent account of its ecology by Zeledon and Rabinovitch (1981). 


\section{Section 2. Diseases Transmitted by Mites and Ticks}

\section{Some Differences}

There are several differences between the diseases spread by insects and those transmitted by acarines; for one thing, there are many more of the former. This is partly because insects are very much more numerous, having been far more successful in evolution, and produced nearly a million different species, compared to a mere 30,000 or so acarines. The abundance of insects is almost certainly due to their development of wings; and this, too, increases their potential for spreading disease by their extra mobility, enabling them to enter homes at long distances from the breeding sites. In contrast, the sluggish bloodsucking ticks and puny mites are largely restricted to outdoor, rural sites, though the ticks compensate somewhat by their long lives and resistance to starvation and, in some cases, their ability to pass on the infection to their progeny via the egg. (Possibly this explains the fact that the tick-borne pathogens are mainly very small Babesia, Rickettsiae and viruses.)

As is the case with most insect-borne infections, those transmitted by acarines are derived from zoonoses, with human cases being accidental offshoots. However, some of the former have become more closely adapted to humans, involving different species of vectors, liable to cause serious interhuman epidemics; and eventually this has reached the stage of strictly human diseases (malaria, louse-borne typhus, onchocerciasis) and approached this situation in others (dengue). In contrast, the majority of blood-sucking acarines being confined to outdoor situations are more restricted to zoonoses, though at least one has reached the stage of a human infection inside dwellings (tick-borne relapsing fever).

In some cases, the pathogens transmitted by insects have developed complex double parasitic cycles in the vector as well as in the main host (malaria, onchocerciasis, filariasis, sleeping sickness). In contrast, most acarine infections merely persist (or simply multiply) in the arthropod, which is quite unaffected. Some of them are almost purely animal-vector alternations which only rarely reach humans via vectors; instead, they can be acquired by contagion from dead animals (by butchers and hunters) or the milk of live ones. True, there are also some insect-transmitted infections which can spread by other means; plague, for example, by its pneumonic form or even by handling infected dead rodents.

In conclusion, it could be said that diseases transmitted by acarines have not had the major impact of the major insect-borne diseases like malaria, plague, typhus, yellow fever, filariasis etc. Therefore, not only has there been less urgency to find acarine control measures (except in the veterinary field), but these offer great difficulties because of their dispersion over difficult rural areas. As a result, the control of tick and mite vectors did not undergo the remarkable history of changes resulting from the introduction of synthetic insecticides, with their nation-wide use in the treatment of dwellings, followed by frequent development 
of insecticide resistance and the anxiety about possible vertebrate toxicity, leading to an urgent search for alternatives. Accordingly, they do not appear later in this book, which deals with these themes.

Generally speaking, the control of acarine vectors benefited comparatively little from advances in chemical treatments. The effectiveness of the newer synthetic insecticides against these vectors was found to be variable; thus, while DDT was fairly toxic to ixodid ticks (especially the larvae and nymphs), it was ineffective against argasid ticks and mites, though they could be killed by $\mathrm{HCH}$ and some organophosphorus compounds and pyrethroids. However, even so, the use of acaricides against ticks or mites in extensive rural habitats was found to be practical only for dealing with limited areas known to be especially heavily infested or likely to be visited by people. For these reasons, chemical control of these vectors has been most successful with modern repellents, especially DBP or synthetic pyrethroids. These could be used in combination with protective clothing, or normal clothing used protectively (e.g. trousers tucked into socks) by people liable to become infested. Another kind of protection, which seems to be unique to acarines because of their long feeding period, is to remove them from bites before they transmit the pathogen, which can take several hours. Also, domestic dogs liable to pick up ticks, which could be dangerous vectors, should be regularly disinfested.

Alternatives to chemical control have been needed for acarine vectors of human diseases, not because of failures due to resistance or toxic hazards, but because chemical means never offered the simple and effective control which insecticides had provided for insect vectors. One obvious alternative was ecological, or environmental measures; for example, to eliminate or modify types of vegetation which provided harbourage for the vectors or their normal hosts. This could hardly be expected to extend over vast areas, but could be valuable for protecting camp sites etc. Alternatively, wild or domestic animals which acted as host for the acarine could be eliminated or excluded from such areas. Planning such operations obviously demands a thorough knowledge of the acarine in question and its relation to the general ecology.

Vector control to reduce disease is an alternative to medical options, some of the more modern of which are valuable in regard to acarine-transmitted diseases; for example, the use of antibiotics to cure infections due to spirochaetes, rickettsiae or bacteria. However, the sporadic nature of most such diseases does not seem to offer opportunities for the use of chemoprophylaxis. In the same way, there are vaccines available for some viral diseases spread by acarines, but their use is normally restricted to people under especial risk.

Finally, dealing with the problem of arrangement (unlike the insect-borne diseases) I decided to classify these according to pathogen. I begin with two which are due to spirochaetes, one of which was probably the first shown to be tick-borne, by British physicians in the Congo in 1905, and the other, perhaps the latest, by a Swiss-born American in the U.S.A. in 1980. 


\section{Diseases Due to Spirochaetes}

\section{Tick-borne Relapsing Fever}

African tick-borne relapsing fever, like tsutsugamushi and the tick-borne viruses, is a disease of which the vector had been suspected by the natives of the countries concerned, which should have provided clues for the physicians seeking the cause (Fig. 1.11). However, while the Japanese doctors first investigating tsutsugamushi were probably influenced by their peasants' stories, Europeans in Africa tended to be sceptical about the ticks said by natives to be the cause of relapsing fever. For example, a certain Dr. Hinde, who accompanied the 1892-4 expedition to drive the Arabs out of the newly set up Congo Free State (by the unscrupulous Leopold II) lost several soldier patients from the disease, but refused to credit the tick's responsibility. His view was shared by most of the expatriate physicians of the time, who had perhaps two excuses. Not surprisingly, the Africans tended to ascribe all kinds of other ailments to tick bites and furthermore, the alternate fever and remission would naturally been ascribed, to malaria.

It seems that the first publication which definitely related the fever to bites of the tick Ornithodoros was that of Ross and Milne in 1904; but a more detailed and explicit account was provided by Dr. John Todd, on behalf of J. Everett Dutton and himself, after going to the Congo to investigate the disease. Dutton had already made several visits to Africa to study tropical diseases on behalf of the Liverpool School of Tropical Medicine, which published the joint account as Memoir No. 17 (Dutton and Todd 1905) although Dutton had died there. Todd began the account as follows: "Four months ago we were in possession of the main facts stated in this paper. Illness and death retarded the gathering of information and the recording of our observations. It is only now possible to publish part of our work. At the end of November we both fell ill with recurrent fever. Dr. Dutton's illness was severe and it was not until the middle of January that his convalescence began, unfortunately he overrated his strength and even before his fever subsided commenced to work harder and for longer hours than before. On the 21st February his fatal illness commenced once more, and on the 29 th he died, after four days unconsciousness. For almost a year and a half Dr. Dutton and I have worked together in the Congo. This communication is only a small part of the results of our observations. . . May any weaknesses in all be recognised as mine and in no way due to my absent comrade." (Details of Dutton's fatal illness suggest cerebral malaria, rather than relapsing fever.)

The Memoir describes the symptomology of relapsing fever, the mortality due to it and what was known of the immunity to it. The spirochaete responsible was described, though not identified (it was subsequently named Spirochaeta duttoni). Ornithodoros moubata was proved to be the vector by transmission experiments with monkeys and a rat, the tick's life history was described and information given of its local distribution and the kinds of dwelling infested. 


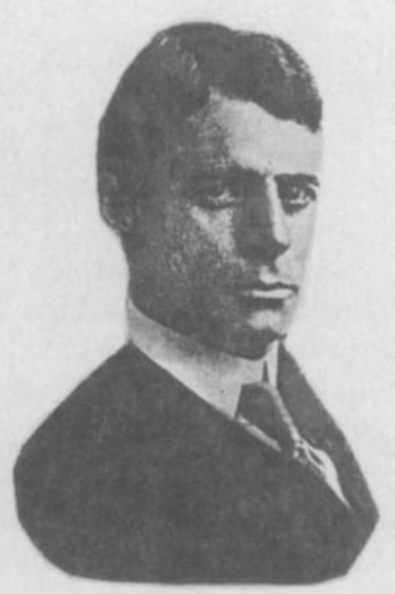

H. T. Ricketts

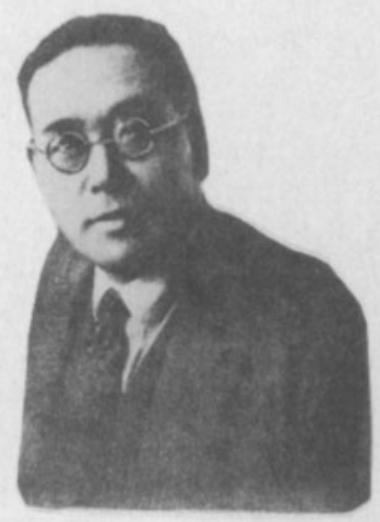

Rinya Kimura

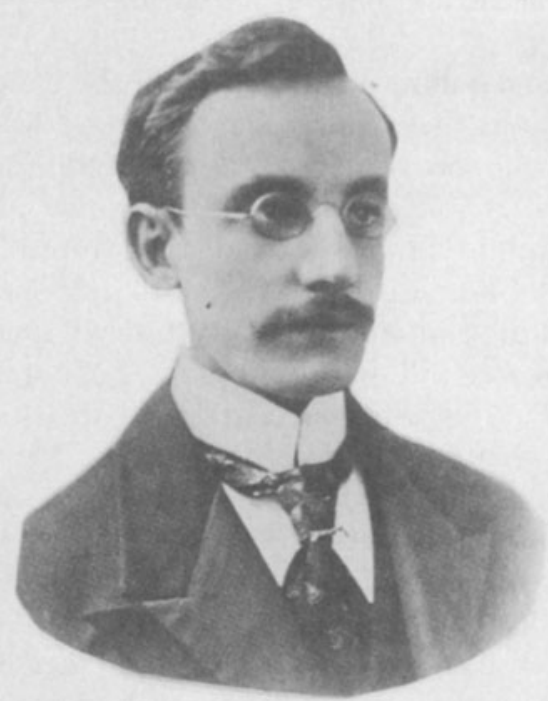

\section{J. E. Dutton}

Fig. 1.11. Some pioneers in the discovery of acarine vectors of disease

Not long afterwards, tick-borne relapsing fever in Central America was independently described by E. Robledo (1909) and announced to a meeting of the Societie de Pathologie exotique in 1908. He concluded that the spirochaete was no different from "S. duttoni" and that it was transmitted in Colombia by "Argas americana".

Over the next decade, investigations of relapsing fever tended to concentrate on the louse-borne form, which was more severe and obviously more evident in 
temperate areas, especially Europe, where epidemics combined with typhus occurred during and after the First World War. Subsequently, however, other species of ornithodoros were shown to act as vectors of relapsing fever. In 1921, Bates et al. working in Panama, proved, by using human volunteers, that a Central American form was transmitted by "O. talaje". Then, in 1926, de Buen showed that " $O$. marocanus" caused a similar disease due to a spirochaete which he provisionally named $S$. (Borrelia) hispanicum; and, in the same year, Brumpt (1926), in Dakar, found that this tick transmitted "S. crocidurae", which had a natural reservoir in shrews.

Eventually, similar infections were recognised in various parts of the world, as well as forms affecting bovines and birds. The nomenclature was revised, with the spirochaetes being transferred to the genus Borrelia and the human diseases restricted to the genus Ornithodoros. These tick-borne human diseases can be summarised as follows:

\begin{tabular}{lll} 
Borrelia & Ornithodoros & Area \\
\hline $\begin{array}{l}\text { duttoni } \\
\text { croccidurae }\end{array}$ & $\begin{array}{l}\text { moubata } \\
\text { erraticus }\end{array}$ & East Africa \\
$\begin{array}{l}\text { parkeri, turicata, } \\
\text { hermsi }\end{array}$ & $\begin{array}{c}\text { parkeri, } \text { turicata, } \\
\text { hermsi }\end{array}$ & Eediterranean, Moditerranean, Middle East, China \\
venezuelensis & Central and western U.S.A., Mexico \\
\hline
\end{tabular}

Most of these diseases are less severe than the original East African form and are zoonoses, usually involving rodents, which occasionally transfer to humans. Some occur in rather wild places, verging on deserts; the people infected are those either living in such places (e.g. parts of Asia) or visiting them as campers etc. The biological and scientific aspects of these infections are of considerable interest (Hoogestraal 1979). It is believed that they originated as symbionts of ticks (chiefly Argasidae) but, from time to time, became parasitic on mammals or birds, which acted as extra reservoirs and amplifiers. As we have noted, they could occasionally transfer to humans, in one case permanently. Moreover, some of them were able to develop occasional epizootic louse-vertebrate-louse cycles and, in one case, this led to the human louse-borne relapsing fever.

So much for the scope of Borrelia infections. Over the period just covered, there was also extensive research on the details of the most serious tick-borne form in East Africa. Investigations of the infection process, involving movements of the spirochaetes through the tick's anatomy, have been excellently summarised by Professor M.R.G. Varma (1962), who himself contributed several papers to the 92 published up to 1962. From an infective feed, some of the spirochaetes pass through the tick's gut, the proportion depending on the tick species and the strain of pathogen. It is also affected by the latter's previous history: whether it had been transmitted naturally by tick bites or artificially 
passaged in the laboratory, when it tended to lose its ability to penetrate the tick's gut.

From the haemocoel, spirochaetes pass to various tick organs (a process first noted by Robert Koch in 1905!), especially the brain ganglion, the salivary glands, the coxal glands and the ovary, so that trans-oval transmission is usual, up to five generations. Since the ticks are long-lived and the adults can survive for a year or more without a blood meal, they clearly represent a serious reservoir of infection. Vertebrate infections result from infection by saliva contamination or by coxal fluid (which is excreted by the ticks to reduce excess water from the blood meals). In some species of ticks, feeding is relatively quick and the fluid is not passed until the tick leaves the host, so that there is little danger of infection by this route. Ornithodoros moubata, however, takes some $20 \mathrm{~min}$ as a nymph and 60 to $90 \mathrm{~min}$ as an adult, so that the wound made by its mouth parts can become invaded by spirochaetes. This is more important in the adult, since the salivary glands of the nymphs are heavily infected with spirochaetes but these tend to become exhausted in the adults (which take several feeds), and later infection depends only on the coxal glands.

In the same year as Varma's survey, Dr. G.A. Walton (1962) published the results of 10 years' work in East Africa, studying the ecology and systematics of the tick vectors. He was able to show that there were several similar Ornithodoros species which could be confused with the normal disease vector and he provided detailed information for distinguishing them. They varied in habits and habitats, so that only one of them was especially dangerous because of its preference for human feeds, especially in the cooler parts of its range. He took this to be the type species (the original having been lost) and it is known as O. moubata moubata. Apart from this, the liability of this tick to transmit disease depended on its opportunities for obtaining blood meals; and this, in turn, depended on the design of various African dwellings (thus expanding on a theme of Dutton and Todd half a century earlier). After examining a large number of such dwellings, he provided plans and diagrams of the different types favoured by various tribes in different locations. It appeared that some fairly minor alterations, which were often welcomed by the inhabitants, might restrict infestations, by reducing opportunities for the ticks to feed on humans.

\section{Lyme Disease}

In 1987 Piesman discussing Emerging Tick-Borne Diseases in Temperate Climates wrote: "Without doubt, the emerging tick-borne disease of greatest public health interest in recent times is Lyme disease. Our present understanding of this disease has come from a concerted effort by scientists of Europe and North America over a span of 70 years". To get this statement into perspective, it should be noted that the present world incidence of the disease can scarcely be more than a few thousand annually; and though it can sometimes be very unpleasant, it is not known to be fatal and can be cured by the use of antibiotics. Therefore, it does not seriously compare with tropical diseases like malaria or 
filariasis. On the other hand, it has become the most widely reported tick-borne disease in the U.S.A. and in various other parts of the world, from Europe to China and even in Africa; this may be because other tick-borne infections in temperate climates have been adequately investigated, whereas Lyme disease poses a host of fascinating problems and has accordingly produced a very large number of scientific papers.

Like other "new" or "emerging" diseases, it is virtually certain that the condition has existed for an indefinitely long time. That it was not detected as an entity before, is no doubt due to the varied and complex signs and symptoms. Most evident is an expanding rash which gradually subsides, but may be followed by intermittent arthritis (sometimes becoming chronic), nervous symptoms (involving facial palsy) and perhaps heart inflammation, the extent of these varying in different patients. It was probably the initial rash which was first noted and described in Europe before the First World War by the Swedish physician Afzelius (1910) as Erythema chronicum migrans (also described as Acroderma chronica atrophicans). In subsequent years, there were intermittent medical publications, but little of importance, since neither the pathogen nor the mode of infection were known (though at one time, the bite of a tick was suspected).

In the 1980s, following the achievements of American physicians in isolating the pathogen and confirming ticks as the vectors, the name of the disease was conveniently changed to Lyme disease, following an outbreak in the neighbourhood of the town of Lyme in Connecticut. This led to an intensive search for the aetiological agent and mode of infection, which was largely solved by Willy Burgdorfer and his colleagues (1982, 1983). In 1981, he showed that a spirochaete was responsible (it was later named Borrelia burgdorferi) and that the main vector in the eastern U.S.A., where the disease was mainly prevalent, was the tick Ixodes dammini. In the western states it was I. pacificus.

Over the last decade, this discovery led to a burst of scientific research on the subject in the U.S.A., Europe and elsewhere. An impression of this activity may be gained from the publication of a recent symposium published ostensibly as part of the Annals of the New York Academy of Science, but actually as a substantial book of 513 pages containing 90 communications by no less than 250 authors (in groups), (Cieseilski et al. 1988; Smith et al. 1988; Stanek et al. 1988).

No doubt due to greater vigilance, the number of cases in the U.S.A. has risen from 491 in 1982 to an average of about 1500 in recent years. By far the greatest numbers have been in the eastern states, which may conceivably be due to the original importation from Europe, since no diseases of this exact type were known prior to 1970 . However, human habits change and so does the ecology of various districts, and these may have had some influence in the observations of the infection.

As I mentioned, the main vector in the east is I. dammini, which has a 2-year cycle. The immature stages feed commonly on white-footed mice, while the adults attack white-tailed deer. Humans generally pick up the larval or nymphal 
stages, though occasionally may be attacked by an adult. People are liable to become infected in outdoor activities, such as camping or walking (the many children infested at Lyme often ran about in the woods barefoot). In addition, folk living in suburban districts with very large gardens liable to be visited by the deer, and often relatively affluent, may be attacked. Actually, the infection is not conveyed for several hours after the ticks attack, so that if they are found and removed at once, it can be avoided.

In Europe, the main vector of the spirochaetes is the sheep tick, Ixodes ricinus, whose biology has been under study for some years as a vector of an encephalitis virus. It inhabits a very large part of Europe, from Spain to the western U.S.S.R, except for the Mediterranean fringe and the far north. Rates of infection in this tick were assessed in samples of 500 to 2500 from various midEuropean countries and found to be between 8 and $20 \%$. In many forested areas, the mammalian reservoir may be deer, though domestic cattle and sheep can also become infected. The exact numbers of human cases are not very clearly noted, but appear to be in the region of up to a few hundreds annually. However, a careful analysis of some 2000 cases distinguishes the various symptoms caused and their sequence in some patients.

\section{Diseases Due to Rickettsia}

\section{Rocky Mountain Spotted Fever}

During the second half of the 19th century, the American occupation of the west of the U.S.A. substantially increased; but as parts of Wyoming, Montana and Idaho became settled by farmers and stock breeders, some of these were attacked by a dangerous febrile disease, with extensive spotting of the body. As it was eventually discovered to be a zoonosis which sometimes afflicted humans, it seems highly probable that the American Indians had sometimes suffered; but their records were vague and sparse. In any case, it had been noted since about 1873 among white settlers, and seemed to be increasing. The first specific report was that of Surgeon Major W.W. Wood of the U.S. Army in 1896, based on data provided by eight Idaho doctors. These detailed the symptoms, but could not suggest a cause, other than that it was probably acquired out of doors in early spring. Mortality was low in Idaho, though elsewhere, as in the Bitter Root Valley and Snake River bed in Montana, it could rise to $70 \%$ or higher. As white settlement increased, so did the disease, which tended to deter possible settlers; so the Montana Board of Health appointed two pathologists, L.B. Wilson and W.M. Chowning (1904), to investigate. They claimed to have discovered piroplasmids in the blood of patients resembling the babesia recently discovered to be the cause of Texan cattle fever; and since this was spread by ticks, they suggested that this might be true of the human spotted fever. Furthermore, since these are protozooans, by analogy with malaria, it seems just possible that quinine treatment might be beneficial; but this proved to be of little help. 
Next, the Montana Board of Health appointed a zoologist, C.W. Stiles, an expert in parasitic diseases, who worked in the Bitter Root Valley for 2 months in 1904. He could find no trace of a piroplasm, as alleged by the former workers, an opinion confirmed by an U.S. Army physician, O.M. Ashburn. His scepticism unfortunately caused Stiles to reject the tick transmission theory and instead, tentatively suggested a bacterial agent, spread by contagion. The association with spring when most attacks occurred, was explained by some unknown effect of melting snow water! In fact, Stiles did little more than quash the piroplasm theory, and his scornful rejection of tick transmission has been suspected of being slightly influenced by local pressure, since tick bites were considered to be almost inevitable and, if they were declared to be dangerous, this might deter settlers and land values would suffer! Not unnaturally, Wilson and Chowning were offended by Stiles excessive rejection of their findings, and Chowning (who was shortly to leave for other work) called in H.T. Ricketts of the Pathology Department of Chicago Medical School to begin what was to be a definitive study.

Howard Taylon Ricketts was born on a farm in Ohio in 1871, but when 2 years old, his father moved to Illinois and engaged in the grain business. Ricketts' parents were earnest, religious people, determined to give their children a good education; and the Northwest Academy was their choice for their son, and later the Northwest University, which he entered in 1890. As his family moved to Lincoln, Nebraska, he transferred to the University there in 1892 and eventually entered the Medical School in 1894, graduating in 1897. During this period, his family suffered financial troubles due to the recession in the early 1890s and Ricketts had to support himself by various part-time jobs. Despite overwork and illness, he completed internship and from 1902 received various appointments, which would have eventually led to a Professorship of Pathology in the University of Pennsylvania in 1910, but for his early death in Mexico in that year.

In 1906, Ricketts began work on the spotted fever in Montana, joined by W.V. King of the Public Health Service. Ricketts was very soon able to maintain a strain of the unknown pathogen by serial transfer in guinea pigs. By (1906), both Ricketts $(1906,1907,1909)$ and King (1909) had independently managed to transfer the infection by the bite of a tick from one animal to another, using the local wood tick, Dermacentor andersoni (then called D. venustus). Actually, a unique human-to-human transmission by the same means had been carried out a year earlier, though this was not made public until 1908, by L.P. McCalla. Both the volunteers, a man and a woman, developed mild cases of the disease, which could have been deadly, as shown by the death of another worker, McClintic, in 1912.

McCalla, however, does not seem to have contributed much else, and it was Ricketts who, assisted by colleagues and students from the Chicago Medical School, made further progress. He soon showed that the infective agent could be passed from one generation of ticks to the next, via the egg, so that the infective ticks in early spring were those inheriting the agent from their mothers in the 
previous year. He also described what he considered to be the infective agent in the blood of victims, as well as in the ticks, describing them as minute, bipolarstaining bacilli. However, he was reluctant to describe them as bacteria because he was unable to culture them on artificial media, according to Koch's criterion. Also, the recent discoveries of pathogen transfer by arthropods had all involved protozoa (fleas had not been incriminated as vectors of plague bacilli). On the other hand, by obtaining concentrates of these organisms from tick eggs, he was able to cause aglutination of sera from guinea pigs which had survived infection (indicating a degree of immunity) but not in others. Apart from this, he tentatively supported Wilson and Chowning's suggestion of a reservoir of infection in wild animals (especially gophers).

Ricketts' paper describing these findings was published in 1909, at which point he was invited to move to Mexico to study "tarbadillo" (typhus), researches which led to his death in May 1910 (as mentioned earlier in this book). Meanwhile, in Montana, the fact of tick transmission having been established, efforts were made to control these pests. Little work on the aetiology was done there for several years, except for some inconclusive work by L.D. Fricks of the Public Health Department and Hideo Noguchi of the New York Rockefeller Center (mentioned twice before: pp 37, 57). However, real progress was made by Simon B. Wolbach of the Harvard University Medical School, who visited Montana in 1916 and stayed there for a few years. (He was later called away to deal with the World War I influenza epidemic and eventually led a commission to Poland to cope with typhus.) His investigations in Montana cleared up some of the problems concerning the Rocky Mountain fever pathogen, and his several papers on the subject were eventually summarised in a long (197-page) issue of the American Journal of Medical Research (Wolbach 1919). He further described the organisms seen by Ricketts as being 0.2 to 0.5 microns wide, and present in enormous numbers; he noted that they actually invaded nuclei of cells, so that they were unlikely to be bacteria and probably a new type of microorganism. He also found that, while the symptoms of the disease in mammals closely resembled those in humans, the infected ticks were quite unharmed by the organisms. By this time, the pathogen of typhus had been described as "Rickettsia" and named R. prowzeki. Wolbach decided that the agent of Rocky Mountain fever, though closely resembling these, showed some differences; so he named them Dermocentroxenus rickettsi.

Although the general nature of the disease was now established, there was a gap of a decade or more before it was recognised in other parts of the Americas. Thus, although local diseases were recognised from their symptoms to be related to typhus and other rickettsial infections, the pathogen was sometimes merely referred to as "the virus", presumably in the non-specific sense of "infective agent". Fairly soon, it was recognised to be prevalent in the eastern U.S.A. and Parker et al. (1933) reviewed the possible tick vectors in the country. They concluded that, while $D$. andersoni was almost exclusively responsible for human infections in the western states, $D$. variabilis, the dog tick, was mainly involved in the east. Infections commonly took place in suburban premises, were 
brought into them by dogs and often infected women and children, whereas in the west, men in the field were mainly at risk. However, mortality rates were considerably lower in the east. Apart from this, the rabbit tick, Haemaphysalis leporis-palustris, appeared to be responsible for maintaining a reservoir of infection in small wild animals, though the disease could also persist by inheritance in the ticks.

It is interesting to note that the original location of the fever, as indicated by a map in Wolbach's paper, shows cases clustered on the foothills of the Rocky Mountains; but in recent years, the eastern form of the disease has been far more prevalent. Accordingly, there have been a number of studies of the conditions responsible (Sonnenshein 1972), which have indicated one cause to be the expansion of the eastern population into rural areas and (as with Lyme disease) increases in rural recreation due to greater prosperity. Also, there was evidence of involvement of another tick species in Virginia, Amblyomma americanum, and indications of the special importance of particular types of vegetation. Meanwhile, in the early 1930s, the disease began to be recognised in other parts of the Americas; in Brazil in 1931, in Colombia in 1937, in Canada in 1938 and in Mexico in 1942. Often this provided an explanation for a disease of unknown aetiology, with local names, such as fiebre manchada (Mexico), fiebre petequial (Colombia) and fiebre maculosa or "Sao Paulo fever" (Brazil). Over most of this huge area, Amblyomma cajennse, was found to be the most common vector tick.

\section{Fièvre Boutoneuse and Tick Typhus}

A febrile disease with profuse spotting, though seldom really dangerous, had been known for many years in the Mediterranean region and described as fièvre exanthematique and later more commonly as fièvre boutoneuse, on account of the button-like eschar which came to be recognised as the site of a tick bite. The earliest good clinical description was that of Conor and Bruch (1910), working in Tunis. Apart from noting some small pimples, which they thought might have been due to insect bites, they did not speculate on the aetiology; yet when, many years later, the pathogen was identified as a Rickettsia, it was eventually named R. conori.

A somewhat similar disease was briefly noted in Mozambique by Sant' Anna (1911), who observed that it often followed tick bites; but he distinguished it from tick-borne relapsing fever, which had recently been described. McNaught (1911) an army surgeon in South Africa, also mentioned a similar disease following tick bites, which he suggested had some similarity to Brill's disease, showing that he recognised the affinity to the typhus type of infection. Nuttall (1911), however, commenting on this infection, simply called it "tick bite fever".

Very little further progress was made on fièvre boutoneuse or South African tick fever for the next 20 years. However, in 1916, J.W.D. Megaw (Megaw et al. 1925) of the Indian Medical Service, was bitten by a tick near Lucknow, which resulted in a fever; he recorded this together with other cases. Initially, he, too, noted a similarity to Brill's disease; but in subsequent papers in 1925, he put 
it more firmly in a scheme of typhus group of diseases, excluding the exanthematic human form as "epidemic" from the others. By 1934, he had become a Major General speaking to the British Medical Association and he was able to reiterate his earlier scheme with confidence (Megaw 1934).

By this time, some extensive investigation of fievre boutoneuse had been in progress in the Mediterranean region by various Frenchmen. Two of the first were D. and J. Olmers, who, in 1928, published extensive observations of the disease with some experimentation.

Most of the time they used laboratory animals, monkeys and guinea pigs, in contrast to later workers, who employed considerable numbers of human volunteers. Though they were unable to detect the pathogen, they pointed out the infection's similarity to Rocky Mountain fever and Japanese river fever, though they could distinguish it from human typhus. Their evidence pointed to dogs as reservoirs and ticks as vectors, though they were unable to transmit the infection to monkeys by the bite or injections of macerated bodies of Ixodes ricinus. Following this, for several years from 1930, there were numerous papers on the subject, by E. Brumpt, Paul Durand, Jean Caminopetros, George Blanc and others, from various parts of the Mediterrean litoral (Tunisia, Morocco, Southern France, Greece and Portugal). Guinea pigs were innoculated with the "virus" and strains maintained for tests. The disease was transferred to volunteers by innoculation and traces from the eschar. Ticks, especially Rhipicephalus sanguineus, the brown dog tick, were shown to be highly infected, but the first tests failed to infect dogs, suggesting them to be immune. However, Durand showed that puppies could be easily infected, so that the dogs previously used had probably had a previous infection from which they had recovered.

In the early 1930s, the equivalent infection was being investigated in South Africa, and in 1934, Pijper and Dau published an important paper on the subject where the infection was shown to be transmitted in rural areas, by larval ticks of the species Rhipicephalus appendiculatus and Amblyomma hebraerum (the "bont tick"), which climbed up stalks of vegetation and attacked men or animals. These were veld inhabitants, not common around dwellings, so that the disease from this source more closely resembled Rocky Mountain fever. However, serological tests showed the pathogen to be very similar to $R$. conori.

By 1940 onwards, there was more general knowledge and understanding of the principles of investigating local forms of disease with febrile symptoms and the spotting which is characteristic of this group of diseases. In Africa, infections due to strains of $R$. conori were shown to be present in many parts of the continent, especially along the coastal areas. Transmission could be due either to the semi-urban dog ticks, Rhipicephalus or Haemaphysalis leachi, or by the bush ticks, $R$. appendiculatus or A. haebraeum. Meanwhile, in India, cases of tick typhus were being reported from various localities, transmitted by different species of tick, but over a wide area by $H$. leachi, the Rickettsia responsible being found to be very similar to $R$. conori.

Rather later, over a wide part of the U.S.S.R., another relative of this pathogen sometimes known as $R$. sibiricus was identified as being responsible 
for a relatively mild form of the disease; clinical details had been noted since about 1934 or 1936 . Transmission was by various ixodid ticks, but especially Demamcentor silvarum and Haemaphysalis concina. Also, in Australia in 1946, a similar febrile illness had been reported, and in the same year identified as a tickborne rickettsial disease; although the pathogen was shown to belong to the spotted fever group, it was sufficiently different to be designated $R$. australis. Various bush-living ticks were found to be the vectors.

\section{Tsutsugamushi (Scrub Typhus)}

The potentially dangerous mite-transmitted rickettsiosis known as tsutsugamushi indicates from its name a connection with Japan, where most of the early scientific work on it was done. The vector $\mathrm{mi}$ 8. and the pathogen are present over a huge range of the Far East and are liable to be hazardous to those in close contact with certain kinds of rough vegetation, usually at particular times of the year. For centuries it was recognised as an annual danger to peasants visiting particular river valleys in China and Japan. Just as the African natives were aware of the connection between tsetse flies and nagana, so some of the peasants realised the connection between the itching creatures picked up in these river valleys and the subsequent illness. Louis Sambon's account, published in 1928, quotes translations of 16th century Chinese writings describing "sand lice" burrowing into the skin and sometimes causing death. The main regions affected in Japan, where much of the early work on the disease was done, are the Niigata and Yamagata Prefectures on the north-west coast of Honshu, the main island. In 1966, I was one of a party of visiting scientists to visit the area, and among other things, we were shown a demonstration of primitive religious rites intended to drive away the mites (including fire-walking by the priests!) Probably the first European to visit the area was Dr. Theodore Palm, a medical missionary. He wrote an account of the disease to a colleague in Scotland, which was published in the Edinburgh Medical Journal in 1878, describing the symptoms and recording significant details of its location and seasonal occurrence. He mentioned the Japanese belief that its cause was a minute creature which burrowed into the skin, and was in fact shown one, which he thought looked like a tiny spider. It was called variously akamushi (red mite) shiromushi (white mite) or tsutsugamushi (disease mite). Another European visitor was the German Dr. Baelz (Baelz and Kawakami 1879), who collaborated with a Japanese Dr. Kawakami to provide a further more detailed description of the disease and the mites, though he cast some doubt on the connection.

From the last decades of the 19th century, Japanese scientists began to adopt more modern technology and made great progress. The eminent bacteriologist Shibasaburo Kitasato (whom we have already noted as contributing to the elucidation of plague, p. 63) began to take an interest in this disease. $\mathrm{He}$ supported the mite vector theory, but unfortunately introduced a "red herring" by claiming to have discovered the pathogen to be a Plasmodium-like organism. However, substantial progress was made by Keisuke Tanaka (Tanaka et al.) 
in 1899, who improved the clinical description, and suggested that the seasonal occurrence could be explained by the emergence of vast numbers of mites in early summer, as the flood waters subsided in the river valleys. At this time of year, the peasants would be venturing into them to cultivate the fields. Aware of the Western discoveries of arthropod transmission of disease pathogens, he suggested a similar situation with the mites.

Over the first two decades of this century, a series of investigations by Japanese scientists established the mites as the vectors, worked out their life histories and contributed to their systematics. Many of these papers were, naturally, in Japanese; but useful summaries became available in English in 1917 (Miyajima and Okamura 1917) and in German in 1918 (Kitashima and Miyajima 1918). By 1908, mites had been proved to be the vectors of the disease, mainly by Kitashima, Miyajima and Okamura. (Blake et al. (1945) in their excellent review of the whole subject, pointed out that, by 1909, three rickettsial vectors had been discovered; that of Rocky Mountain spotted fever by Ricketts and King, of epidemic typhus by Nicolle et al. and of tsutsugamushi by these Japanese.) The biology and life cycle were revealed by the same workers and by Nagayo et al. (1917) between 1914 and 1917. These studies showed that the only parasitic stage was the larva, which emerged from eggs laid by overwintering adults in early summer. These larvae would climb up grasses or other vegetation and cling to any passing warm-blooded creature, the usual hosts being various rodents, especially voles. They would crawl about to find a suitable place to burrow into the skin; on the voles, this was usually inside the ears, where they could be found in clusters. Humans attacked were usually peasants going out to cultivate the ground laid bare as the river waters receded in spring. After a few days, the larvae would drop off into the soil and moult to form the nymph and later to become the adult form, neither of which were parasitic, but lived on small arthropods in the soil.

Systematic studies were still needed. Back in 1899, Tanaka had pointed out the affinity of the mites to the "chiggers" and "harvest mites" of the west and had provided some illustrations. However, these did not correspond to the actual vector species when this was identified. By 1921, Nagayo et al. (1927) had described four related species found in the infected area, and this allowed identification of the vector, which was by far the most common found on humans. It was found to be Trombicula akamushi, already described by Brumpt in 1910. This was the vector in Japan; other mites might be important elsewhere: for example, $T$. deliense in Malaya.

By pooling collections of these mites from the voles, and injecting them into monkeys, it was shown that they carried the pathogen; but very large numbers had to be used, indicating that only very few of the mites were actually infected (Kawamura 1926). Since the larval mites fed only once on their host, it was evident that the infective agent must be transmitted to the next generation. Although it was possible that the mites themselves could act as a reservoir of the infection, it seemed very likely that the normal vole hosts would be a reservoir. This was difficult to prove until many years later by some experiments of Kawamura and Imagawa (Kawamura and Imagawa 1931). 
Although both the vector and the reservoir of the disease had been found, the actual pathogen was still uncertain and usually referred to as the "virus" (in a general sense). As I noted early in this book, (p. 8), this is quite possible, and even offers a way of reducing a disease by controlling the vector or the reservoir. However, it is obviously very desirable to identify the pathogen, and more easily find a curative drug or vaccine. As regards tsutsugamushi, there already existed a clue from the similarity of the clinical and epidemiological features of tsutsugamushi and Rocky Mountain spotted fever, which was recognised by Dr. Miyajima of the Institute of Infectious Disease in Tokyo as early as 1908 . He discussed the idea with Ashburn and Craig (1908) when they were all on a visit to the Philippines and he invited them to Japan, where they fully endorsed the theory. Nevertheless, despite this clue and the gradual recognition of the rickettsial species responsible for other diseases of the type (Kitashima and Miyajima 1918), the pathogen of tsutsugamushi was not finally named until 1931. There had been, in fact, earlier claims: that of Hayashi in 1920 (Theileria tsutsugamushi) and of Sellards in 1923 (Rickettsia nipponica), both of which were dismissed as unsound. Nagayo et al. made a good case in 1930 (Rickettsia orientalis), which was accepted by Blake et al. in 1945; but the modern preference is for the description of Ogata (1931) ( $R$. tsutsugamushi).

This account gives the basic facts of the discovery of the vector of tsutsugamushi, but a vast amount of additional information was to accumulate. During the period up to the Second World War, the disease, having been recognised in various parts of the Japanese Empire and other regions of the Far East, needed investigation of the specific vector (often Trombicula deliense) and the rodent reservoirs. The operations in that part of the world during the Second World War brought many troops into close contact with vegetation of a type to harbour rodents infested with the vector mites, so that there were numbers of casualties among them. These sudden cases caused especial alarm, being unexpected and, at that time, without a cure. The disease became known among Allied forces as "scrub typhus", because the common location was liable to be an area of "scrub" vegetation infested with rats. A very great amount of research was done by both sides in the conflict; summaries are available by the Americans Blake et al. (already mentioned) and Philip (1948), the British in Malaya, Audy and Harrison (1951) and the Japanese M. Sasa (1954). Though the epidemiology was put on a much firmer basis (which assisted in the control work), I do not think that any strikingly new principles of vector relationships were discovered, but the mites are now transferred to the genus Leptotrombidium (e.g. L. akamushi, L. deliense).

\section{Rickettsial Pox}

An unusual and interesting kind of rickettsial infection came to light only in 1946 when outbreaks of what was first diagnosed as chicken pox occurred in blocks of flats on the outskirts of New York (Shankman 1946). Further cases occurred throughout the year, affecting 124 out of the 2000 people in the buildings. With commendable speed, a thorough investigation was conducted 
by the New York City Health Department and, in a series of papers published in the course of a year, revealed the nature of the pathogen, the vector and the reservoir of infection (Huebner et al. 1946; Greenberg et al. 1947).

Serological tests distinguished the disease from various possible alternatives: leptospirosis, typhoid, brucellosis and endemic typhus. However, the nature of the syndrome suggested affinity to the typhus group and this was supported by a partial immunity to Rocky Mountain spotted fever, Confirmation came when in the course of animal innoculations from patients, Rickettsia were detected. The highly urban nature of the location suggested an indoor vector, and perhaps, reservoir. The vector was found in the mite Allodermanyssus sanguineus, which is parasitic on mice and sometimes bites humans. These mites were found to be very numerous in places in the buildings and found to harbour the pathogen. (One of the investigators was infected with the disease in the course of the work.) As a result of these investigations, the disease was named rickettsial pox and the pathogen Rickettsia akari (akari being Greek for mite). A few years later, it was recognised to be the cause of the disease in a patient in Boston, by serological tests and, after some technical troubles, the pathogen was recovered from house mice in, the patient's environment (Fuller et al. 1951). Two years later, in 1952, there was a further group of cases in West Hartford, Connecticut, and mites caught in the vicinity were shown to contain the same pathogen (Eustis and Fuller 1952). The life cycle and habits of these mites were studied in detail by H.S. Fuller (1954) and compared to two other peri-domestic kinds; Dermanyssus gallinae, which attacks chickens, and Bdellonyssus bacoti, which infests rats. Both species will sometimes bite humans, but neither has been found to transmit any specific disease in this way.

The publication of these findings drew the attention of various physicians to similar diseases which had either been unidentified or recorded as chicken pox. As a result, rickettsial pox was discovered to occur in various parts of the eastern U.S.A. and even in distant countries. In what was then French West Africa, a series of untypical cases of "varicelle" (chicken pox) had puzzled the local doctors until one was found to be identical to chicken pox, by serological tests in 1951 (Le Gac and Giroud 1951). (The French called it rickett-siose vesiculeuse.) About the same time, Russian workers had been describing an unusual rickettsial disease which they traced to being transmitted by various mites with a reservoir in domestic rodents. The pathogen was described as $R$. dermocentoxenus murinus (or merely $R$. murinus; but it is probably identical with $R$. akari. A similar disease is apparently present in South Africa, though the infections are said to occur in the bush, so that the vectors must be parasites of wild rodents, which presumably act as a reservoir (Gear 1954).

\section{Q-Fever}

In 1935, there were some serious cases of a new kind of febrile disease in Brisbane, Queensland, and several of the patients died. Dr. E.H. Derrick (1937) of the local Department of Health was asked to investigate, and he published his 
findings in 1937. From the signs and symptoms and some serological tests, he suspected a rickettsial disease, which was confirmed by Burnett and Freeman (1937), and the organism named R. burnetti. However, there were several unusual features of the infection and Derrick named it "Q fever" (standing for "query", not Queensland). Thus, other rickettsial diseases were transmitted by arthropod vectors, usually ticks, but none of the patients afflicted had histories of tick bites. Significantly, as will shortly appear, five of the original eight patients had worked in an abattoir and the other three had worked on dairy farms. This connection with cattle and slaughter houses was frequent in the subsequent cases noted by Derrick, when he summarised the information in 1944 (Derrick 1944). Accordingly, he and his colleagues sought infection among cattle ticks and, suspecting a wild reservoir of infection, among wild animals and their ticks. Some suggestive results were obtained when three wild bandicoots and six of their ticks were found to be harbouring the pathogen. These ticks (Haemaphysalis humerosa) were proved capable of transmitting the organism to guinea pigs.

Meanwhile, two Americans, Davis and Cox (1938) described the isolation of a very small Rickettsia (which they claimed to have passed through a Mandler filter) from the tick Dermacentor andersoni and they named this Rickettsia diaporica. However, shortly afterwards, this was shown to be identical to $R$. burnetti. Serological tests showed that infection with this organism had occurred in numbers of people in the Western U.S.A., though there had been no reports of overt cases (though one laboratory worker was infected in the course of the investigations). However, an outbreak at the National Institute of Health in Washington suggested to Hornibrook and Nelson (1940) that infection could result from inhalation of infected dust. Derrick (1944) noted this, but still considered the important cycle to be among ticks and wild mammals, transported to herds of cattle or sheep and thence to humans by tick bites or perhaps tick faeces when handling the beasts.

With this background, Army medical officers (Robbins et al. 1946) were presented with a series of outbreaks of over 1000 cases of "atypical pneumonia" among Allied troops in the Eastern Mediterranean region in 1944-45. Originally described as "Balkan grippe", it was soon identified as a rickettsial disease due to $R$. burnetti. Virtually none of the men had complained of previous tick bites; but most had lived in billets close to cattle or other farm animals. It was therefore concluded that infection had occurred through inhalation of infected dust.

Subsequent investigations (summarised by Cox 1959) confirmed the usual infection of humans to be indirect, often via the faeces of infected ticks, which remained active for long periods, so that contacts with contaminated hides of cattle or sheep could be dangerous; alternatively, infected cattle and sheep were found to excrete the pathogen in their milk and also in birth fluids and afterbirth. These facts raised the possibility of infection through drinking raw, unpasteurised milk or, in the case of the abattoir workers, from aerosols arising from the carcases. 
By 1950, the series of publications on the unusual epidemiology of Q fever had drawn the attention of international health authorities to the matter. In that year, the 3rd World Health Assembly (prompted, no doubt, by technical experts) had called attention to the potential danger of the disease and the gaps in our knowledge of it. A programme of assessment and research in 33 countries was initiated and, by 1955, Kaplan and Bertagna had completed a survey of the world distribution (though actually preceded by an independent survey by the Americans Berge and Lennette (1953). The disease was found to exist in most of the 33 countries of the survey and further data added another 18 (altogether 51 countries in five continents). Those with negative replies (e.g. Ireland, Netherlands, New Zealand, Poland and Scandanavia) were noted as importing "very few domestic ruminants", which was possibly significant.

Also in 1955, the British scientists Stoker and Marmion (1955) discussed the Natural History of the disease. They concluded that the pathogen $R$. burneti was a very successful and adaptable parasite. It was known to occur in over a score of tick species (mainly ixodids with a few argasids) and in a considerable variety of (usually small) wild animals. Tick-animal cycles of the parasite in various places had shown the possibility of transfer to domesticated ruminants, with obvious danger to those tending them or dealing with milk or carcases. It was true that humans were not the natural hosts and that infections had been "dead ends". Yet there was at least a possibility that a strain could develop with ability to spread directly from person to person effectively. Thus, it was known that live $R$. burneti had been isolated from urine, sputum and even, on one occasion, from placenta of human patients. However, the absence of any serious outbreaks in the last 25 years should be reassuring.

\section{Diseases Due to Viruses}

The protean nature of virus diseases, including those due to arboviruses, was emphasised earlier in this book (p. 36). Added to the range, from nearly harmless to very grave, is the unreliability of symptoms for classification, which had to await new developments in serology and other techniques. These facts somewhat delayed recognition of some viral diseases and their vectors, especially those borne by ticks which, being rural and sporadic, did not command the intense medical attention of such plagues as yellow fever earlier in the century. However, by the late 1930s, tick-borne viral diseases began to be recognised, allowing Colorado tick fever to be distinguished from Rocky Mountain spotted fever. Soon after the Second World War, as a result of the destruction and upheaval, some severe local epidemics of tick-borne fevers occurred in the U.S.S.R. A very substantial amount of investigation was carried out by Soviet scientists, published in Russian and not readily available, so that I have had to rely on abstracts and reviews. However, as a result of the east-west alliance during the war, scientific collaboration greatly improved and there were further advances in the subject. 
Finally, it should be mentioned that there are several viruses transmitted by ticks among wild (or even domestic) animals, by species which rarely or never bite humans. (e.g. Omsk haemorrhagic disease). Such infections can sometimes be acquired in other ways such as skinning of wild animals by hunters or via the milk of domesticated ones. I have not attempted to deal with these.

\section{Colorado Tick Fever}

During the second half of the 19th century, when the United States was extending to the western half of the country, there were reports of febrile infections which, on later consideration, might well have been due to this tickborne virus. It occurred in the same general region as Rocky Mountain spotted fever (though first investigated in Colorado) and was sometimes thought to be a non-eruptive form of that disease, since there was no rash. It was not distinguished as a distinct entity until F.E. Becker (1926) began to suspect that it was and stated it more definitely in 1930 (Becker 1930), assuming that tick bites were responsible on the basis of the fact of recent tick bites in most patients. This was still the only evidence in, when Topping et al. (1944) conducted a clinical study, and were still ignorant of the etiological agent. Finally, in 1944, Florio et al. were able to demonstrate transmission from ticks to an experimental animal. They concluded that the fever was "a mild, non-fatal infection of unknown etiology, closely resembling dengue fever, except for the skin eruption". By 1945, Sabin and Schlesinger identified the pathogen as a virus, and in the next year, Florio et al. (1946) finally proved it to be distinct from dengue. The virus, in fact, belongs to quite a different group. The vector is $D$. andersoni.

\section{Tick-Borne Encephalitides}

Russian Spring-Summer Encephalitis; European Tick-Borne Encephalitis and Louping Ill. Cases of paralytic encephalitis, with a fairly high mortality $(25-30 \%)$ were known to occur in some of the eastern forested regions of the U.S.S.R., but no specific disease was recognised until the late 1930s. The victims were mainly lumbermen or hunters and the disease was commonly called "woodcutter's disease". Infections usually began in the early summer, so that it eventually became known in the west as Russian spring-summer encephalitis (RSSE). The causative agent was identified as a virus by Silber in 1939; and, about the same time, analysis of the epidemiological evidence (sites of infection; absence of contact infections) suggested an arthropod vector and Ixodes persulcatus came under suspicion (Sinorodintseff et al. 1939). It was shown to be an efficient vector in the laboratory, though prolonged feeding was necessary for transmission, but afterwards the ticks maintained the pathogen for long periods and could pass it on to the next generation, via the egg. Samples of ticks from one site revealed nine out of 1900 to be infected, and 28 out of 1917 from another 
site. Although the persistence of infection in the ticks and the passage to the next generation suggested that they might be a form of reservoir, it was believed that latent infections in wild animals (chipmunks, squirrels, mice, hares etc.) might be more important.

Comparatively little was known about this disease in the west until the Second World War, which enhanced cooperation between Russian and Western scientists. In 1941, a strain of the virus was transported to the U.S.A., where in the course of further investigations, it was shown to be related to one causing louping ill, a disease of sheep in Britain, by Casals and Webster in 1944. Louping ill had been known in Britain for at least 100 years and was suspected of being transmitted by ticks as early as 1899 . By 1930, its viral cause was established (Pool et al. 1930) and 2 years later, McLeod and Gordon (1932) identified the tick vector as Ixodes ricinus. Some mild human cases had been recorded from 1948 onwards (noted in a review of the acarology of louping fever by Varma 1963 ) and no doubt there had been earlier unidentified ones. That is probably also true of Central European tick-borne encephalitis, the causative virus of which was first recovered from patients and ticks of the species I. ricinus by Czech scientists in 1948 (Pond et al. 1953). Serological tests showed this to be a strain of the RSSE/louping ill complex, which was eventually recognised as extending (in places) over a huge band across Europe and Asia, transmitted to humans by I. ricinus in the west and I. persulcatus in the east. Various wild animals (and some domesticated ones) acted as a reservoir of the virus, which was transmitted among them by different species of ixodid ticks. It can also be acquired by consuming milk or cheese from infected cows.

\section{Crimean-Congo Haemorrhagic Fever}

According to Hoogstraal's substantial review, (Hoogestraal 1979) a type of haemorrhagic fever which he believes to have been the Crimean-Congo infection was described by a Persian physician who died in 1136 in an area which is now Tadzhikstan. The cause was thought to be a small, tough parasite like a louse or tick. The same disease appears to have been well known in past centuries to the inhabitants of southern Uzbekistan. However, there were no reliable records prior to the Second World War, apart from some clinical and autopsy notes by a physician in the U.S.S.R. over a period from 1927 and 1943. What brought the matter to modern medical attention in that country was a series of fairly severe epidemics in the war-devastated Crimea in 1944-5 and subsequently in Astrakhan (1953-68) and Bulgaria (1953-73). The initial outbreak in the Crimea involved over 200 cases among people gathering the harvest in the steppe region and among soldiers, whose medical staff reported the disease to the All-Union Institute of Experimental Medicine (Gajdusek 1953). The Director, Professor M. Chumakov, organised investigatory expeditions in 1944 and further investigations from the Academy of Medical Sciences in 1945 and 1946. These teams isolated a virus from the blood of patients which was shown to be different from that of sandfly fever, dengue or Q-fever. Furthermore, the studies of 
A.G. Grobov indicated on epidemiological grounds that the disease was transmitted by the common tick Hyalomma marginatum, with occasional interhuman passage and a reservoir in hares.

In subsequent years, there have been extensive investigations into various aspects of the disease in the U.S.S.R. and, in 1967, Soviet workers adopted a new technique of using newborn mice inoculated to detect the virus, which greatly simplified the work. Moreover, soon after this, collaboration developed between Soviet and American workers (especially M.P. Chumakov and J. Casals) which further extended the understanding of the disease. The virus was found to be present in places over a wide band between Bulgaria and Uzbekistan and south through Afganistan, Pakistan and the east coast of India; it was also present in a wide band across Africa, from the Rift Valley to the Atlantic.

The virus was found to be present in many small wild animals (though seldom in birds) including domestic animals such as goats; these could provide a reservoir of infection. Examination of numerous insects (including large numbers of mosquitoes) were negative, but many species of ixodid ticks were positive, especially Hyalomma spp. Since the virus was shown to persist for long periods and be passed through different stages (and apparently via the egg to the next generation) these, too, could act as reservoirs.

Infection of animals (and usually of humans) is normally by tick bites; but some human cases have occurred by crushing ticks (e.g. when sheep shearing) and there have been hospital cases by contamination with bloody discharges from patients. Only recently has a vaccine been developed for people specially at risk. Prevention normally depends on avoiding tick bites, by use of repellents or protective clothing or general care.

\section{Kyasanur Forest Disease}

In March 1957, the Virus Research Centre in Poona was informed that numerous monkeys had been found dying in the forested area of a district in Mysore State. Hitherto, the presence of dying monkeys in a forest had been an indication of a local zoonosis of yellow fever (which is, of course, absent in Asia); accordingly, an immediate investigation was ordered by the Director, T.H. Work (Work et al. 1957). It was found that the epizootic was accompanied by many cases of febrile disease in the region. Tests of blood samples from patients excluded bacterial and rickettsial infections and eventually the pathogen was shown to be a virus. A similar virus was isolated from sick monkeys and, though the human patients' pathology indicated haemorrhagic signs, this was found to be closer antigenically to tick-borne encephalitis than to the Crimean haemorrhagic fever.

The possibility of an arthropod vector was soon investigated by Varma et al. (1960). Mosquitoes seemed to be excluded by the absence of day-biting species; nor were other biting diptera (midges, sandflies) common in the area. These observations, and the relatively slow spread of the disease, suggested ticks as a possibility. Accordingly, extensive collections were made from the ground, 
from tree barks and from animals in the area. (In the course of this work, three of the collectors fell ill with a febrile disease which was identified as due to the virus in question.) A total of over 2000 specimens was collected, of which the great majority (over $90 \%$ ) were species of Haemaphysalis, especially $H$. spinigera, the nymphs of which were commonly found on bonnet and langur monkeys, both of which were susceptible to the infection. Adult $H$. spinigera were also collected from cattle and buffaloes in the area, though the prevalent ectoparasite on these animals was the tick Boophilus microplus.

Samples of the unfed ticks were tested for the presence of the virus and it was detected in large pooled groups of $H$. spinigera nymphs and larvae taken within the endemic area but not on those collected from outside (Trapido et al. 1959). Moreover, it was not found in (smaller) pools of several other genera of ticks.

These facts did not actually prove $H$. spinigera to be the vector of the human disease, especially as many specimens were taken from the clothing of the collectors, without having bitten them; however, it seems a strong indication of their involvement in the transmission cycle. Further laboratory tests by Varma (Varma et al. 1960) proved that larvae of this species can pick up virus from infected chickens and pass it on to the nymphal and adult stages. The nymphs were shown to be capable of transferring the infection to chickens and the adults to a young buffalo calf. It therefore appears almost certain that the immature stages of $H$. spinigera can infect monkeys (and probably birds, which would spread the infection) and the nymphs are capable of infecting humans. Cattle and buffaloes may be infected and act as a reservoir of the virus.

\section{A Tick-Borne Bacterial Disease}

\section{Tularaemia}

This is a protean disease, with numerous ways of transmission rendering it difficult to classify; and in addition, there are two forms of it (presumably depending on strains of the pathogen) - the "typhoidal" or septicaemic type and the "pleuropulmonary" type. It occurs over a vast range of the northern temperate zone, in North America, Europe, the U.S.S.R. and, to some extent, in Japan. Most of the investigations, and certainly the earlier ones were conducted in the U.S.A., where it was first recorded as a specific disease in 1911, being an infection of ground squirrels in Tulane County, California (hence the name). The pathogen responsible was described by McCoy and Chapin (1912) as an unusual cocco-bacillary organism. Shortly afterwards, human cases were recorded by Francis $(1919 ; 1921)$ who showed that the same pathogen was responsible and named it Pasteurella tularensis (from a resemblance to the plague bacillus; later, however, it was transferred to the genus Francisella, in his honour).

Many patients had noted being bitten by a deerfly (Chrysops discalis) shortly before the attack and, as it had left a lesion, it was thought to have been responsible. On the other hand, Francis could not recover the organism from 
deerflies trapped in the area where the human infections had occurred. However, from the first reports of the outbreaks, it seemed most likely that the human infections had been acquired from the local epizootics, which drew attention to the mode of transmission in such cases. In 1924, Parker et al. (1924) working at the Rocky Mountain Laboratory, showed that the infection could be passed among animals by the bites of the tick Dermacentor occidentalis and soon afterwards, with Spencer, he demonstrated stage-to-stage transfer of the infection in the tick and even to the next generation via the egg. Other ticks were also incriminated as vectors, notably $D$. andersoni and the rabbit tick Haemaphysalis leporis-palustris. Furthermore, it appeared that infection to humans could occur through the tick faeces by contamination of mucous membranes.

There was thus a case for a zoonosis in the western states of the U.S.A. with occasional transmission to humans via ticks (Parker et al. 1937); but in the eastern states, infected ticks seldom attacked man and there was a general belief in transmission by deerflies. Moreover, apart from transmission by arthropod vectors, there are many human (and possibly, animal) infections due to simple contagion or infection. The former is liable to occur by contamination with dead animals by hunters or trappers when the bacterium can obtain entry via mucous membranes; infection can occur from infected materials frequented by infected animals and can enter via the respiratory system. A further route can be from water in which infected animals have died, which is then drunk by campers. Human infections by contamination with wild animals is most liable to occur during the winter months, the hunting season, especially for rabbits (Guerrant et al. 1946). In contrast, the tick infections occur in early summer and those from deerflies in the autumn.

An examination of the scientific papers published on the subject during the last 80 years shows that the greatest interest has been in the vertebrate reservoirs of the disease and its crude epidemiology, rather than in the details of the actual mode of transmission by arthropods. For example, Thorpe et al. (1965) recorded the results of a survey conducted in the western part of Utah in which 31,300 mammals, 1,712 birds and 141,674 ectoparasites had been examined for the presence of the pathogen. The animal tissues examined included skunks, various kinds of mice, rats, squirrels and birds, while the ectoparasites included ticks, fleas and lice. In addition, serum samples were found positive for antibodies in 25 species of wild mammals as well as in cattle and sheep. These findings obviously indicate the very extensive presence of the pathogen and provide a warning against skinning trapped wild animals or handling them or their parasites. Nevertheless, there were at that time many cases of the disease (another paper (Brooks and Buchanan 1965) records some 2000 cases a year or 18 per million of the U.S. population; and similar incidence was apparently occurring in the U.S.S.R. and in parts of Europe). The situation is improving and the danger of the disease, which could be very serious in untreated cases, has declined to less than $1 \%$ with the introduction of antibiotics.

While these findings are obviously useful from the public health viewpoint, there still seems to be little known about the details of arthropod transmission, 
which seems to sustain the epizootic reservoirs. The actual fact of tick transmission was established experimentally by Parker and his colleagues in the early 1920 s, but the incrimination of deerflies (tabanids) seems to rest on circumstantial evidence (patients claiming to have been bitten by the flies and the coincidence of abundance and cases of the disease). Apart from this, the pathogen has been recovered from bulked samples of dozens of the flies; (Klocr et al. 1973) there do not seem to have been investigations of the behaviour of the pathogen in these vectors and it has been suggested that their transmission is merely mechanical (contamination of mouthparts). Evidence for transmission by fleas or lice is even more vague (Hopla 1980). One is left with the impression that human infections can scarcely be described as vector-borne as a rule, though this may be essential for the epizootics.

\section{Some Concluding Remarks Regarding the Transmission of Arthropod-Borne Disease}

The previous sections have dealt with the discoveries of arthropod transmission of some major diseases, discoveries which must have greatly benefited the medical profession which had been quite ignorant of the mode of infection. Accordingly, it seems fitting to conclude the first part of this book with a brief tribute to the pioneers responsible for the discoveries, and secondly with a short assessment of the likelihood of the emergence of new diseases of this kind.

\section{A Tribute to the Pioneers}

These accounts have shown that the complete unravelling of all aspects of the arthropod-borne diseases have often taken many years; yet, as I mentioned earlier, it is "the first step that counts". However, although my account celebrates the imagination and persistence of those who demonstrated arthropod transmission of diseases, it is fairly certain that they built on the concept of pathogens, rather than vague effects of climate or soil. The "germ" theory of disease had been firmly established only in the 19th century by Pasteur, Henle and, above all, by Robert Koch; and, although, as I have shown, it is possible to demonstrate disease transmission by a vector, it seems most unlikely that any one would attempt it without the idea of a specific pathogen. Yet it is not merely the imagination and ingenuity of the early pioneers which we must admire, but their courage, since, like other medical discoverers, they were dealing with dangerous diseases, not knowing how they were transmitted. Some of them died, not only from the inevitable accident, but because some of them intentionally exposed themselves to infection to test their theories; for example, Jesse Lazear, an American member of Walter Reed's team trying to elucidate the mode of spread of yellow fever. Others who succumbed to this disease in Africa were Dr. Stokes, an Englishman, and the Japanese-American Noguchi. Less well known is the Peruvian Daniel Carrion, whose name is commemorated in the 
name of a disease. Plague claimed a victim in an Austrian member of a Plague Commission in India early in the century and about the same time, the Englishman J. Everett Dutton died in the Congo (possibly from the relapsing fever which he was investigating, but more probably from malaria). In Mexico, in 1912, Howard Ricketts, an American, died from louse-borne typhus which he was studying, and the same disease killed von Prowazek, an Austrian working on the same problem in Europe, while a dozen years later it claimed an English entomologist, A. Bacot. Perhaps, too, we should also honour the many who volunteered to act as "guinea pigs" to resolve theories, not all of them the actual investigators. (One wonders about the inducements, since some of the diseases had no specific remedy early in the century!) Even those who survived must have suffered anxiety as well as pain before recovery. Moreover, some of the trials were not only dangerous but disgusting and I think that only a determined investigator would have undergone them; Ffirth, wallowing in the excreta of yellow fever patients, Clot-Bey and Bullard innoculating themselves with pus from Egyptians with the plague. Less dramatic but worthy of note, was the patience and ingenuity of those who worked isolated and with little or no technical help, in difficult conditions in the tropics. Manson, for example, dissected mosquitoes with a penknife [try it!] and records that he made himself an incubater from a packing case, while Ross complained that the lens of his microscope was cracked and that the screws were becoming rusted with his sweat. Both of them would have used a simple lens for dissection, since a microscope would have reversed the movement of the hands; but it is by no means easy to dissect the salivary glands of a mosquito, even with a stereoscopic binocular microscope. Simond experimented with plague-infected rats in a tent in India in the rainy season, while Chagas investigated malaria and dissected triatomine bugs in a converted railway carriage in the Brazilian jungles. Even the "laboratories" of the British Plague Commission in India during the early 1900s, look remarkably like converted warehouses in the photograph published in the Journal of Hygiene, and the workers are not wearing protective clothing.

Finally, I am going to venture a comment which is now almost tabu; namely a reminder that the discoveries of the transmission of arthropod-borne diseases (which happen to be mainly tropical) were made by men from the temperate regions. Among them, I am proud to note, were many British, especially Scots (though I am not one):-Manson, Ross, Bruce, Blacklock, Malcolm Watson and even Finlay, whose father was Scottish. Not surprisingly, many enterprising physicians have sought the cause and cure of diseases in their own countries; but these men were dealing with dangerous diseases in the tropics, the inhabitants of which had suffered from them for eons. True, their first efforts would have been to save the lives of their compatriots; but there was also concern for the native inhabitants, as shown by Europeans trying to combat plague in Egypt in the early 1800 s and in India at the beginning of this century. Moreover, it happened that the first insect-borne disease to be elucidated was filariasis, which rarely affects Europeans; nor do many of them suffer from sleeping sickness or onchocerciasis. Analogous claims could be made in regard to the efforts to control the vectors (which will be discussed in the rest of this book). 
There is no doubt a connection between these events and colonialism, which is generally regarded as an unmitigated evil. No doubt, it had some callous features, though slavery was not one of them (and indigenous slavery, which already existed in Africa, was usually suppressed). In any case, the fight against disease was mutually beneficial to inhabitants and intruders. This, however, is old history and European colonialism is moribund, if not extinct. Paradoxically, in its last phases, the developed countries began, more and more to work for the amelioration of the lives of tropical peoples, either collectively through the World Health Organization and the Food and Agricultural Organization etc, or individually through national agencies, such as the British Overseas Development Agency.

\section{The Possibility of the Emergence of New Arthropod-Borne Diseases}

A review of all kinds of "emerging new infectious diseases" was provided by Dr. Cedric Mims in 1980, and it is largely relevant to the special case of arthropod-borne infections. He listed some of the factors responsible for the emergence of various diseases (\$ome, such as plague and syphilis, actually not new), thus: (1) Crowding, presumably due to population growth combined with urbanisation, which has offered opportunities for the spread of respiratory diseases and also (under conditions of lowered sanitation) of enteric infections.

(2) Domestication of animals, responsible for psittacosis and (more importantly) of salmonellosis. (3) Encounters with new infection cycles as a result of moving to new habitats, responsible for Lassa fever and Marburg virus (and plague). (4) Increased Rate of Movement of Peoples, especially by air, which obviously accelerates the spread of disease, though not necessarily of new ones. (5) New Patterns of Sociosexual Behaviour which have apparently transformed herpes simplex into the more serious sexual complaint due to herpes 2 and also modified glandular fever. (6) Increased Survival of Susceptible Individuals. This would explain the danger to Europeans of such diseases as poliomyelitis (having been protected from infection) on encountering it abroad. (An inverse of this might be the danger of such diseases as measles to exotic natives from colonising Europeans.)

Mims' analysis of the circumstances producing emerging diseases can be expanded in two ways. Firstly, the factors listed can often be combined (perhaps synergistically). Thus, acquired immune deficiency syndrome (AIDS), which became a matter of general concern after his article was published, is often considered a new infectious disease, but it is probably a modification and extension of an existing viral infection. Its recent emergence of a major scourge is probably due to a combination of Mims' factors. Its origin as a human disease seems to have occurred in rural Africa, acquired perhaps from other primates and become magnified with the drift of people to urban centres; then, around the world, by modern transportation. Finally, greater promiscuity and homosexuality added to the spread.

Another additional consideration relates to "crowding", which is obviously secondary to population growth, in turn responsible for many population 
movements. These could be voluntary (people seeking new homes or livelihoods), or involuntary (as when some governments rid themselves of embarrassing urban poor by wholesale transmigration to virgin territory). In both cases, the people would be exposed to diseases new to them. Finally, population growth not only exerts pressure on food resources, but lowers living standards and reduces hygiene. This makes it difficult for benevolent governments (or international agencies) either to improve living standards, or to combat the diseases due to poverty.

Having listed some of the tendencies responsible for the emergence of new kinds of infectious diseases in general, the situation regarding arthropod diseases in particular should be considered. First, it may be helpful to examine the numbers of them which have actually appeared during the past fifty years. It is my impression that scarcely any can be described as due to entirely 'new' pathogens, but rather to the extension of existing ones to new areas, or perhaps to modifications in a few cases. These, no doubt, demand serious attention, but the possibility of entirely new kinds seem less urgent, though not entirely to be dismissed. However, as noted in the Prologue (p. 1) a microorganism becoming a parasite (the first step to becoming a pathogen) not only has to adapt to a vertebrate (eventually human) but also to an arthropod vector. As far as the type of microorganism likely to be involved, one of the viruses would seem most probable, as they are prone to relatively rapid mutation and there is evidence of large numbers in what may be a half-way stage. Gordon Smith (1960) quoted A.B. Sabin as remarking on the considerable numbers of viruses detected serologically, which could be described as 'being in search of a disease'; and Smith added in connection with the many minor illnesses of unknown origin, there may be many diseases in search of a virus, especially in the tropics. An additional point to consider is that, while antibiotics and other drugs are available for most other pathogens, coping with new viral epidemics requires the (slow) development of a suitable vaccine.

In regard to arthropod-borne infections, however, there is always the alternative of attacking the vector. This appeared to be an easy and inviting method when the fact of arthropod transmission was established early in the century. But the history of the various attempts during the past ninety years or so, have revealed failures as well as successes. There are also records of human ingenuity which will be described in the second half of this book, which may even be helpful for those trying to deal with the most recent failure of synthetic insecticides which seemed to offer an almost complete solution in the 1950 s and 1960s.

\section{References}

Mims C (1980) In: Stanley NF, Joske RA (eds) Changing disease patterns and human behaviour. London, $666 \mathrm{pp}$

Smith CEG (1960) Trans R Soc Trop Med Hyg 54;113 